

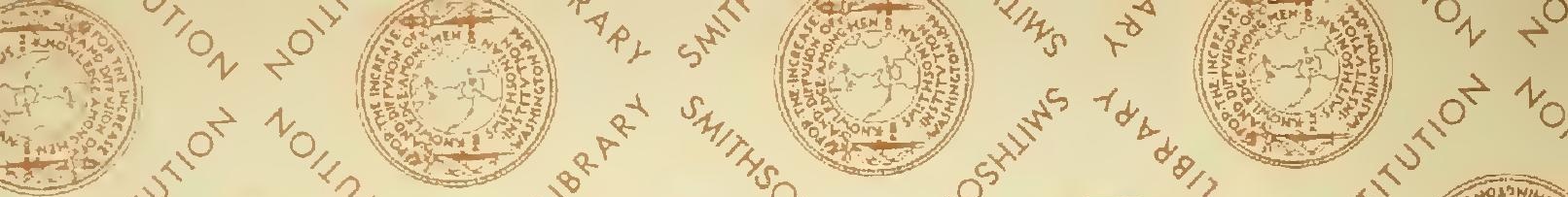

5

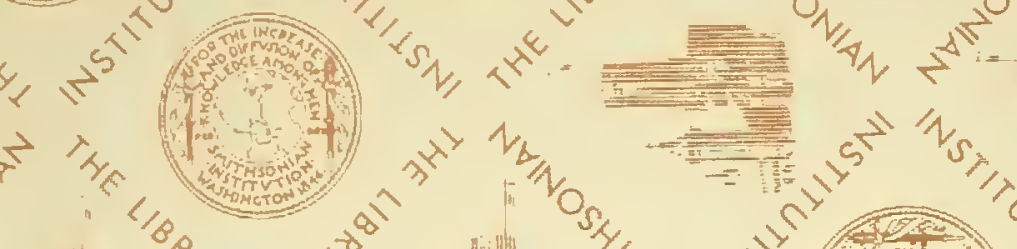

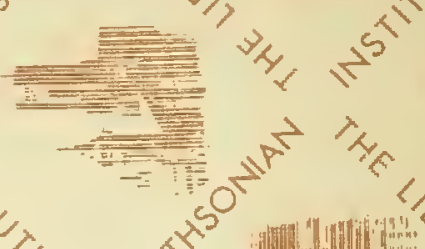

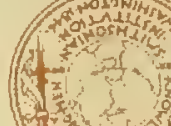

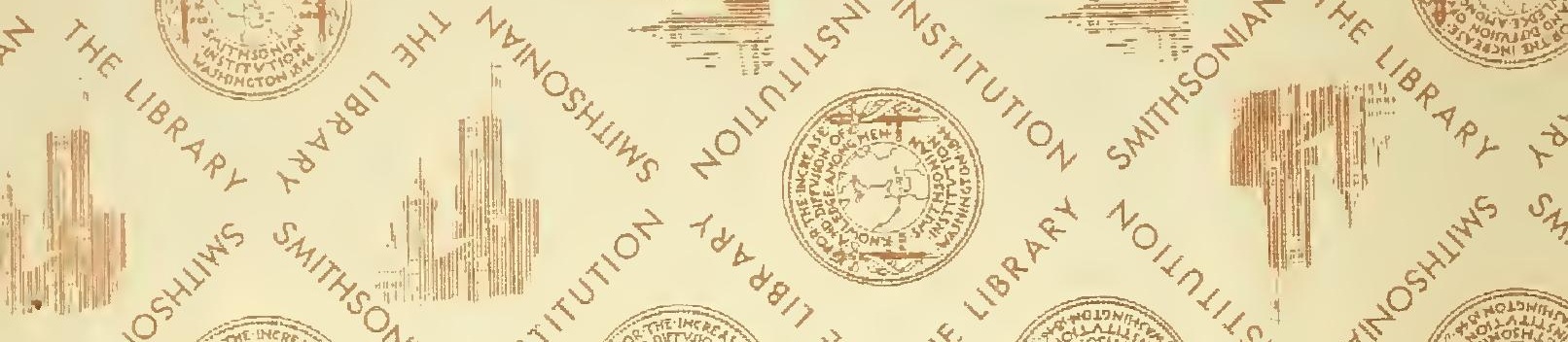

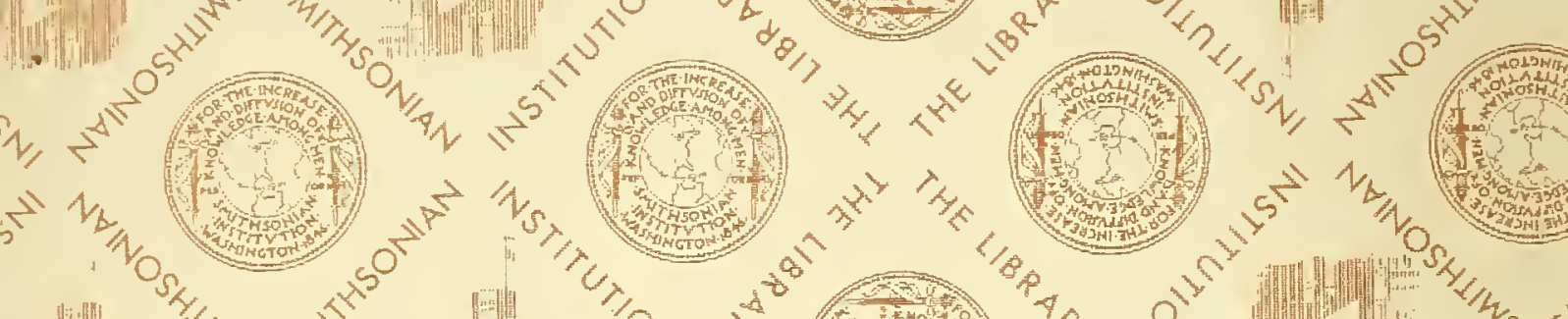

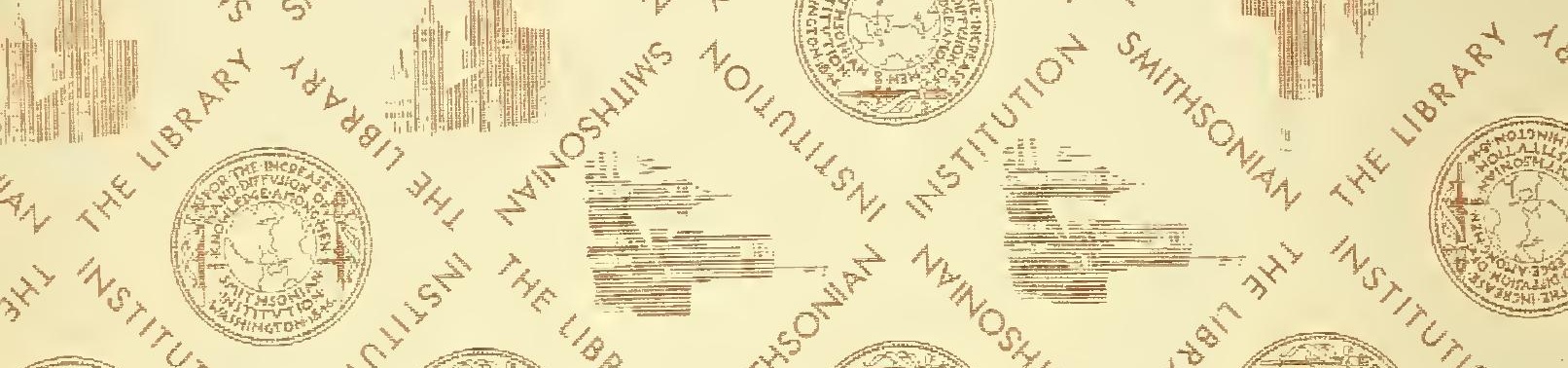

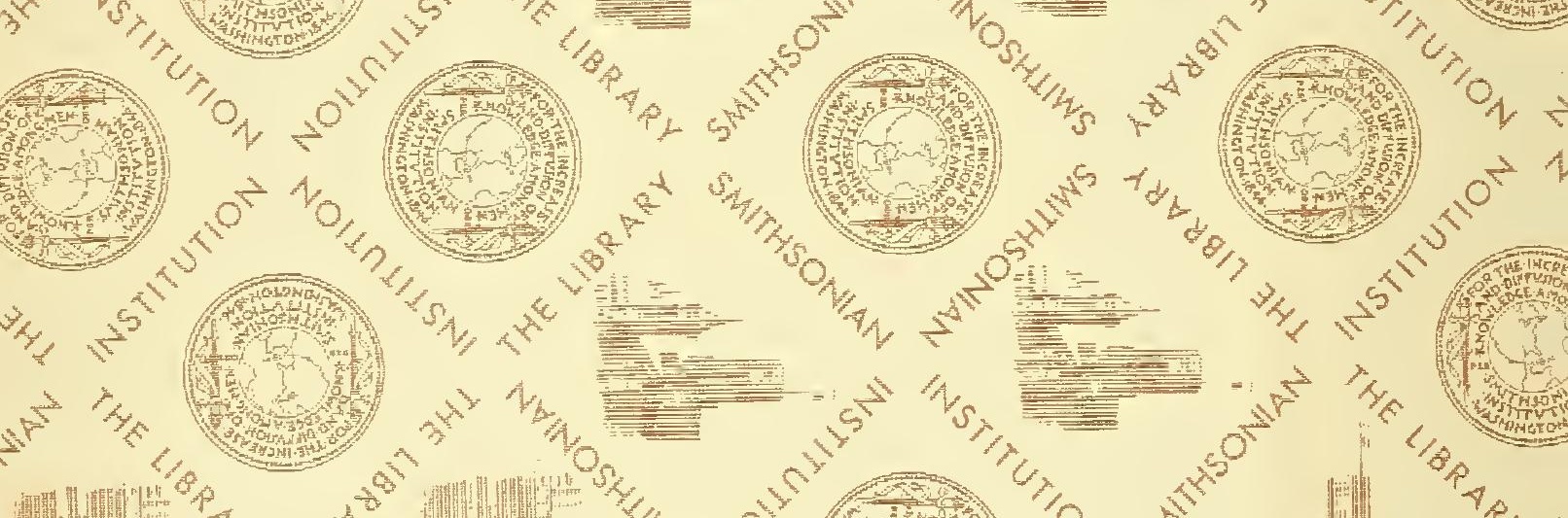

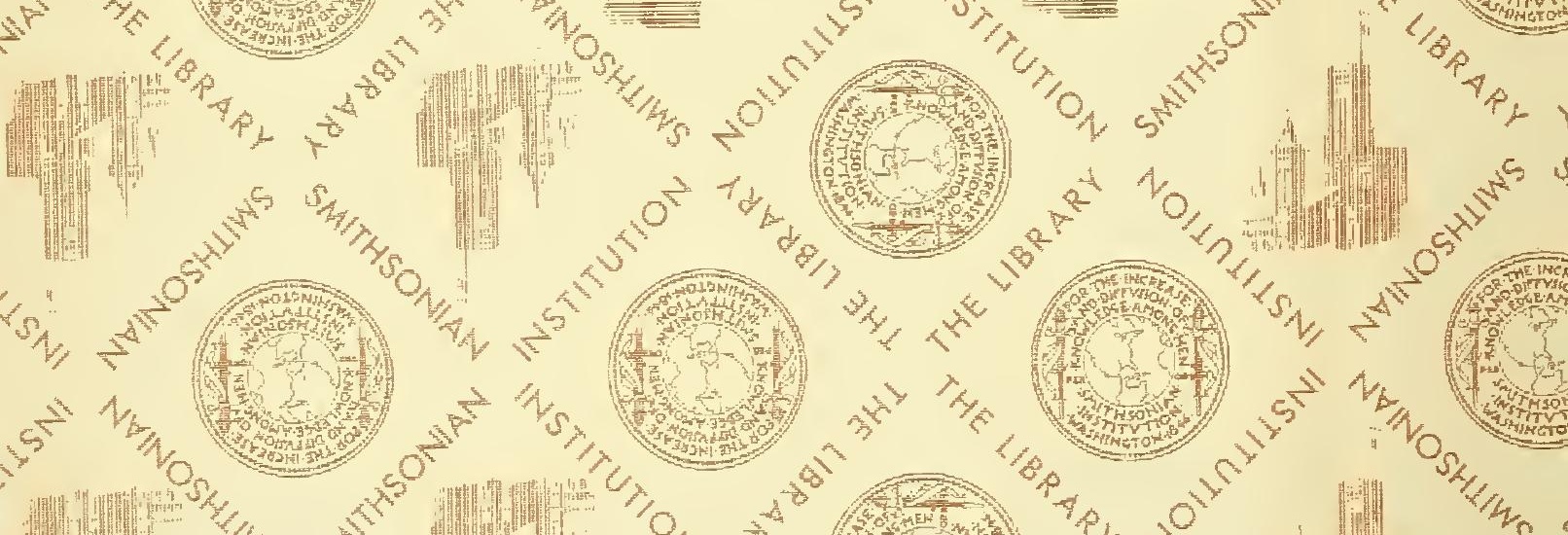

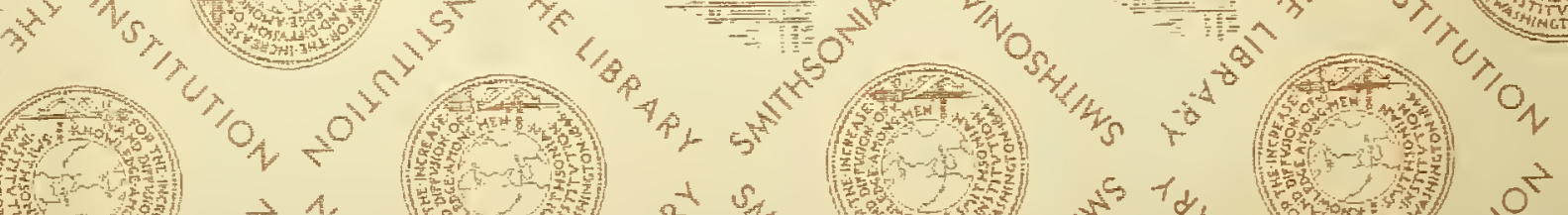
M. 





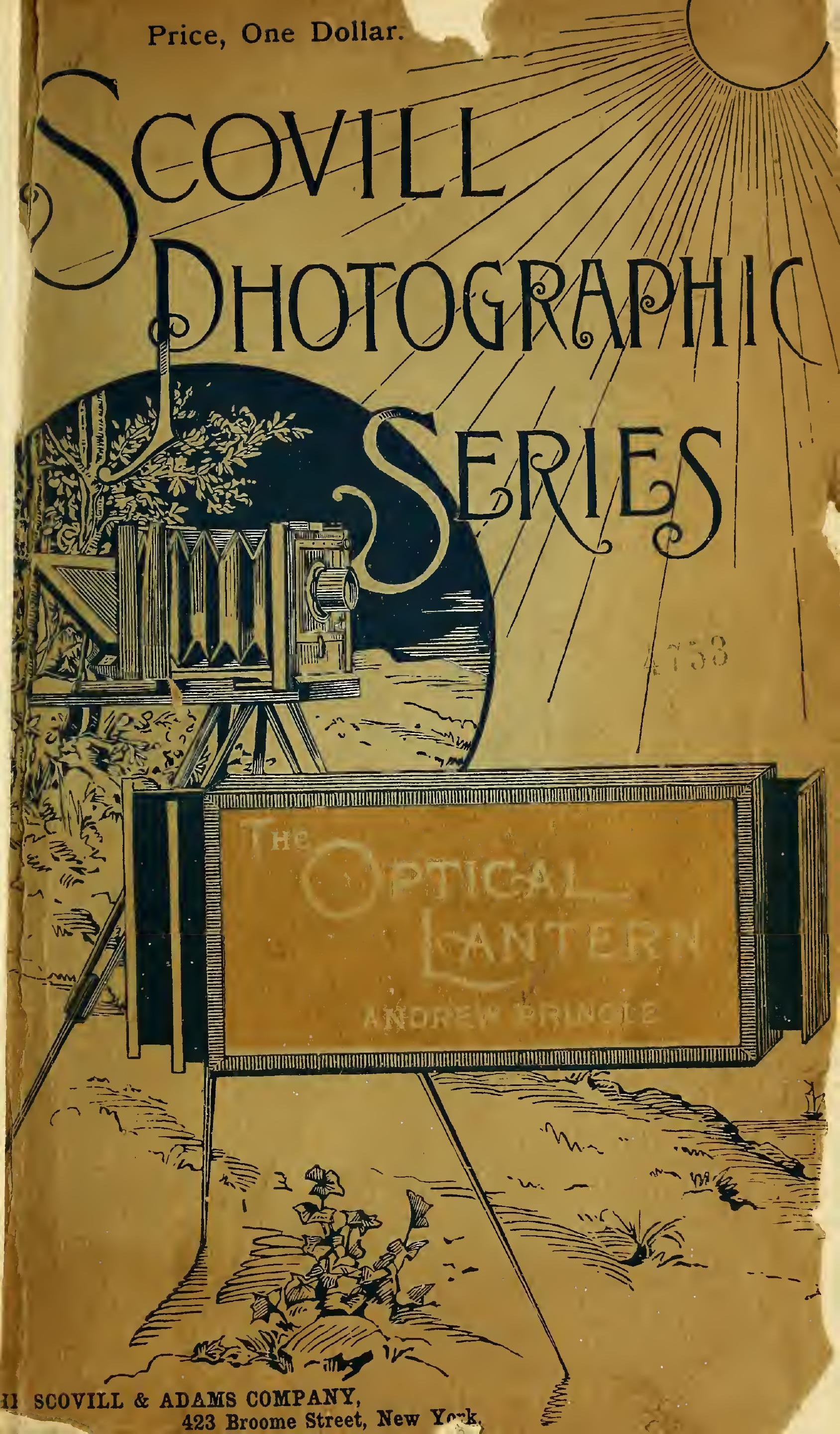





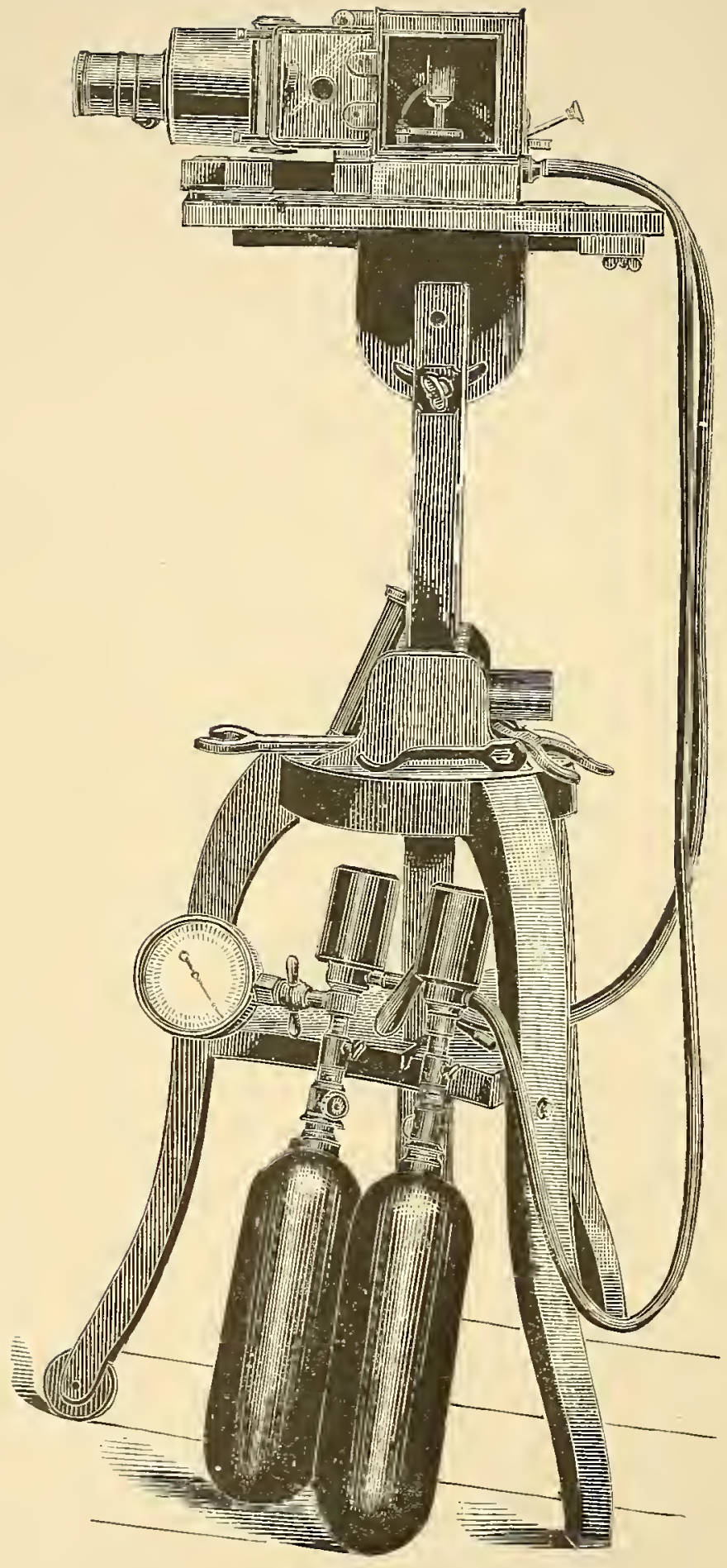

The Author's Apparatus. 


\title{
THE
}

\section{OPTICAL LANTERN,}

FOR

\section{Instruction and Amusement.}

\author{
BY \\ ANDREW PRINGLE, F.R.M.S.,
}

President Photographic Convention of the United Kingdom, I889, Author of "Practical Photo-Micrography," "Lantern Slides

by Photographic Methods," and Joint-author of "Processes of Pure Photography."

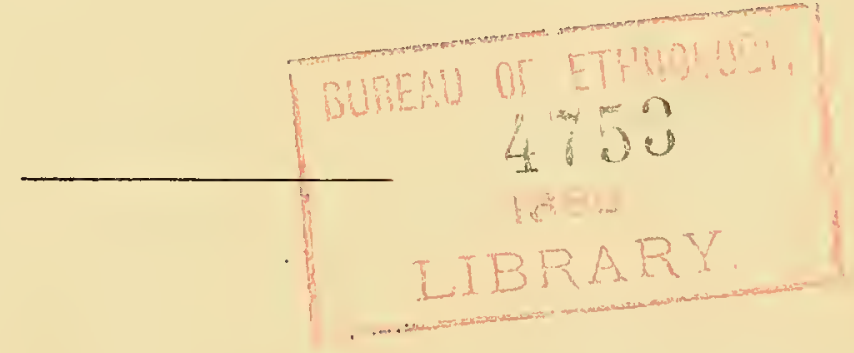

NEW YORK:
THE SCOVILL \& ADAMS COMPANY, 423 BROOME STREET. 


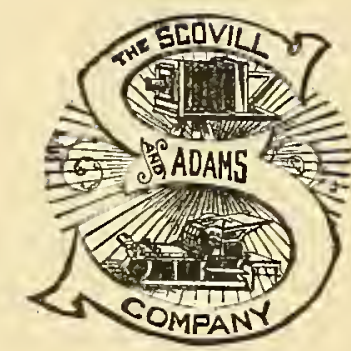

Copyright, I8go,

The Scovill \& Adams Company. 


\section{PREFACE.}

It may fairly be said that this book fills a place not occupied by any other at present before the public. For the present treatise deals with the Optical Lantern only; it does so, I trust, as fully as is required for any purpose; no attempt is made as in other books on the "lantern" to give, instructions for lanternslide making, still less for the production of negatives. The present is in fact a lantern book, and a lantern book only. As such I hope it will be useful.

I have written less for the popular public lecturer than for the photographer and the teacher. If in any degree my writings popularise and simplify the use of the optical lantern, specially if they tend to give the lantern a locus standi as a permanent part of the paraphernalia of the lecture room, I shall be happy in the consciousness of having done some good.

ANDREW PRINGLE. 



\section{CONTENTS.}

CHAPTER I.

PAGE

INTRODUCTORY,

CHAPTER II.

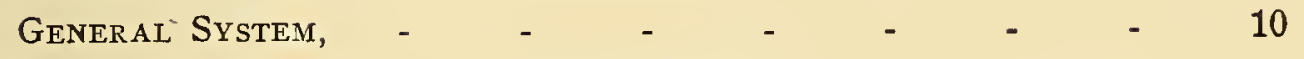

CHAPTER III.

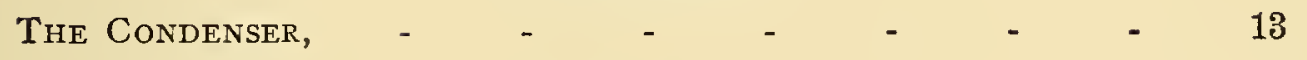

CHAPTER IV.

The Projecting Lens,

The Lantern Body,

CHAPTER V.

CHAPTER VI.

Double and Triple Lanterns, Dissolving Views, “Effects," Etc. 29 CHAPTER VII.

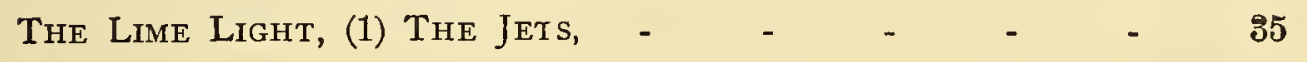

CHAPTER VIII.

Jets Continued, Details And Accessories, - $\quad$ - $\quad$ - 44

CHAPTER IX.

Preparation of Oxygen and Hydrogen, $\quad$ - $\quad$ - $\quad$ - 47

CHAPTER X.

Storage of Gases (1), In Bags, Pressure Boards, Etc., - 54

CHAPTER XI.

Storage of Gases (2), Cylinders, Regulators, Gauges, - 59

CHAPTER XII.

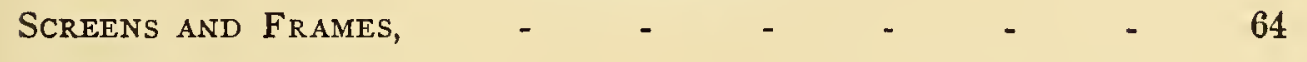


CHAPTER XIII.

Supports for Lantern, Slide Carriers, Reading lamps, Etc.,

CHAPTER XIV.

Lanterns and Apparatus for Experiments

CHAPTER XV.

Practical Working of the Lantern, Oil Lamps, Blow-through JETS,

CHAPTER XVI.

Practice with Mixing Jets,

CHAPTER XVII.

Preparations for a Lecture

CHAPTER XVIII.

Management of Lantern During a Lecture, 91 CHAPTER XIX.

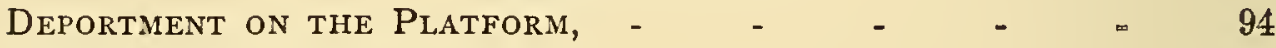

CHAPTER XX.

Arrangements for the LANTERN in a Lecture-Room,

CHAPTER XXI.

Enlarging with the Optical Lantern, $\quad$ - $\quad$ - $\quad$ - 101 TABle of ENLARgEMENT, ETC., - $\quad$ - $\quad$ - $\quad$ - $\quad$ - 105

Memoranda for a Lantern Display, - - $\quad$ - $\quad$ - 106 


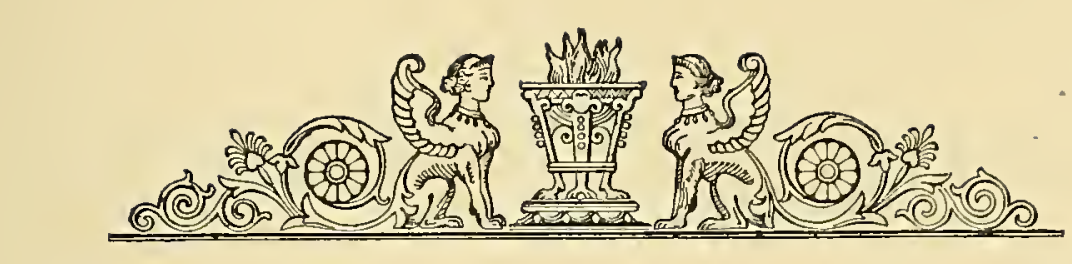

\section{THE OPTICAL LANTERN.}

\section{CHAPTER I.}

\section{INTRODUCTORY.}

WHEN we consider that in a coat pocket one can with ease carry a dozen lantern slides, and when we realize that each of these slides can be projected as a picture of (say) twenty square feet in size by means of an optical lantern, the utility and importance of this scientific optical appliance must be very evident. We should also consider the ease with which these lantern slides may be made, either by photography or by hand; we have also to take note of the variety of subjects amenable to reproduction as lantern slides, and we should further note that we are not even tied down to lantern slides as objects for the lantern, but that we may by our lantern project enlarged images of opaque objects, chemical and physical experiments and microscopic objects. When, finally, we find that all this is accomplished by an instrument which can be purchased by a moderate purse and carried by the feeblest hand, we are bound to own the merits of such an instrument, more especially because we know that what it pretends to do it does well.

No defence of, nor plea for, the optical lantern is needed in addressing circles or societies addicted to photography, for 
there are but few photographic memberhoods that have not their optical lantern, or at least their occasional lantern display. But most singular is the slowness of the progress in lantern use among societies and in educational institutions not purely photographic. True, the chief of our learned societies nowadays have their optical lanterns however unworthy the instrument may in some cases be; but there is in no educational institution, so far as the writer knows, a regular system of teaching or illustration by lantern projections. From a purely ocular point of view, diagrams, maps, blackboard designs and the like are inferior to the much larger and clearer lantern illustrations, and the shortsighted student must miss much of what the more fortunate normal-eyed may catch. But taking higher ground, it may be asserted that where it is important to study things as they really are, and not as the teacher is able to draw them, or thinks they are, or wishes them to appear, the optical lantern, with or without photography, must have the strongest claims on our attention. However well a physiological or pathological object may be drawn by hand, such a drawing is impotent to carry conviction and to impress memory in comparison with an enlarged photograph or an enlarged image of the object itself. When was ever a spectrum, drawn by hand and colored by any method, able to compare with the actual spectrum projected on a screen by means, for instance, of an electric arc?

Many professors have admitted to the writer the claims of the optical lantern as a useful scientific appliance; some have owned that photographic lantern slides would be far superior to any other known method for educational demonstration; but each and all of these able men have been deterred from inaugurating the system we recommended by the most extraordinary and imaginary misgivings as to the cost of installment, and the difficulty and even danger of working the apparatus. The difficulty, strange to say, most commonly foreseen, was that of darkening the lecture-room-with a touch of doubt as to the conduct of young students in a darkened room, and there was the usual dubiety as to the safety of the gases used for the lime light. 
The prime object of this book is to remove dangers and difficulties from the imagination (for there alone they exist) of many who are prepared to admit the advantages, but who question the practicability, of using the optical lantern as an educational and recreative instrument.

There are many persons, especially photographers and public lecturers, as well as philanthropists striving for the good of their fellow-men, who use the optical lantern, but they use instruments of such poor quality, and appliances so nearly obsolete, and they so little understand the means for getting the best results from the appliances they have, that the writer feels it no impertinence on his part to try to put "lantern matters" before the public in a succinct, and, as he hopes, clear and intelligible manner. He will endeavor to cover all essential ground, to reject all side issues, and to deliver himself in terms precluding possibility of mistake.

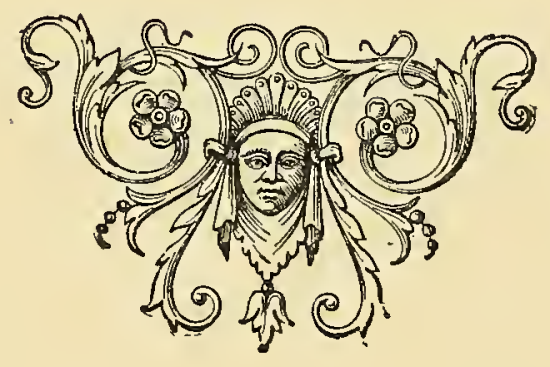




\section{CHAPTER II.}

\section{GENERAL SYSTEM.}

THe essentials of the optical lantern as a means for the projection of enlarged images from smaller objects on a suitable surface are very simple.

The optical system consists essentially of (1) a radiant; (2) a condensing system for collecting and concentrating on the object the light rays furnished by the radiant; (3) a projecting system for collecting, projecting, enlarging and focusing the image of the object as illuminated by the rays from the condenser ; (4) a "screen" or surface for receiving the enlarged image and making it visible to the eye.

The entire system will be easily understood from Fig. 1 . In this figure enough is drawn to show the general optical principles involved, the projection lens is made with an unusually large back combination not necessary with symmetrical combination lenses.

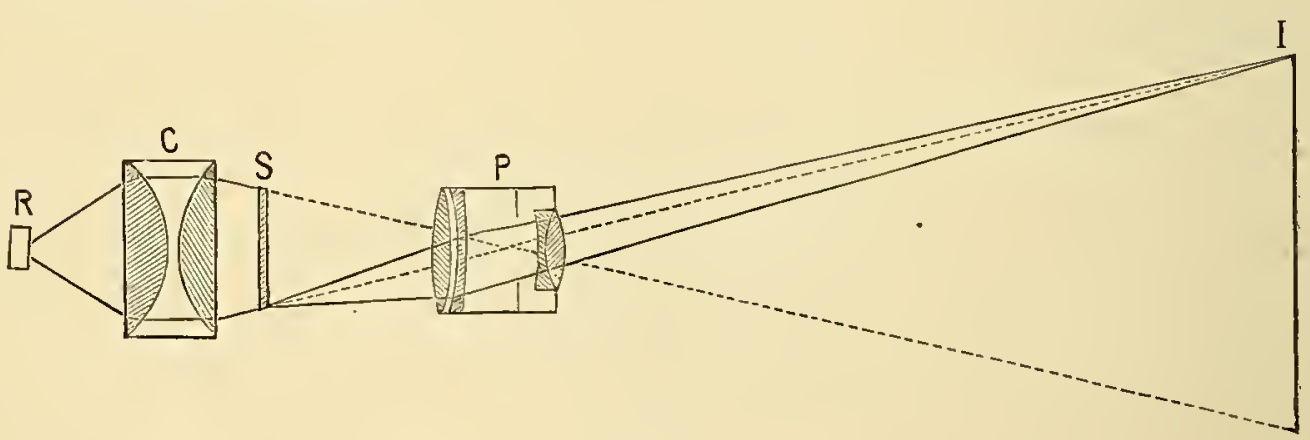

FIG. 1.

$\mathrm{R}$, the radiant ; $\mathrm{C}$, the condenser ; $\mathrm{S}$, the lantern slide ; $\mathrm{P}$, the projection lens; I, the screen or plane where the enlarged image is received.

We may begin by describing what in most cases is the object to be illuminated and to be reproduced on a scale so much larger and at some considerable distance from the site occupied by the object. In the vast majority of cases this object is a transparent positive picture on glass, and the size 
of the picture actually to be projected is usually about three inches, as the diameter of a circle, or three and three-quarter inches, as the diagonal of an oblong. For convenience the glass plate is usually made three and a quarter inches square, an opaque mask having an aperture circular or oblong being used as a protection to the film of the "slide," and as a preventive of unsightly and superfluous light on the screen. The "slide" may be a "lantern slide" produced by photography, or it may be a hand-sketched design ; for the present we will assume it to be a "transparent positive" on glass three and a quarter inches square, with a mask having an aperture circular or oblong of the above dimensions.

The radiant may be one of several kinds, but our chief consideration is that it may be a point of light, approximately, as an incandescent point on a lime cylinder; or it may have a surface of incandescence or be formed of several incandescent surfaces as in a multiple-wicked lamp. The more nearly the radiant approaches to being a point of incandescence the better, provided that the incandescence is sufficiently brilliant. The point of incandescence must be precisely in the focus of the condenser if the best result is to be obtained; enlarging the area of incandescence is a makeshift and often a very bad one. Still, as oil lamps are used, and are often convenient, we must consider wicks as our radiant as well as limes or ares.

The condenser collects the light rays from the radiant, and compresses or condenses them on the slide which should be as close as convenient to the condenser. The rays pass from the condenser through the slide to the front conjugate focus of the condenser, and at or near that front focus the projection lens takes up the image of the slide, and projects it forward to the screen which is usually white and opaque, but is sometimes translucent. The sharpness of the picture on the screen depends upon the slide and the screen being in the planes of the posterior and anterior conjugate foci of the projection lens; and as the screen once erected is to be considered immovable, while the position of the projection lens varies with its focal length in its relation to the slide, the lens requires to have a certain amount of range of focus, that 
is to say, must to a certain extent be adjustable as regards its position with respect to the slide. More technically, the projection lens should have a rack and pinion focusing movement.

An optical lantern is simply a device for holding the radiant, the condenser, the slide, and the projection lens in suitable positions with regard to each other; and that the radiant may not directly illuminate the screen, nor interfere with the view of the spectators, the lantern usually takes the form of an oblong box, the light and part of the condenser being inside the box, the slide-carrier and projection lens attached to the front. A lantern box ought to be fairly light tight; and it ought to be as small as possible consistently with giving room for the radiant and not itself becoming too hot. In our opinion optical lanterns are made ridiculously large, and we hope to see in the future our lanterns for lime-light much more convenient and less weighty and expensive. With oil lamps we have to deal with the very important matter of draught or ventilation, which must govern the size of the lantern box to a considerable extent.

The slide is usually held in the lantern, or passed through it, by means of what is called a "carrier"; the screen is often sustained by a "frame" or suspended from a roller; these details are not essential to the system and will be treated later, each in its proper place.

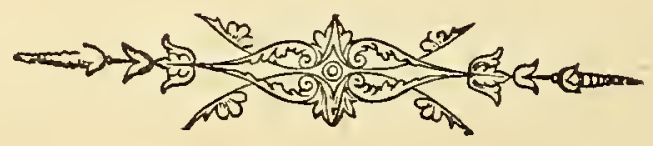




\section{CHAPTER III.}

\section{THE CONDENSER.}

THE condenser is used to collect rays of light that would without it be lost so far as illumination of the slide is concerned. The radiant is stationed at one conjugate focus of the condenser, while the projecting lens is or ought to be somewhere near the other conjugate focus of the condenser; and the pencils of light travelling from the condenser in convergent lines towards the front focus ought to illuminate the entire aperture of the slide. The first point we have to consider with regard to a condenser is its area, or more conveniently, its diameter. A large condenser will illuminate a larger area of slide than a small condenser. But a large condenser requires to have a long focus practically, so that we lose light, as will be shown later. And in the matter of focal length of condensers, we have always to remember that there is a limit of shortness of that focal length, for such a radiant as incandescent lime, not to mention an electric arc, cannot, without grave danger to the condenser, be brought nearer than, say, two and a half inches from it.

In practice, then, we have to choose between condensers having diameters of three and a half, four, and four and a half inches. If the reader will examine our figure, he will see that in order to illuminate the whole surface of a slide the condenser must have an area at the very least equal to the surface area of the slide. If now our slide has a mask with round aperture three inches in diameter, and if the slide is pretty close to a three and a half-inch condenser, the whole of 
the aperture in the slide will be illuminated by the condenser, as in Fig. 2.
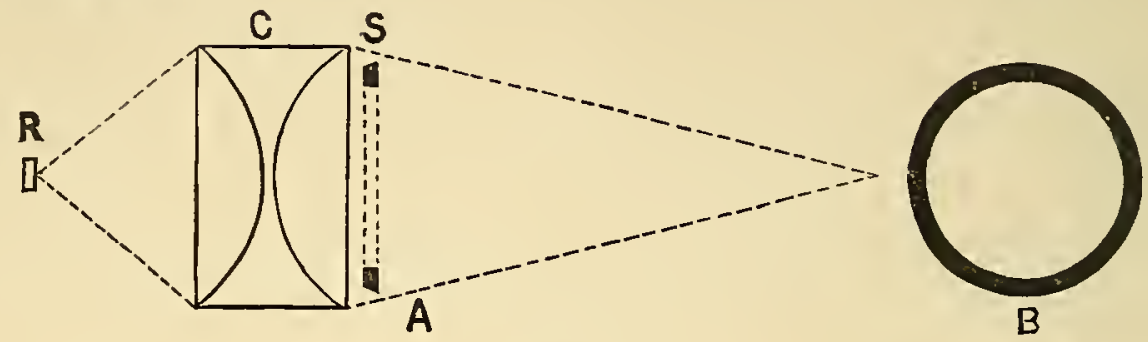

Frg. 2.

If in fact, the whole of a three-inch condenser were effective, and if the slide could be placed close up against it, a threeinch condenser would suffice to illuminate a three-inch aperture slide. But in practice the entire surface of a condenser cannot be made available, and we cannot as a rule

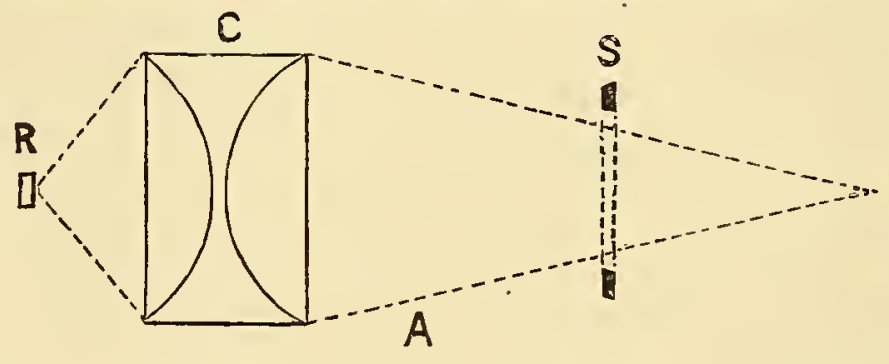

FIG. 3.

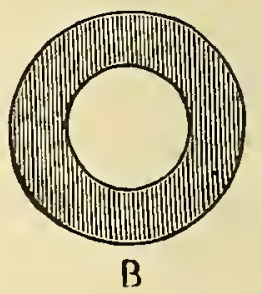

B

place the slide close up against the condenser, and so we may take it that a three and a half-inch condenser is the smallest practically available for a three-inch aperture slide. In Fig. 3 , we show the effect of an exaggerated. distance between condenser and slide, A being a longitudinal and B a vertical section on the optical axis of the system. But suppose we

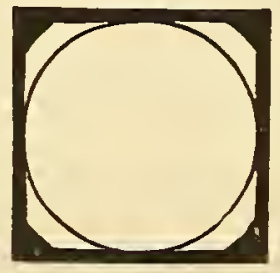

FIG. 4.

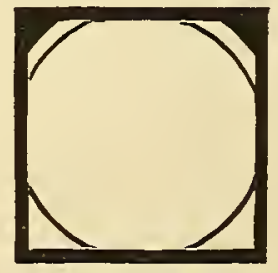

FIG. 5 .

have or intend to use an aperture say of the shape known as "cushion shape." A reduced plan of such a mask is given in Fig. 4, and we have placed inside it a three and a half-inch 
condenser on the same scale but not quite touching the slide. Plainly, taking the condenser of three and a half inches at its best, it cannot illuminate the cushion which in actual measurement has diagonals of three and three-quarter inches. It will, however, be found that a condenser of four inches diameter will cover the ordinary cushion shape aperture, or the dome, Fig. 5, and so we may accept four inches as sufficient diameter for a condenser for any picture on a three and a quarter inch slide, provided that the slide be placed near enongh to the condenser.

Some people seem to think that they will improve matters and make quite sure by using a four and one-half-inch condenser. There are slides made, or there were at one time slides made, of the same size as a "quarter plate," i. e. $4 \frac{1}{4} \times 3 \frac{1}{4}$ inches. These with their masks required a four and one-half-inch condenser sometimes, but we believe this size of slide is now obsolete, certainly it has no advantages over the commoner size, three and one-quarter inches square. There is a positive disadvantage in a four and one-half-inch condenser which we must point out. A four and one-half-inch condenser must almost necessarily have a longer focal length than a four-inch if aberrations and absorptions of light are to be avoided, and aberrations in a condenser are most serious defects. The focal length of a condenser may be taken for our present purpose as the distance between the radiant and the condenser.

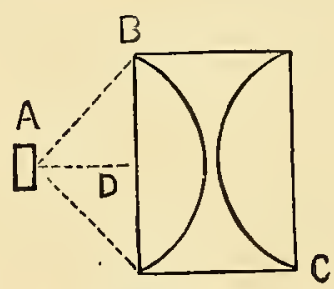

FIG. 6.

In figure $6, \mathrm{~A}$ is the radiant, $\mathrm{B} \mathrm{C}$ the condenser, and $\mathrm{A} \mathrm{D}$ the focal length of $\mathrm{BC}$. With a three and one-half-inch condenser of any ordinary type the distance A D may be about two and one-half inches, with a four inch about two and three-quarter inches, with a four and one-half-inch it will be about three and one-quarter inches or more. Now according to the well known 
law the intensities of the light acting at $\mathrm{D}$ vary inversely as the squares of these distances, that is to say the four-inch condenser has the advantage over the four and one-half-inch one, in approximately the proportion of four to three. We cannot with safety shorten the focus of our condensers beyond the limits named, two and one-half inches, because with lime or electric light there would be the great danger of cracking the back combination of our condenser by the heat of the radiant. So to sum up, we may say that a four-inch condenser is on the whole the best for general use; if only round apertures are to be used in the slides a three and one-half-inch condenser will be better; if larger slides must be used the condenser must be larger. (See Chap. XXI).

We now turn to the construction of the condenser. The simplest form is known as a bull's eye, and consists of a single piece of glass plano-convex in form. Practically it is useless for our purpose, it is not achromatic, has gross aberrations, and is curvilinear.

The construction usually found now-a-days is that of two plano-convex glasses, placed with their convex sides nearly in contact, as in figure 1, C. The pair of glasses are mounted in a brass cell which fits in the front of the lantern, and it is important that there should in the circumference of the cell be air holes, so that when the condenser gets heated the air may escape from between the glasses, and "sweating" be thereby avoided. The glasses, moreover, should not be too tightly mounted in the cell, so that on being heated they may have room for moderate expansion.

In the Almanac of the "British Journal of Photography" 1888, we find Mr. J. Traill Taylor, a prime authority, recommending a form of condenser which we believe to be older than the one last described by us. This form consists, as will be seen from figure 7 , of a plano-convex or slightly meniscated lens in close proximity to a double convex. Mr. Taylor then rightly points out the loss of light certain to arise with this form of condenser unless the focus be long, which will entail loss of intensity, and he proceeds with his usual ingenuity to suggest the interposition of a third lens of plano- 
conrex or menscus form between the light and the doublet combination previously representing the entire condenser. The figures are Mr. Taylor's, and almost explain themselves.

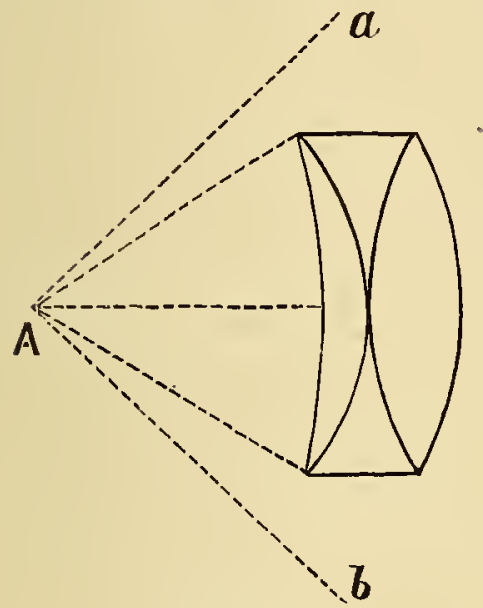

Fig. 7.

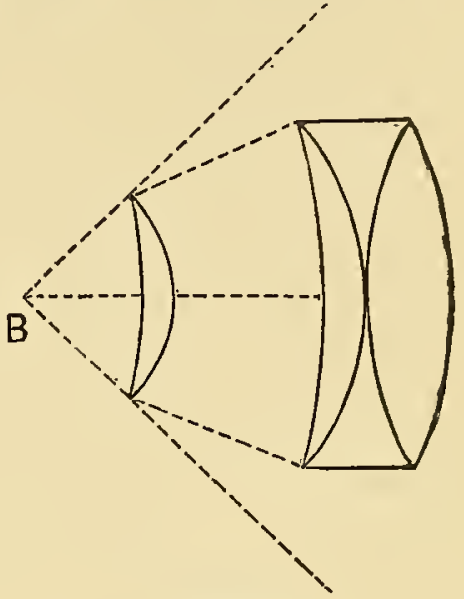

FIG. 8.

In $\mathrm{A}, \mathrm{a}, \mathrm{b}$, represent rays that are lost, while in $\mathrm{B}$, (fig. 8) they are refracted and utilized by the addition of the third and smallest lens. Mr. Taylor therefore concludes in favor of triple condensers.

Our experience is confined to the form first figured (fig. 7) and the part of Mr. Taylor's figure A, of these we prefer the two plano-convex glasses, (fig. 1.).

A very good double condenser is that of the late Mr. J. H. Dallmeyer, who described it to the Photographic Society of

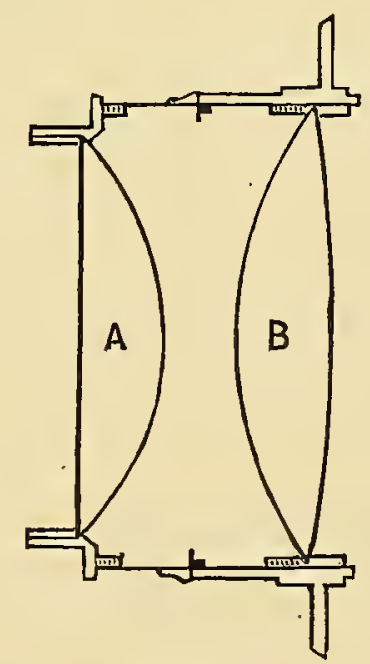

FIG. 9.

Great Britain in April, 1880. As it is of somewhat curious form we give a diagram of it. 
The effective diameter is four inches, the equivalent focal length two and three-quarter inches. The lens $\mathrm{A}$. is a flint plano-convex, three and five-eighth inches diameter, while B is a crown glass double convex four inches diameter. A. gou's next the radiant.

Mr. Dallmeyer, in the paper wherein he described this condenser, dwelt upon certain points which we cannot do better than emphasize here. A condenser, especially the lens next to the slide, must be of the most perfect glass, white, limpid, and free from bubbles, streaks, striæ and scratches. Any mark, on the front element in particular, will show on the screen to the great detriment of the picture. The greatest care must be taken to preserve the condenser from ill-usage and noxious vapors.

No condenser that ever was made will work well if the radiant be not centred with the condenser and in the focal point of the condenser. If the radiant in a lantern be out of centre the image on the screen will be unevenly lighted; if the radiant be behind or in front of the condenser's focus there will be abominable fringes of color round the margins of the disc on the screen. In oil lanterns the light is usually centrally placed in the optical axis, and the lamp has to be pushed and pulled till the focus of the condenser is found-as nearly as it may be found with a multiple-wicked lamp.

Note.-Frequently, when a projection lens of long focus is used-say, 8 inches or over-a condenser of longer focus will be required, which, as a rule, implies a condenser of larger diameter. Thus with front lenses of 8 inches or over we generally require to use our $4 \frac{1}{2}$-inch condenser The reason of this will be evident to any reader who will trace the course of rays from an ordinary 4 -inch condenser; he will find the rays cross before they reach the projection lens of long focal length. 


\section{CHAPTER IV.}

\section{THE PROJECTING LENS.}

The "Projecting," or as it is often loosely called, the "Front" lens is in certain respects of no less importance than the condenser. It so happens that ordinary photographic lenses are in the main well adapted for use as projecting lenses for the lantern, and so as a rule there is little fault to find with the lenses used by one who is a photographer or by a photographic society. But in the hands of the general public we often find projection lenses totally unsuited for their work.

A projection lens requires in particular three qualities. It must be accurately corrected for the visual rays of the spectrum; it must have a wide working aperture, and it.must be free from spherical aberration. On account of the corrections of a photographic lens wherein the visual and chemical rays are made to coincide in focal point, such a lens as we have said is usually well corrected for the visual rays, but when a lens is only corrected for visual rays, and the actinic rays unheeded, that lens may be a splendid lantern lens, but cannot without modification be used as a photographic lens. A photographic lens of the type used for portraiture, in particular one of the rapid lenses invariably used in the days of wet collodion, meets practically every want of a projection lens. A portrait lens has usually a flat field, and area of aperture large in proportion to its focal length, so that we get a good picture on our screen with brilliant illumination. Decidedly, but not necessarily much, behind a portrait lens for our purpose, comes a so-called "single" lens, such as is often used in photography for landscapes; the chief drawback to this class of lens being that to secure a flat field we have to "stop down" the lens and so entail loss of light. Better perhaps than a portrait lens is a lens made specially for the lantern by several 
opticians, of whom we may mention Mr. Dallmeyer, of London, and Messrs. Taylor and Hobson, of Leicester. We are enabled to give a diagram of a lens by the latter firm, we have worked one of eight inches focus made on these lines and it leaves notling to be desired.

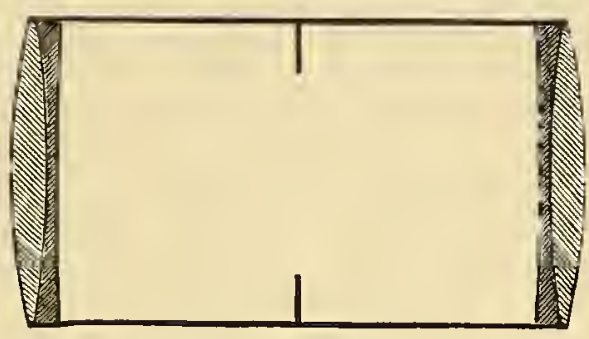

FIG. 10 (a).

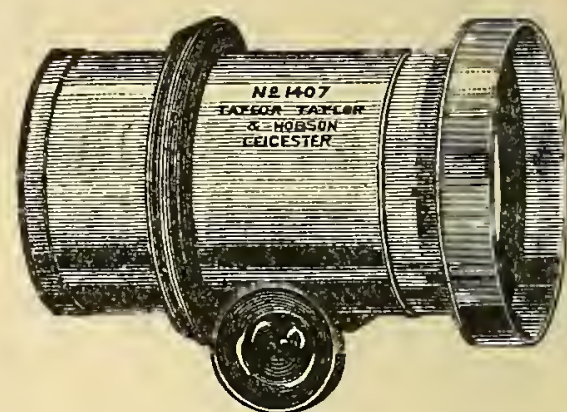

FIG. $10(\mathrm{~b})$.

Some remarks as to the focal length of the projection lens seem to be called for. Given a certain distance from lens to screen the shorter the focus of the lens the larger will be the disc on the screen. Given a certain lens the nearer it is to the screen the smaller the disc on the screen. Given at a certain distance from lens to screen a disc too large, we can make is smaller either by taking the lantern nearer to the screen, or by using a longer focus lens. A four inch lens will give at any distance a disc just twice the diameter of that given by an eight inch lens at the same distance. Mr. Chadwick gives a table that the writer has often found convenient. We quote it here :

Let $\mathrm{S}=$ Aperture of slide-mask in inches.

$\mathrm{F}=$ Focal length of projection lens in inches.

$\mathrm{L}=$ Distance from lens to screen in feet.

$\mathrm{D}=$ Diameter of disc in feet.

Then :

$$
\mathrm{L}=\frac{\mathrm{D} \times \mathrm{F}}{\mathrm{S}} \quad \mathrm{D}=\frac{\mathrm{L} \times \mathrm{S}}{\mathrm{F}} \quad \mathrm{F}=\frac{\mathrm{L} \times \mathrm{S}}{\mathrm{D}}
$$

Another useful guide to find the distance required from lens to screen for a certain disc is: calculate by how many diameters the disc is greater than the slide opening, add one to this number and multiply by the focal length of the lens. Thus: we require a 15 feet disc with a 6 inch lens; 15 feet is 60 
times 3 inches, which we suppose to be our slide aperture; $61 \times 6=366$ inches $=30$ feet 6 inches, distance required from lens to screen.

It is for various reasons usually a mistake to choose a lens of very short focal length. If the room is small there is not much choice, but in a larger hall we like to get as far back as we can up to 80 feet, at this distance a 12 inch lens gives a 20 feet disc. But beyond this we do not go if we can help it. If the lantern has, on account of shortness of focal length of lens, to be placed, say, 25 feet from the screen in a moderate sized hall, many people behind the lantern will be prevented from seeing properly, and the apparatus will probably be surrounded by part of the audience, which is objectionable and even dangerous if bags are used. Moreover, if the screen is placed on a raised platform the lantern has to be canted up and the screen tilted forward to an inconvenient degree, whereas if the lantern were, say, 60 feet distant from the screen, the necessary cant and tilt would be much less, and the loss of light by greater distance is not nearly so great as some thoughtless persons seem to fancy, for the oft-repeated formula about the "intensity of light varying as the squares of the distances" does not hold here at all. The loss of light in enlarging a three inch disc to a fifteen feet disc is, coeteris paritus, practically the same whether the enlargement be produced by a four inch lens or an eight inch. But if our projecting lens las a focal length eithur so short or so long that its back combination fails to grasp some of the rays proceeding from the condenser through the slide, then surely we shall lose light (see note to Chap. III.). By altering our condenser's focal length we may cram more pencils of light into a long focus front lens, but then we shall lose some of the pencils of light between the radiant and the condenser, or else have to remove the radiant further from the condenser, in which case our ancient formula will hold good as touching the illumination of the condenser itself. Reference to our Figure 1, will show at once that if the front lens have a very short focal length it will not catch all the pencils of light passing through the slide, unless it, the lens, has a very wide back 
combination, and again, if we get an aperture very wide in proportion to our focal length we shall have a lens impossible to correct for aberrations. So, as usual, it is a case of "give and take," we cannot have perfection in anything optical. Speaking from experience, we may say that from a quarterplate portrait lens of about five and a quarter inches focal length to a lantern lens of eight inches, we have no trouble in using our four inch condenser; with a ten or twelve inch lens we have had to use a four and a half-inch condenser; while with a very short focus lens we happen to possess, our four inch condenser does not work very well. We are perhaps safe in saying that for all-round work a lens of about six inches focal length and a condenser of four inches as usually made will do as well as any other one-lens battery. The most useful lens we have for the lantern has a focal length of eight inches, at forty feet we get a grand fifteen feet disc, using a circular slide mask. 


\section{CHAPTER V.}

THE LANTERN-BODY.

As ALREADr stated, the functions of the lantern-body or box are simple, and consist merely of holding the parts of the optical system together and enclosing the illuminant so that damaging rays of light cannot reach the screen to spoil the image, nor the eyes of the onlookers to dazzle them.

When the radiant is an oil lamp the lantern body must be fairly large, for the lamp is sure to be of considerable size if a powerful one with say three wicks; there must be a certain amount of unoccupied space inside the lantern to give draught and adjustment room for the lamp; and, as a rule, the lamp requires a somewhat tall chimney to ensure draught. The body of the lantern is almost always "jacketed" wholly

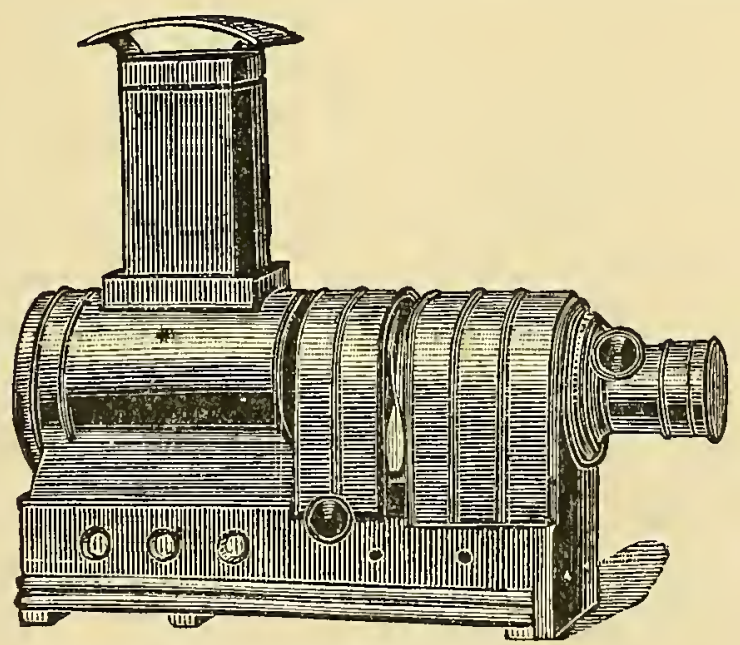

FIG, 11.

or in great part, in order to meet the great heat given off by the lamp; sometimes the outer jacket is of metal, sometimes it is of wood, the inner jacket being invariably metal.

Perhaps the first really business-like lantern introduced with any success was the now well-known sciopticon of Mr. Marcy. In many points it formed a standard for later modifications. Fig. 11. 
The double wick of the sciopticon lamp was soon found to be faulty in several ways, and a third wick was by various makers and in various forms added. Messrs. Newton greatly improved the performance of the lanterns of that day by placing a suitably curved reflector behind the wicks, their oil lamp being known as the "Refulgent." In most oil lamps will be found in front of the wicks a piece of flat glass to prevent breakage of the condenser. In our experience a well-arranged trio of wicks is better than two wicks only; we are informed that even five wicks have been successfully introduced. It must never, however, be forgotten that number of wicks does not necessarily mean increase of effective light, and so far as our knowledge goes we believe the best multiple-wick combination to be one of three wicks, placed longitudinally in the optical axis, the two outer wicks slightly inclined inward towards the centre one. The dangers with many-wicked lamps are : great heat, and a shadow down the centre of the image on the screen.

Messrs. Laverne \& Co., of Paris, who have vast experience in lantern making, turn out a serviceable lantern sold in
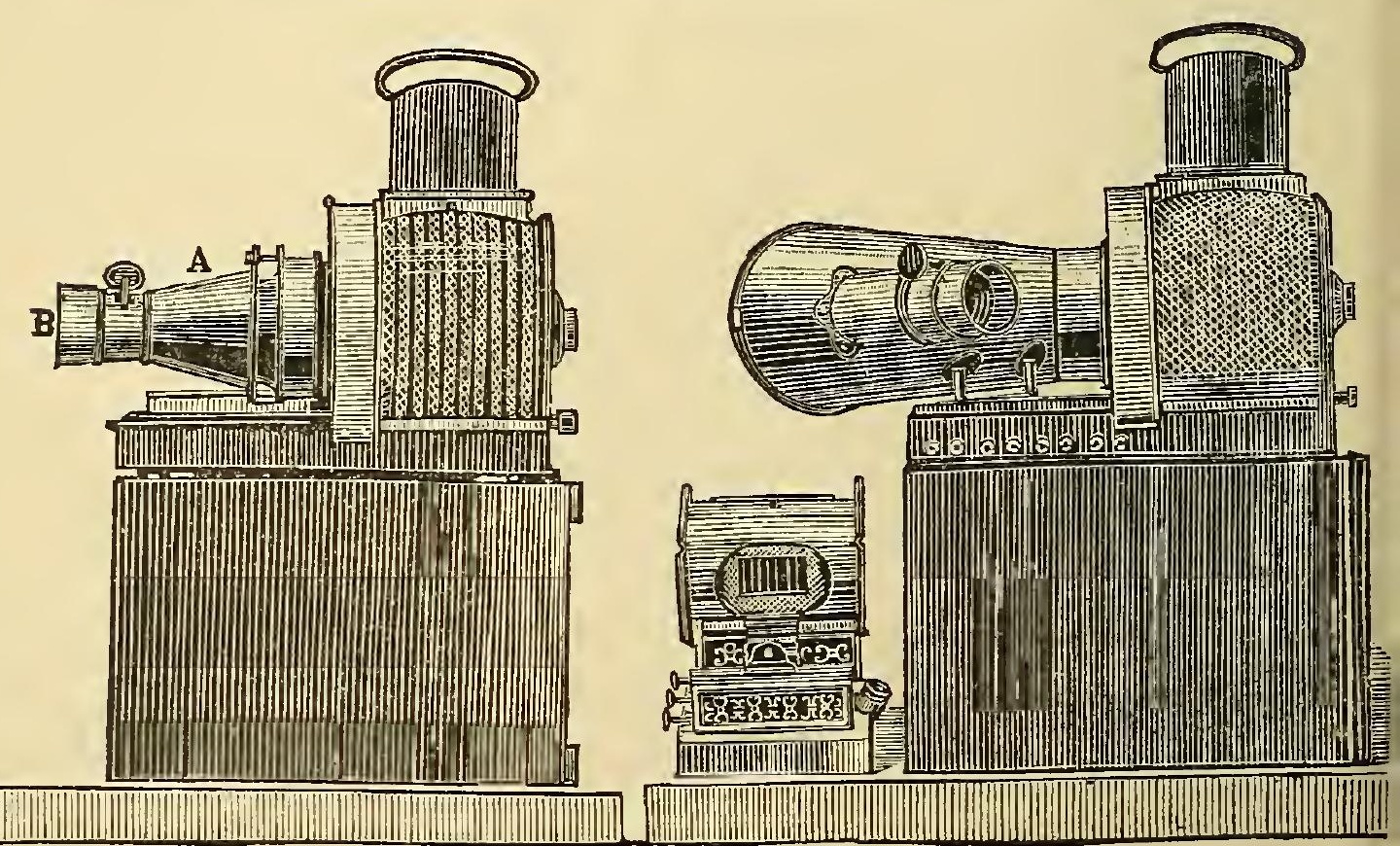

FIGS. 12 (a) AND 12 (b).

America as "The Scovill." It is made of Russian iron, 
jacketed, with a cool-air chamber round the condenser; and can be had with three, four, or five wicks. Also often fitted to it is a front for showing opaque objects on the screen. Figs. 12 (a) and 12 (b) show this complete apparatus.

But while a lantern-body for an oil lamp is necessarily of considerable size, we are convinced that lanterns for use with oxyhydrogen jets are usually made ridiculously large. A modern lantern, as usually made, is about three times as large and twice as heavy as it need be. With a lime jet there is no occasion for much unoccupied space, for no such draught is required as with an oil lamp, no chimney is required at all, and the only inconvenience to be feared is that of great heat. If the body be well jacketed, especially if the outer jacket be of wood, the total size of the lantern-body may be very greatly less than it usually is without affecting in any way the performance of the apparatus. Fig. 13 shows a lantern made by Messrs. Newton, of London, to the writer's order, and it embodies all the essentials of a perfect single lantern, though it is at least twice too large.

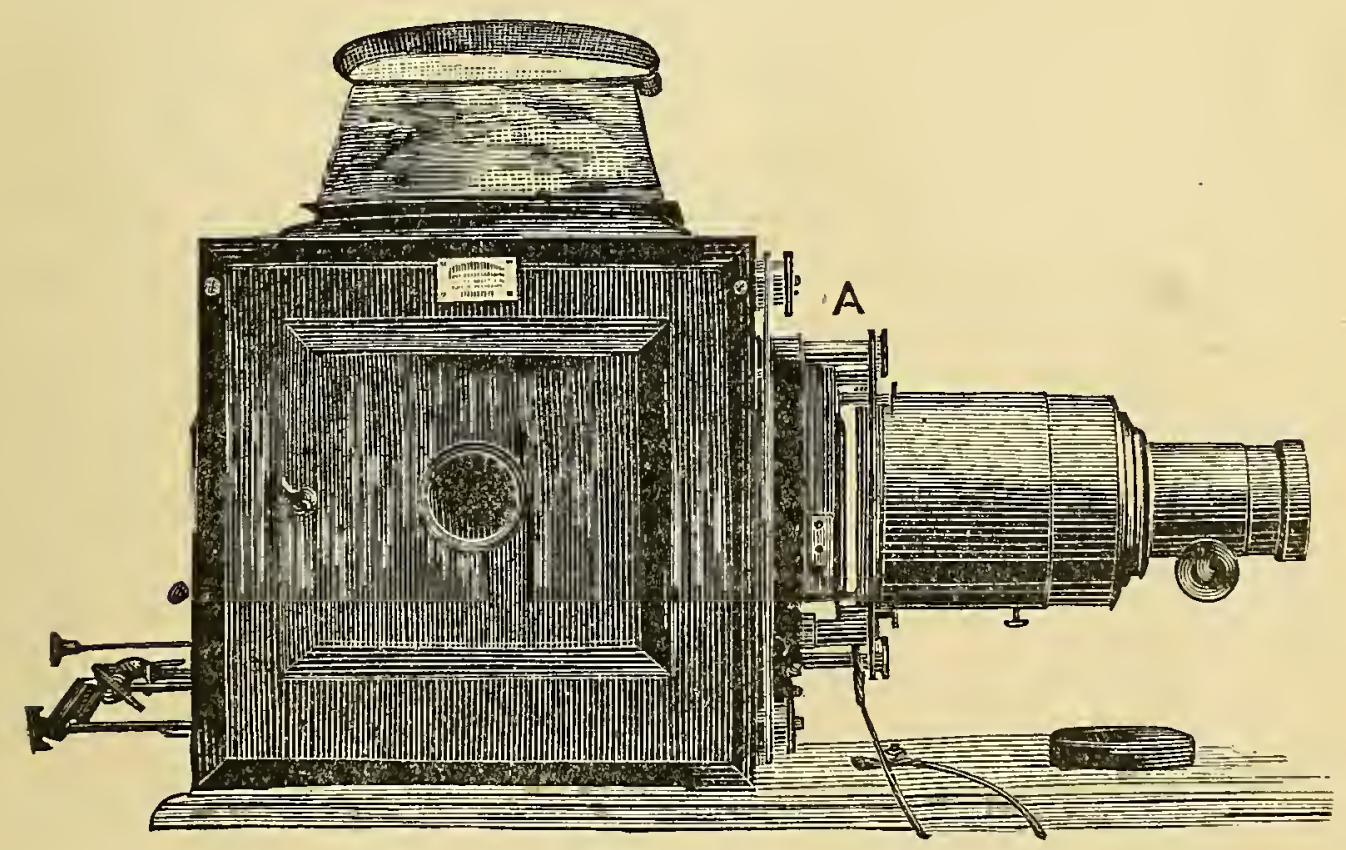

FIG. 13.

The receptacle at $A$, whereinto the "slide-carrier" goes, should lave its front provided with a spring sufficiently 
strong to hold the carrier in position while slides are being passed through. We propose to add to this part a couple of pinch screws, whereby the carrier once in position shall be clamped there. The space between the front of the condenser and the back of the "cone" or nozzle-tube to which the projection lens is screwed is sometimes required for a watertank or other scientific article whose image requires to be projected upon the screen. An "open stage" is easily devised, or a lantern specially adapted for such demonstrations may be used (see Fig. 42, page 77).

The projection lens is screwed or otherwise fixed to the "nozzle" of the lantern. This nozzle should "telescope" to a reasonable extent outwards, for on occasion a long-focus lens may be required, eight, ten, or even twelve inches focal length. It is very awkward to find that the nozzle will not stretch far enough for such a lens, when of necessity the lantern has to be a considerable distance from the screen. (If the lantern is to be used for "enlarging" purposes in photography there is all the more need for a long stretch of nozzle).

Our next figure (No. 14) shows a lantern constructed for us by Messrs. Oakley, of London, and though much smaller than the lantern shown in fig. 13 , it is precisely equal to the larger lantern in performance, the same condenser and lens being fitted to both. The dimensions of this miniature lantern are as follows: A to B six and one-half inches. $\mathrm{C}$ to $\mathrm{A}$ six and three-fourths inches. Width, five and one-half inches.

The entire lantern-body is of iron, rivetted throughout. When packed the lens goes inside, while the back of the condenser is protected by the tray, which keeps the lantern from falling forward when the apparatus is set up in use. The condenser is a four inch.

Messrs. Newton also make a "miniature" lantern, and Mr. W. C. Hughes makes one with a cylindrical body. If the condenser were made square the size of the body might be still further reduced; but as we can with ease carry our own lantern, packed with all its fittings, lenses, carrier and jet, in one hand, there seems to be no cause for further reduction of size. 
Lanterns have always side doors, sometimes a door on one side only, sometimes a door on each side. The door is usually provided with a window of colored glass by which the worker is supposed to view the light without hurting his eyes. The writer has never yet been able to judge of the light through such a window, and has never felt any bad effect from looking directly at the light with half-closed eye-lids, a way by which he can judge of the quality of the light. It is certainly necessary to have at least one door which, however, during a display

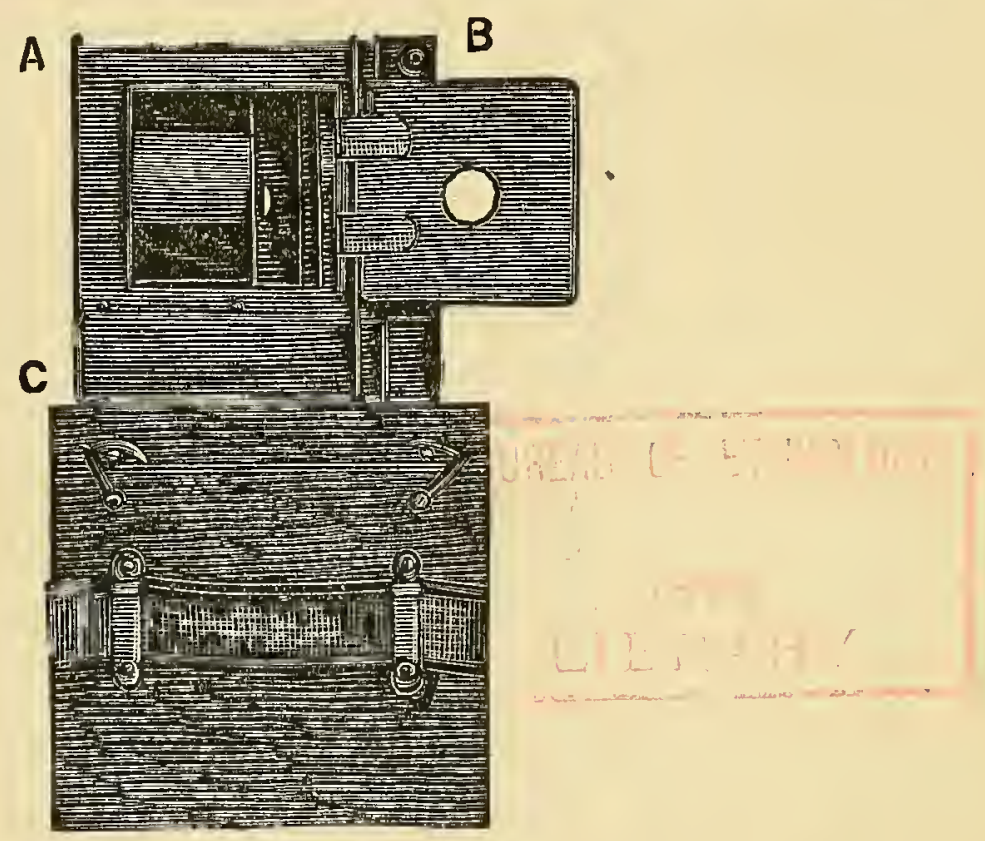

FIG. 14.

should be very seldom opened. In every lantern the writer remembers to have seen there has been a considerable opening at the back of the lantern where the jet goes in, and lecturers of any experience must have noticed the mischief caused by this opening if any of the audience happen to be seated behind and near the lantern. A person so situated can see next to nothing on account of the glare from the lantern. If the lantern have a wooden outer body a curtain of thick velvet should be fixed to the top of the back of the body, and hang loosely down over this objectionable opening; our large lantern, figure 13, has at the back a door sliding in runners, and this door is pushed down after the jet is in position, but even this is not a sufficient protection in all cases. When the 
lantern body is of iron a similar piece of cloth may be hooked on to the lantern by metal hooks so bent as to make the curtain hang free of the hot metal body, if the body ever becomes hot enough to singe cloth, which it ought never to become if the lantern be properly arranged.

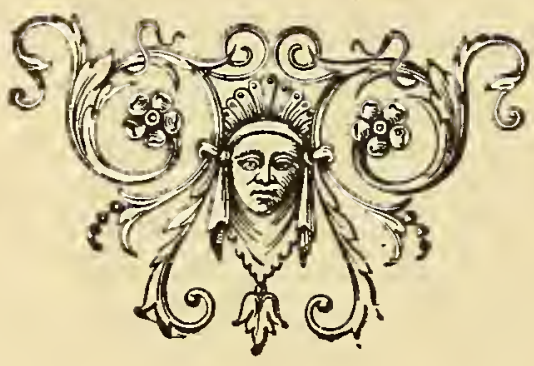




\section{CHAPTER VI.}

\section{DOUBLE AND TRIPLE LANTERNS, DISSOLVING}

VIEWS, EFFECTS, ETC.

WE now come to those edifices known by varions names and consisting of two or more lanterns made to work concentrically, which appear to be as necessary to the professional itinerant lecturer as they are useless to the scientific demonstrator or the photographic amateur, except in a few very rare cases. The chief uses of these multiple-lanterns are: For what is called "dissolving" one picture into another, and for producing so-styled "effects" which are peculiarly the province of the popular public lecturer. Some of these "effects" are interesting, "effective," sensational, and really pleasing, and ought not to be despised; we allude to changes from day to night, from one season to another; while others on which great ingenuity in slide-making is spent, do not come within the province of this book nor touch those for whom this book is specially intended. There are some who think that in the display of a series of ordinary photographic lantern slides there is an advantage in "dissolving" from one view to the next; that is to say, these parties prefer to see one image die gradually away and the next on the list grow gradually in a weird or "uncanny" sort of way out of the ghost of the last, rather than to have one picture follow another in the natural way. For our part we distinctly object to the dissolving business for ordinary slides, but provided the masks of the slides be all of one size and shape, and the lanterns accurately registered, and the views or pictures reasonably adapted for such treatment, which they very seldom are, then by means of a double lantern the desideratum may be attained. 'And further, if it is deemed requisite or desirable to have the appearance of a curtain being drawn at 
the beginning of, and persisting throughout the lecture, it can be achieved by means of a third storey of lantern, the lantern being then a triple or more gloriously a "triunial," the top storey being sometimes lighted by oil. All these luxuries are obtained only at the expense of a double or triple set of jets to look after, and to keep burning with equal brilliancefor if one disc is less bright than the other the effect is simply atrocious. If we are using, say, a double lantern, we have an arrangement usually very ingenious, often highly intricate, called a dissolver; if we are using gas in all three lanterns of a triunial the dissolver becomes a matter, sometimes, for a life-study. Still we do not seek to discourage the triunialist, nor to underrate the value of good "effect" displays.

In the early days of double lanterns the two lanterns were usually placed side by side, and the "dissolution" effected by serrated shutters in front of the projection lenses. We are indebted to Mr. George Smith, of the Sciopticon Co., London, for this detail sketch of the dissolver attached to his instrument. Of course there was a lamp in each lantern. Fig. 15.

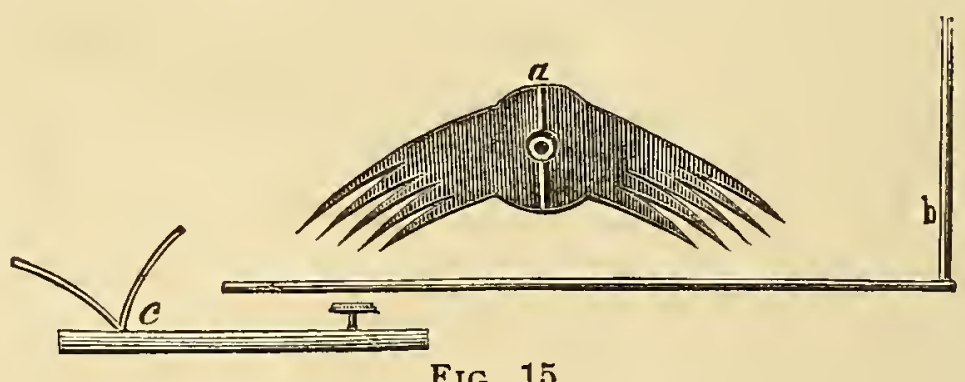

FIG. 15.

The dissolver $a$ is mounted on the arm $b$ by means of a screw, as seen in Fig. 15, so as to cover alternately the lenses as it swings from side to side. The horizontal part of $b$ slips into $c$ till the length of the united axle just allows the dissolver to swing clear of the lenses, and the whole is held in place by a socket spring at each end of the base-board.

The dissolver is operated by the handles at $c$, which are adjusted at the proper angle to limit the lateral movement of $a$ to the distance between the lenses.

Now, however, nous avons changé tout cela, and we place the lanterns one on top of another. There must be an 
arrangement for cansing the two discs to coincide precisely on the screen; this, of course, is managed by giving facilities for tipping the upper lantern down or the lower lantern up, or both. Or the hinged parts may be entirely in front of the lantern-box proper, and the tipping may include only the front plate and all in front of it. The latter system is perhaps the most convenient. Double or biunial lanterns are generally made all in one piece, and the two lanterns cannot be separated, but it seems customary to make triples

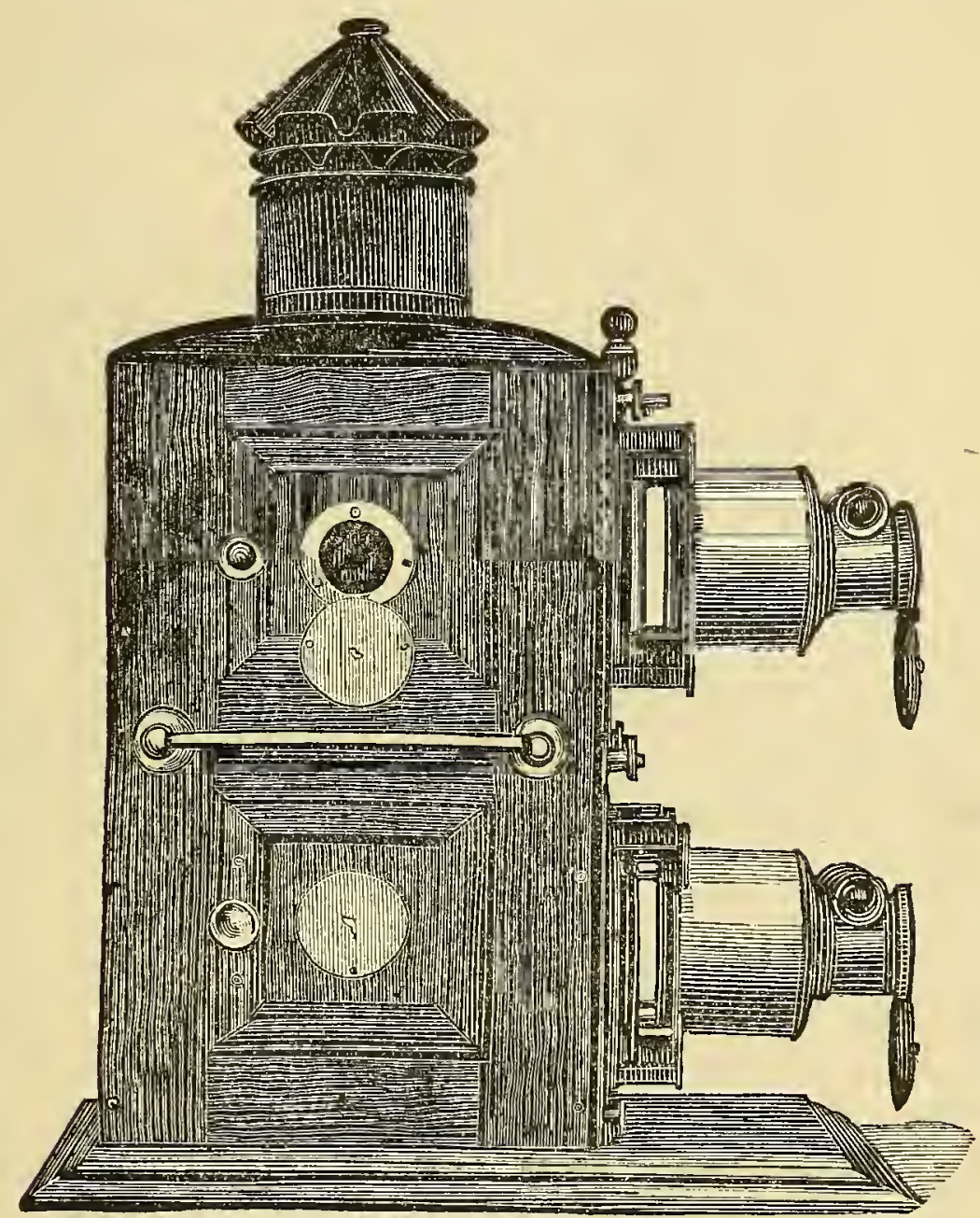

FIG. 16.

in separate parts-the top lantern almost always can be removed-so that if we have a triunial we have three separate lanterns. We figure a double and also a triple lantern which will stand each as a type of its own class; so far as we have 
seen, the chief variations in these articles consist rather in the amount and finish of the brass-work, and in the price, than in any really essential qualities.

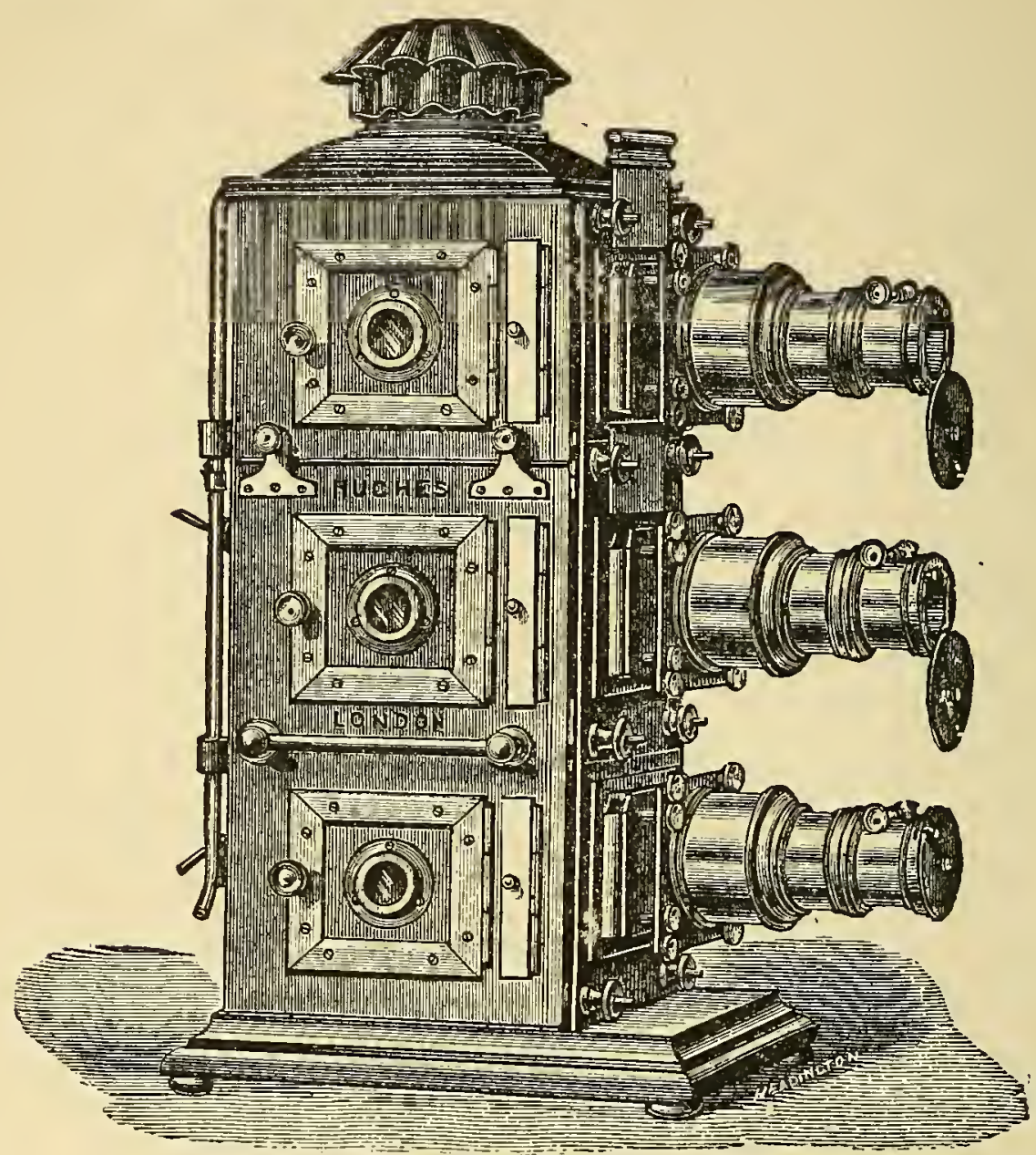

FIG. 17.

From what has been said it will be readily believed that the arrangement for the distribution of the gases in suitable proportions to each jet, without loss of time or uncertainty from any one to any other of three lanterns, without waste of gas, must be a problem of considerable difficulty of solution. It is, however, excellently solved by more than one "dissolver." We shall figure only two, and while Fig. 19 explains of itself the working of the instrument called the "One Plug," and made by Messrs. Otway \& Son for triple lanterns only, the other gives a better idea of the general arrangement of a dissolver for a double lantern. 


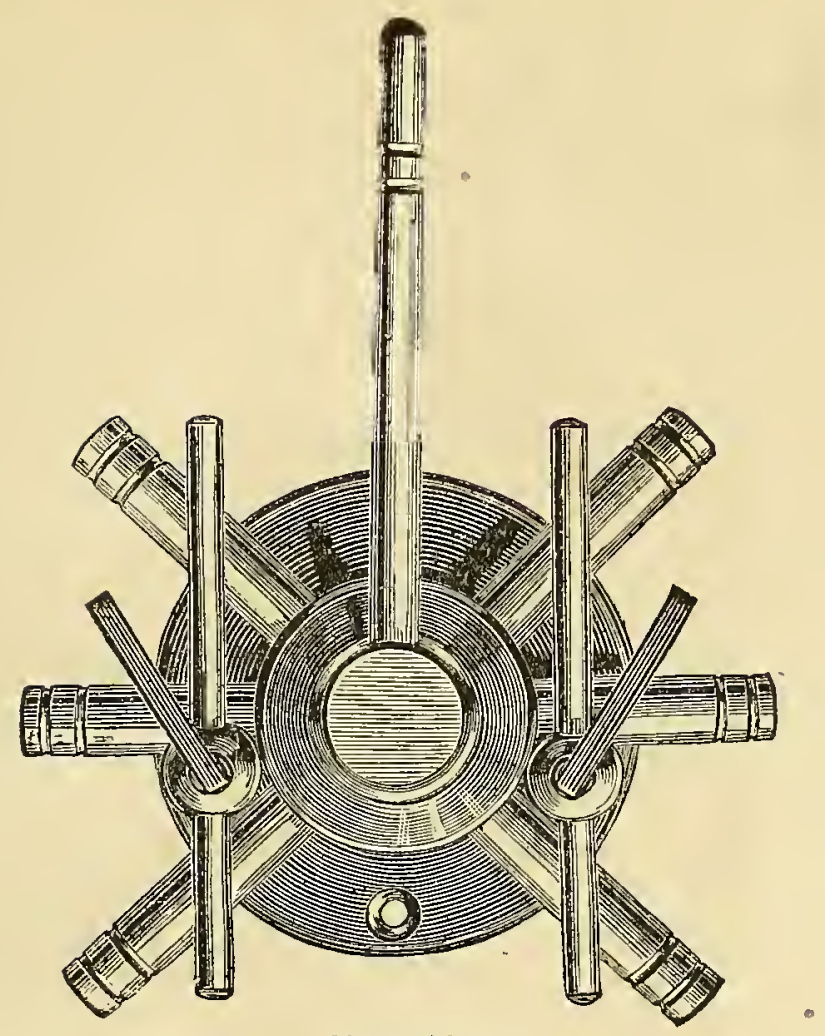

FIG. 18.

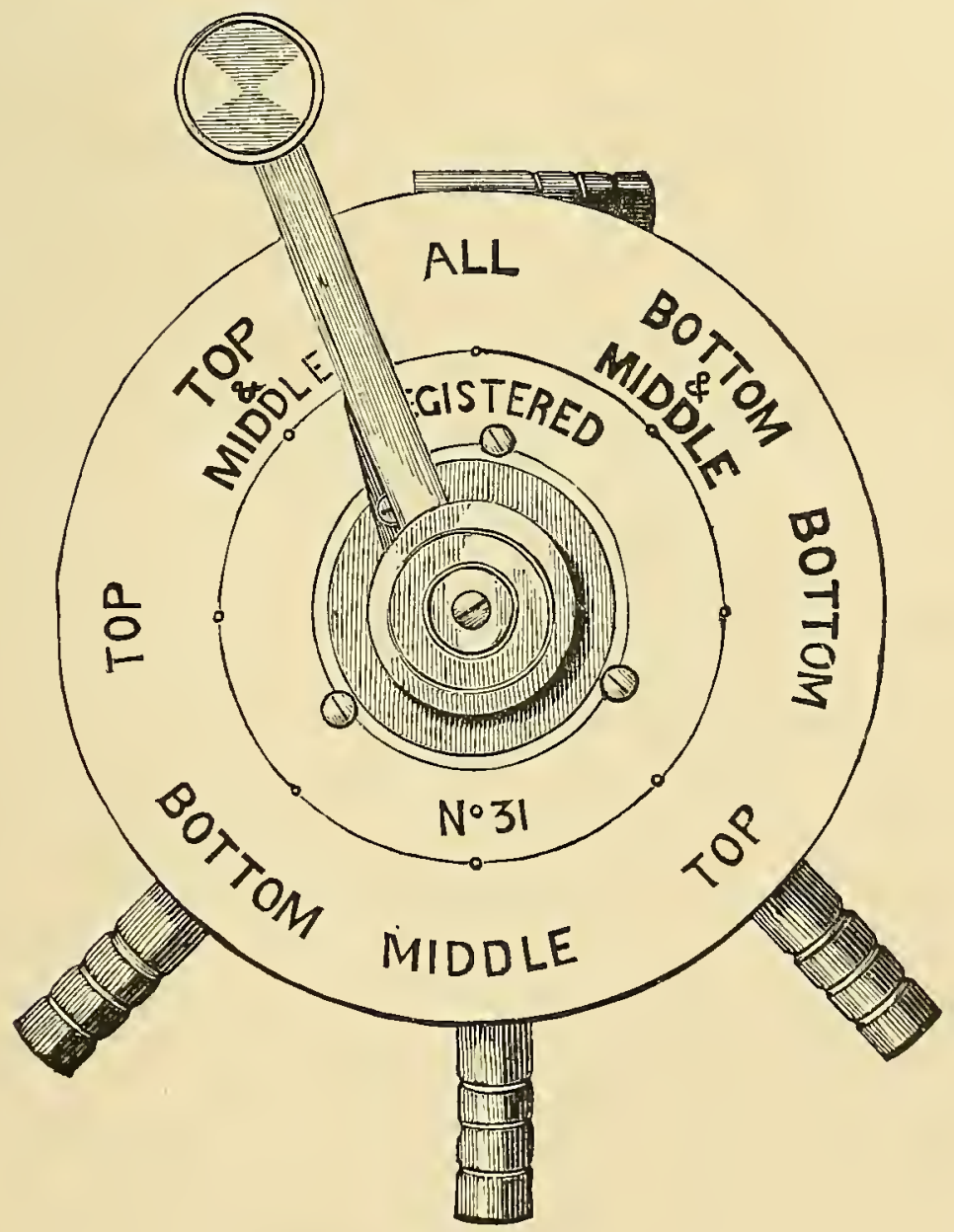

FIG. 19. 
In all cases, of course, there must be a "bye-pass" on the hydrogen; in some there is a bye-pass on each of the gas tubes, with a pair of "blow-through" jets, for instance, it is necessary to have a bye-pass on the oxygen as well as the hydrogen. It will be noticed that the "Star" dissolver, as it is called (Fig. 18), has a bye-pass (the small tap) on each side, as well as the long arm for the regular "dissolution." The bye-pass on the $H$. side has its evident use; the O. bye-pass is requisite to prevent a "pop," or slight report, on dissolving after a prolonged time of projection from the other lantern. In testing a dissolver we have to note whether there is any noise on effecting the change, whether any time is lost before the second lime is fully beated, and whether any gas is wasted. A dissolver that requires only one hand to work it is naturally preferable to a less convenient one. For certain reasons we recommend that the long arm in Fig. 18 be prolonged to the same extent as shown, on the other side of the central boss.

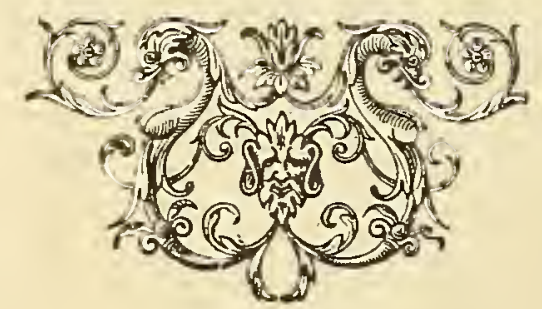




\section{CHAPTER VII.}

\section{THE LIME LIGHT. 1. THE JETS.}

The radiant most commonly used, and as we think the best to use in the optical lantern, is known as the lime-light, or sometimes as the oxy-hydrogen lime-light. A point on the surface of a disc or cylinder of unslacked lime is rendered incandescent by the action of an oxy-hydrogen blow-pipe; the lime is very "refractory," i. e. very difficult to cause to burn, but when it is rendered incandescent its incandescence is very brilliant. There are "soft" limes and "hard" limes, the soft ones being rendered incandescent more easily than the hard ones, and so the former are used when the heating power of the blow pipe is not very great, as for instance, with the so-called oxy-calcium light, or the "blow-through" or "safety" jet. But to get the best result possible with the lime-light, i. e. to get the greatest brilliance over the least area, we must use the hardest lime and a blow-pipe of proportionate heating power.

The oxy-calcium light calls for little remark; it is much less brilliant than the next higher light, the blow-through. In the

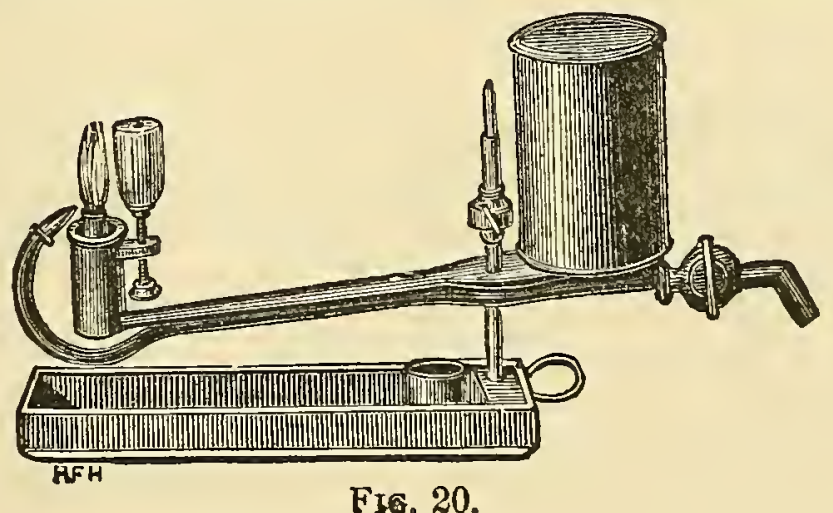

F5. 20.

oxy-calcium system we have a reservoir of spirits of wine; a tube from reservoir to nozzle, where there is an ordinary wick. 
The spirit is lighted at the wick in the usual way, and a stream or jet of oxygen gas is driven through the flame to the lime which is rendered incandescent, and gives a fairly bright light, estimated approximately at " 150 candles."

We figure (No. 20) an oxy-calcium jet.

The blow-through jet comes next in order of brilliance of light attainable.

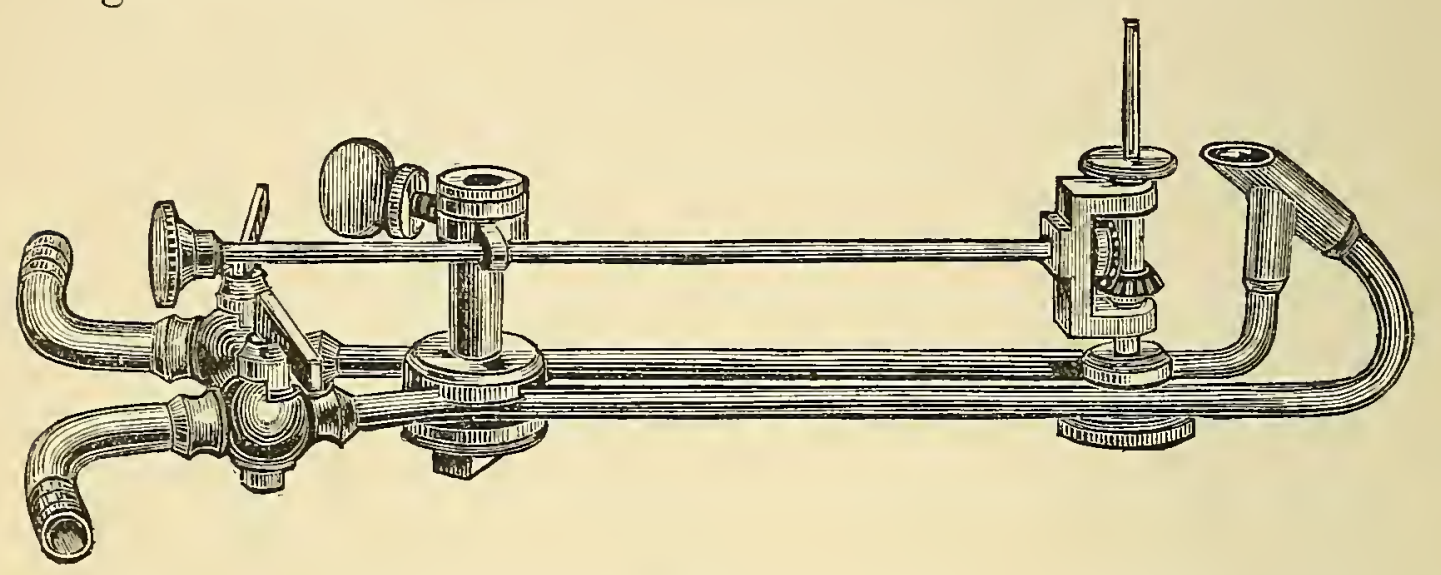

FIG. 21.

The nozzle is made in slightly varying forms, but fig. 21 shows a very good form, made by Mr. Hughes, of London. In the blow-through jet we use a fairly large column or stream of hydrogen gas, either direct from the usual house-supply or under a pressure low when compared with that of the mixingjet. In or near the ceutre of this quietly burning stream of hydrogen is a small nipple, through which oxygen is forced at

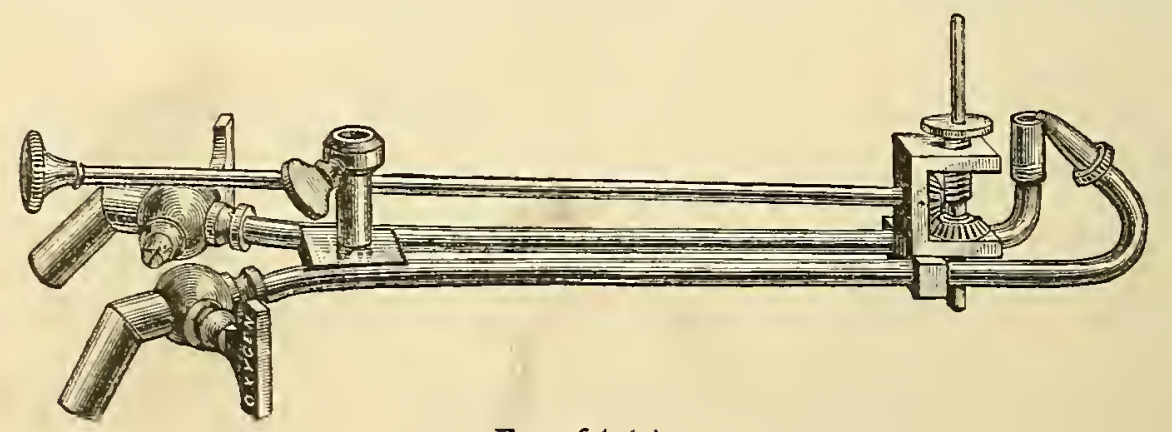

FIG. $21(a)$.

some pressure greater than that on the hydrogen; the oxygen is blown through the hydrogen flame, whence the name given to this jet, which is also sometimes called the "safety." Fig. 21 (a) shows a form of blow-through jet which gives as good 
a light as any form known to us. It is made by Messrs. Newton. The estimated power of a good blow-through jet is 250 candles, but a disadvantage of this system is that the area of incandescence is generally large when the greatest total of light is given off, and the light is apt to be red in tint.

The same gases are used in the mixing-jet, but both gases are usually under high pressure, and they are mixed in a chamber before they emerge from the nipple where they are lighted. The reason for the nomenclature is thus evident, and on the completeness of the mixture of the gases depends in a great measure the amount of heat, and consequently of light produced. Our fig. 22 shows a very good style of mixing-jet,

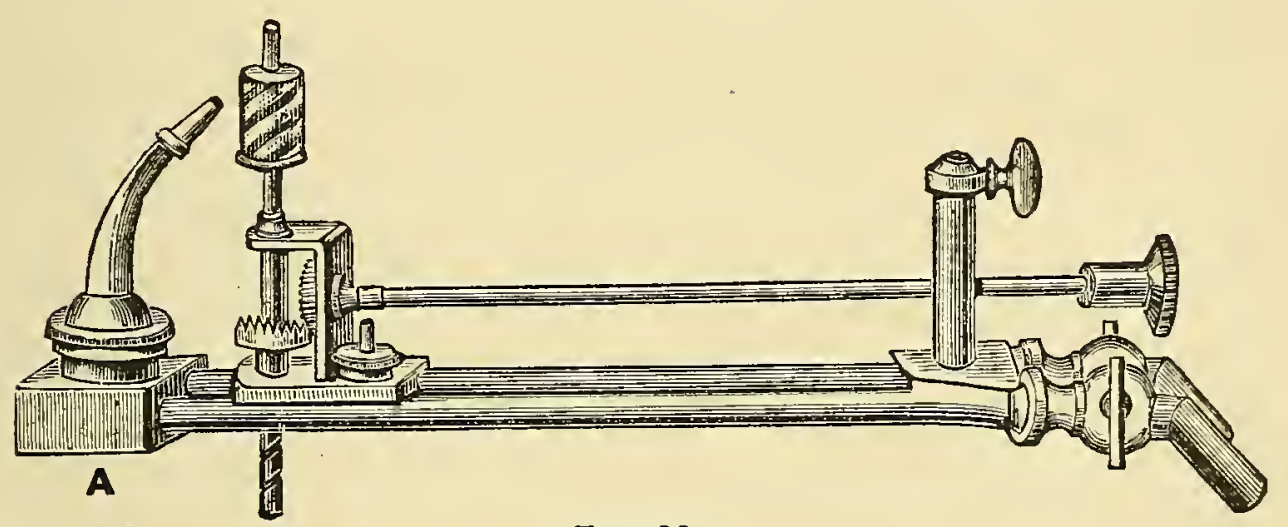

Fig. 22.

made by Mr. Place, of Birmingham, England, at a cheap rate. A. is the mixing chamber.

In order that we may obtain the very best results certain principles must be attended to in the construction of all kinds of jets where the gases are under pressure, however low.

In the gas-way there should be no sharp turn or acute angle corners; even in the mixing chamber the "jostling" of the gases may be too violent. We do not ourselves recommend the putting of any obstacle whatever in the gas-way. Many jets by the best makers contain near the mixing chamber pieces of fine gauze. Whether this is intended to insure effective mixing of the gases, or whether it is put there with an idea of greater safety we cannot say, but we invariably remove and throw away the gauze. Some makers have themselves admitted to the writer that they knew of no advantage 
belonging to the gauze, but that it was put there in deference to public opinion only. Many other substances have at one time or another been put in the gas-way-cotton, wool, shot, powdered pumice-stone, and even lengths of cane; for what object unless to cause failure and danger we have never yet been able to ascertain. With ether tanks and such arrangements there must be value in any device that will prevent a suck-back of gàs, or will extinguish gas if sucked back lighted. We would not be misunderstood with regard to our position on the ether-oxygen question. There is no necessity whatever for accidents with the "eth-oxo" system; accidents with it have occurred always through some mismanagement, or misunderstanding, or carelessness; but the fact remains that they have repeatedly occurred, even in experienced hands, and when they do occur the results are always alarming, often disastrons. Were there no system except the ether one, the writer's opinion might be modified, but as oxygen and hydrogen are easily made, if not easily procured, and as the common oxyhydrogen light is certainly equal to, probably superior to the ether-oxygen, the writer does not dare to recommend the only system that has, so far as he knows, led to any disastrous results, except such as could be accounted for by the very grossest carlessness or ignorance on the part of those who

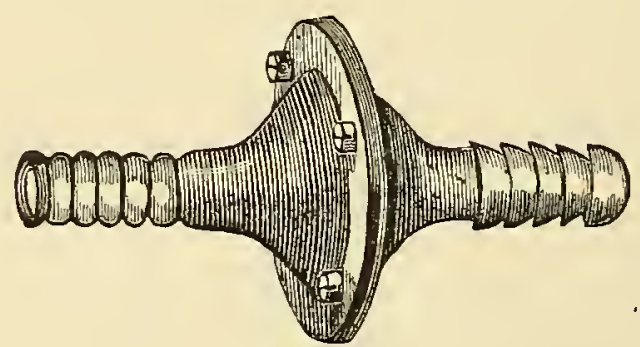

FIG. 23.

came to grief in working the ordinary system. The writer is the more satisfied as to his wisdom in this matter from the fact that he is professedly writing for beginners in lantern matters. There should be no obstruction, then, in the gas-way, but if there is to be obstruction at all the gauze alluded to will do little harm, and a certain safety-valve may give confidence to a timorous worker. We show this valve, figure 23 ; by means 
of a simple internal arrangement gas is allowed to pass one way only. We believe Mr. W. I. Chadwick devised this.

A very important point toward the production of a good result is the angle at which the gas-stream impinges on the lime. A simple figure (No. 24) will illustrate this.
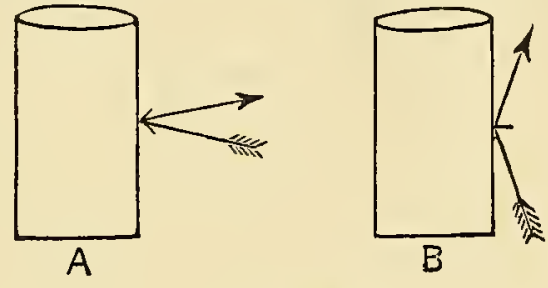

FIG. 24.

$A$ and $B$ may be taken as extreme cases. If the angle of impact be such as suggested at $A$, the nipple of the jet would come between the point of radiance and the condenser, and in fact there would be a shadow of the nipple on the condenser. Moreover, the lime would be worn into a very deep "pit," which always hurts the light and endangers the condenser, because the little brilliant pit might have its heat-focus on the condenser, and even the flame itself might glance off the lime at such an angle as actually to strike the condenser. On the other hand, in $\mathrm{B}$. the gas-stream impinges on the lime in such a slanting manner that the impact would be very imperfect, and there would be a want of "grip," so to speak. Mr. Lewis Wright, a great authority in such matters, worked out the theory and practice of this subject, and as a result Messrs. Newton of London, England, produce a mixingjet which is in the writer's opinion perfect, and has been in his practice invaluable (Fig. 25).

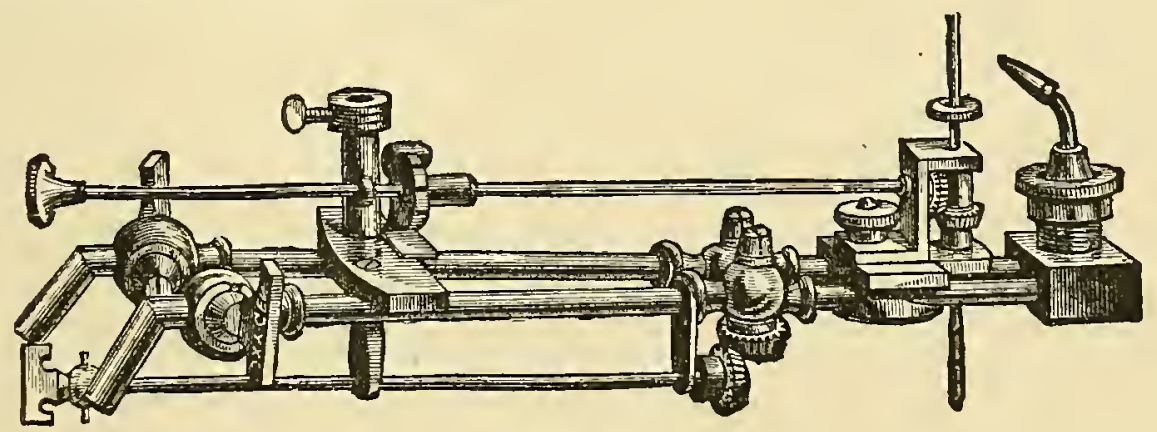

FIG. 25.

As this jet shows some novel features we shall have to recur to it. 
The bore of both tubes and nipples varies in various makers' jets. It is impossible to lay down any laws on this matter. Perfection of light depends not on any absolute or isolated item, but on the proper adaptation of one part of the system to another. In particular, it may be said that the pressure of gases regulates all other conditions. A small bore tube may give a better light than a large bore, at a less expenditure of gas, if the pressure happens to suit the smaller tube. A large bore nipple works at a decided disadvantage if the pressure of gas be not up to a corresponding point. Doubtless the very best light is to be got from a large bore with a great pressure. Perhaps the greatest mistake made in ordinary practice is having a bore too large for the pressure. For general use the calibre of both tubes and nipple should be small rather than large.

Every one who has worked with lime-light knows the unpleasant effect of "hissing," "buzzing," "whistling," or "roaring," by the jet. These noises may be due to various causes; improper proportion of the gases to each other, improper position of the lime in relation to the nipple, pitting of the lime, etc.; but the commonest cause is roughness in the tubes or nozzle, protrusion of shreds of metal into the gas-way, square corners in the gas-way, in fact, any rough edge or unevenness inside the tubes. Sometimes the noise may be stopped by cleaning, or broaching, or riming out the tubes, but sometimes jets are so badly made that noise is inevitable at any pressure over a very low one. Any jet may be noisy under certain conditions; a jet should not, ipso facto, be rejected on account of noise. If a jet is a good one otherwise, but is noisy, it should be examined, cleaned out, rimed out, if necessary; failing these remedies, if the noise is intolerable it may be rejected, but reduction of pressure is likely to obviate the noise.

The "nipple" of the nozzle of a jet sometimes screws on to the nozzle, sometimes is in one piece with it; sometimes is entirely of brass, sometimes has a platinum tip let into it. Some first-class lanternists find no advantage gained by the platinum tip, while others advocate it. If the tip is used, it must be properly adjusted to the brass, so as not to form a projection into the gas-way. Sometimes in very 
powerful jets the platinum-tipped nipples lead to trouble, on account of the platinum separating or burning out from the brass. In our opinion the bore of the nipple should be an uninterrupted cone in shape.

All taps and fittings of a jet, especially of a mixing or highpressure jet, should be of the best manufacture and finish. The nozzle often is removable from the nixing-chamber, a very good plan, but the collar by which the junction is made must fit accurately and be tightly screwed up. There should never be any leakage even under the highest pressures.

Jets are sometimes made "interchangeable"; that is, supposed to act either as blow-through or mixing by a change of nozzles. We do not recommend this kind of jet, the same kind of "chamber" is not well adapted for the two systems.

As ether tanks, or "ether saturators," and saturators for use with other volatile substances, are frequently used, and as they are very convenient when hydrogen is not obtainable we shall describe one or two such contrivances, drawing attention, however, to the danger incurred if carelessness creeps in, and to the fact already mentioned, that we do not expect any gain of light over that of a good mixing jet. The principle on which ether saturators all work is this: Oxygen is passed over ether, which may be sulphuric or petroleum, and in passing is saturated with the vapor of the ether and then is conducted to the $H$ tap of the jet, while part of the oxygen that reaches the tank passes directly and unsaturated to the O. tap. In some tanks the ether is in the liquid state, lying in divided chambers, over which the oxygen passes; in others, flannel or a similar substance is thoroughly wetted with the ether, and the oxygen passes over or through layers of the damp material. The Broughton ether tank, for instance, is a simple oblong vessel of copper, divided longitudinally into two parts, the lower part having a number of compartments wherein the ether lies. The oxygen passes over the ether into the upper part of the tank, and thence to the jet, while, by means of a T-piece at the entrance to the tank, part of the oxygen is conveyed direct to the jet, while the rest is charged with ether vapor, as described. The Ives saturator is different in form 
from the Broughton, and the Ives contains flannel impregnated with the volatile liquid, but the principle is the same.

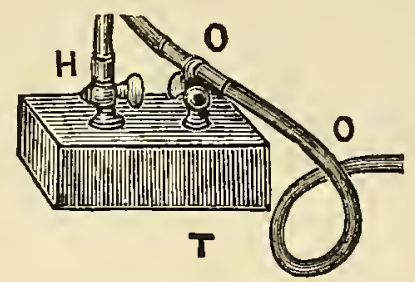

FIG. $25(a)$.

Figure $25(a)$ shows Broughton's, Figure $25(b)$ shows Ives' saturator.

In both cases, $O$. represents the oxygen supply, $H$. the saturated oxygen tube leading to the $\mathrm{H}$. tube of the jet.

Quite recently Mr. A. W. Scott has introduced a saturator, wherein he uses benzole, benzoline or gasoline; the principle

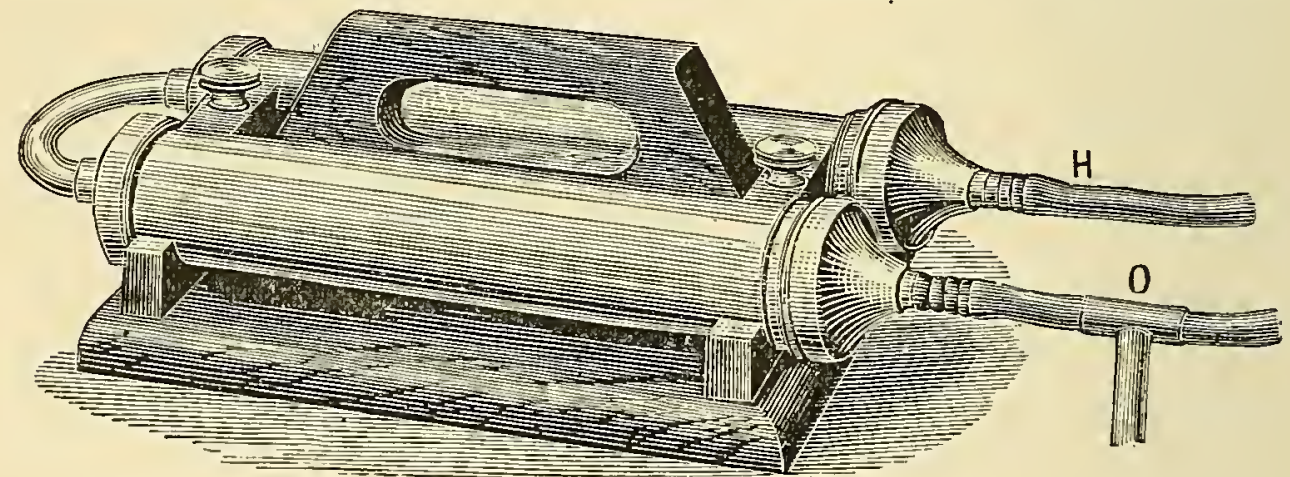

FIG. $25(b)$.

of saturating the oxygen remains the same, but the manner of carrying it out differs somewhat in Mr. Scott's contrivance from the saturators just described.

Figure $25(c)$ is a section of Mr. Scott's gasoline saturator. The central chamber (shaded in the figure) contains flannel, which is impregnated by pouring the volatile fluid in at $\mathrm{E}$. $F$ is a "night-light" or small candle, used to heat the air around the fluid slightly. C. is connected with the oxygensupply, B. with the oxygen tap of the jet, $\mathrm{A}$. with the hydrogen tap. As before, part of the main oxygen supply goes direct to the jet, part passes through gasoline, benzoline, or benzole vapor and thence to the jet.

With all saturators, when the light is to be extinguished it 
should be done at the jet taps first; if the gas supply is cut off at the bag or cylinder first, a small explosion will probably occur, a "pop" at least.

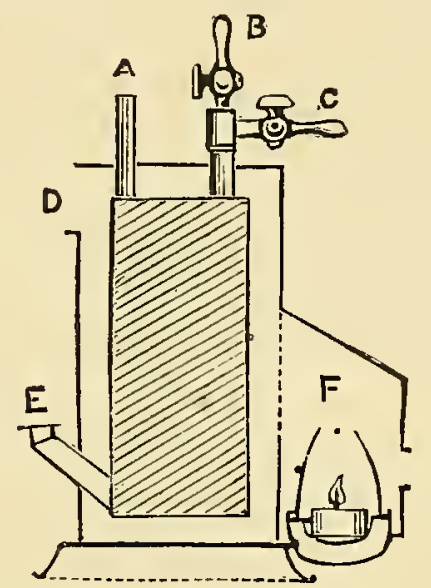

FIG. $25(c)$.

A "safety-chamber" should be used with saturators always; this chamber may be the "mixing chamber" of the jet or near it, and the best material for packing it appears to be pumice stone in small pieces. It need hardly be said that the greatest care must be taken not to overturn a tank containing liquid volatiles, nor must any oxygen or other gas be pressed into the liquid itself. 


\section{CHAPTER VIII.}

\section{JETS CONTINUED, DETAILS AND ACCESSORIES, TUBES AND TAPS FOR GASES LIME TURNERS, JACKET.}

IT is always important to know at the very instant, and without possibility of mistake, which tube conveys the oxygen and which the hydrogen. Often, too, it is important to know by touch as well as by sight. Accordingly we recommend that one tube be blackened, the other left bright. Further, we advise that the two taps be of different shapes. Our own practice is to have the $\Pi$ tube black and its tap the common T-shape, while the $O$ tube is bright and has an "arm-tap," such as seen in Fig. 24, which, moreover, we roughen or nick with a file.

As the impact of the burning gases on a small area of the lime sooner or later bores a small hole in the lime-in technical language the lime becomes "pitted"-or a "pit" is formed -and as this pit not only spoils the illumination but endangers the condenser, it is important to have a good system and apparatus for turning constantly or frequently a new part of the lime's surface to the action of the gases. The more powerful the blow-pipe heat the more frequent the necessity for a fresh lime surface. With the most powerful jets it used to be considered almost essential that the lime be constantly turning; this was usually effected by clockwork; with an average mixing jet and pressure the lime ought to be turned at least once every minute. But with a blow-through jet of ordinary power the lime-point does not attain its full incandescence till the gases have played upon it for, say, one second, and in this case the lime ought not to be turned so often. We have some very crude methods of turning the lime, some very neat 
ones. The old inconvenient method consisted in opening the lantern door and turning the "chair" round with the hand. Nowadays the chair is usually operated by a rod and some kind of $\operatorname{cog}$ wheel arrangement, the rod being long enough to protrude backwards to the outside of the lantern, in a manner shown in all our figures of lanterns with jets. Mr. Place, of Birmingham, designed an exceedingly good quick motion action for the lime turning. Messrs. Newton further improved this by adding a check-action, or click action, the effect of which is that the points presented consecutively to the gas-jet follow a regular spiral course round the limecylinder, the eighth pit being directly below the first 'see Figs. 22 and 25).

Fig. 25 shows a detail not yet explained, but in the opinion of competent judges a valuable addition to a jet. Below the jet proper may be seen a rod with a T-piece at one end and operating toothed wheels under the jet tubes. In each of the two tubes is placed an extra tap, that on the oxygen tube being a complete "cut-off," while that on the $H$ tube is a "byepass" allowing a small quantity of $\mathrm{H}$ to pass even when the tap is turned off as far as it will go. The two taps work equally, and are simultaneously operated by means of the rod and the toothed wheel attached to it. If now these two taps be turned full on by means of the cross, or T-piece, and if the light be then adjusted at its best by means of the ordinary jet taps, the light may be turned down by the "cut-off" arrangement, the hydrogen will continue to burn a small flame, and the lime will be kept hot, and when the full light is required all that is necessary is to turn up the "cut-off" arrangement to its full extent. Thus, 1st, gas is not wasted; 2nd, an experienced hand may regulate the light, turn it down and leare it; any person, however inexperienced, may then turn up the "cut-off" and find the light just as the expert arranged it; $3 \mathrm{~d}$, the proportions of the gases being maintained the total brilliance of the illumination may be regulated by one motion; where miscellaneous slides are being passed through a lantern, some dense, others thin, this facility of, regulation will be found of value. This "cut-off," devised by the author, is made by Messrs. Newton, of London, and others. 
Messrs. Oakley, also of London, make an arrangement similar in intention but dissimilar in execution.

Lime-cylinders are very apt to crack during an exhibition, and a lime once cracked never gives a perfect light. Considering that draughts of cold air acting on the lime causes this cracking, undoubtedly the case often, Mr. E. G. Wood, of London, devised a "shield" of metal a little wider than the lime-cylinder, and long enough to protect the cylinder even when turned to its highest point. Of course an opening in the side of the shield allows the gas to impinge upon the lime.

Most persons of a mechanical turn of mind will notice the very insecure way in which the jet is nsually fixed to the pin or standard forming part of the "lime" tray. The jet is fixed in such a position that the slightest force on the long arm of the lever must uncentre the whole jet. Few attempts have apparently been made to improve this matter, but Mr. Pumphrey, of Birmingham, Eng., has an arrangement worthy of notice. Fig. 26.

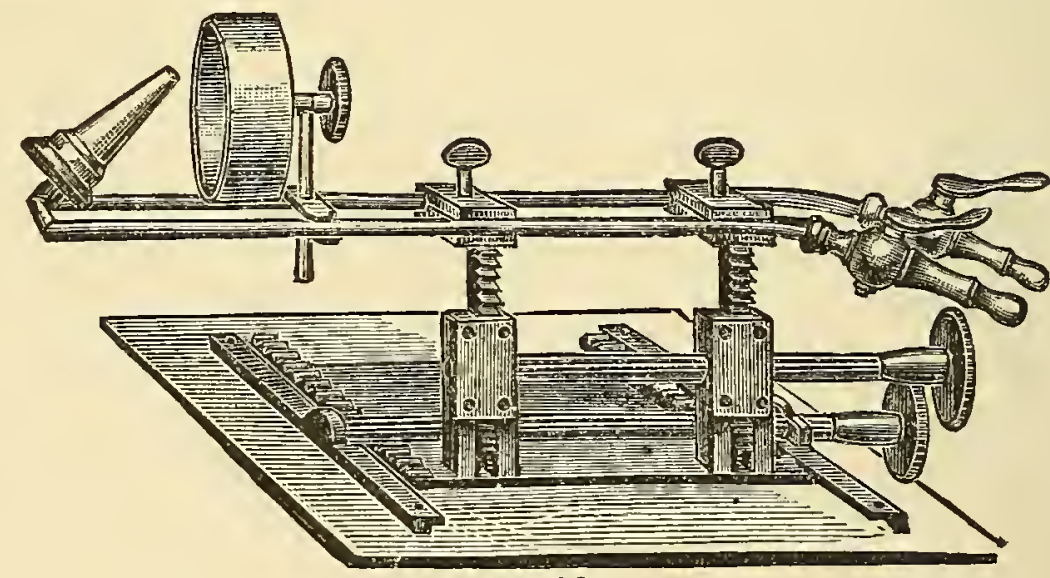

FIG. 26.

Here, in Mr. Pumphrey's "mechanical stage," we have the usual backward and forward sliding motion of the tray, and also a raising and lowering rack as well as a "traverse" and a double grip of the jet. The figure also shows the receptacle for lime-discs, seldom used now so far'as we know.

The writer effects a double grip on the jet by means of a pair of "jaws" so arranged as to clamp the jet by the mixing chamber to the bottom of the lantern when once the centre and focus are found. 


\section{CHAPTER IX.}

\section{PREPARATION OF OXYGEN AND HYDROGEN.}

Chlorate of potash heated to a fairly high temperature will yield oxygen, but the evolution of the gas in such a case is apt to be unsteady and difficult to control. If, however, "black oxide of manganese" (manganese dioxide), is added to the potash salt, the gas comes off at a lower temperature and more steadily. But when the manganese is used a certain amount of chlorine comes off with the oxygen; and this chlorine, being destructive to india-rubber bags, and even to metal fittings as taps and tubes, should be as far as possible eliminated before the oxygen reaches the bag or gas-holder where it is to be stored. We heat our chlorate of potash and oxide of manganese-the mixture being sometimes called "oxygen mixture"-in a retort made of metal; the oxygen with its accompanying chlorine is passed through water containing a chemical which abstracts the chlorine, thereafter the oxygen is sometimes dried over sulphuric acid, sometimes passed direct into the bag or other receptacle for storage.

The chlorate and manganese do not combine in the oxygen mixture, nor does the manganese undergo any permanent change during the heating, but is probably converted for the time being into permangate of potash, which is at once decomposed. After the operation of gas-making the manganese oxide remains, and can be used again if it is considered worth the trouble of washing and drying what remains in the retort. Manganese dioxide gives off oxygen at a red lieat, but is not so far as we know used for this purpose.

The usual instruction for nlaking oxygen gas is to take four parts of $\mathrm{KClO}_{3}$ (clilorate of potash) and one part of $\mathrm{MnO}_{2}$ (manganese dioxide) and mix them. These proportions are a very good average, but our own practice is to take the 
required amount of $\mathrm{KClO}_{3}$ and stir up with it $\mathrm{MnO}_{2}$ until every crystal of the former is black with the latter. The mixing should be done with a wooden or bone rod or spatula, not with a metal instrument. As a rule the $\mathrm{KClO}_{3}$ is pure enough as sold, but sometimes the ignorant or unscrupulous trader adulterates his $\mathrm{MnO}_{2}$ with soot or charcoal, and sometimes by accident sulphide of antimony is substituted for or mixed with $\mathrm{MnO}_{2}$. Either soot or the antimony being present in the retort with the chlorate would be a source of great danger, but the mixture may be very easily tested. If a few grains of the mixture be placed in a test tube and held over a flame, and if on gentle heating little sparks are seen accompanied perhaps by a slight crackling, the mixture is correct. But if there is a flash or a little explosion, the mixture is dangerous. When $\mathrm{KClO}_{3}$ is bought in bulk there is almost always mixed up with it a quantity of organic matter, bits of wood, paper, we have even seen moss; these must be carefully removed, as they might lead to trouble in the retort.

One pound avoirdupois (sixteen ounces) of the oxygen mixture will yield four cubic feet of oxygen-theoretically it ought to yield rather more, but we never could get more ont of it, using ordinary chlorate of potash of commerce, which is good enough for the purpose. Some years ago it was suggested that in place of or in default of $\mathrm{MnO}_{2}$, common kitchen salt might be used. And certainly this is the case ; if the chlorate be pounded along with the salt, or the salt carefully mixed with the pounded chlorate, the oxygen comes off very gently and steadily, and the yield of oxygen in proportion to the chlorate is good. Iron rust or sand, and doubtless other substances may be used for the same purpose as $\mathrm{MnO}_{2}$, and we note that Mr. Hepworth* uses both $\mathrm{MnO}_{2}$ and salt. We find nothing works better than $\mathrm{KClO}_{3}$ blackened with $\mathrm{MnO}_{2}$.

The mixture being ready is placed in the retort. Figure 27 shows the kind of retort that we can recommend from experience.

* "The Book of the Lantern." By T. C. Hepworth, F.C.S. Wyman: London, 1889. 
The body is conical in section, made of wrought iron, brazed and riveted. The neck screws on to the body and a washer of mill-board or felt impregnated with asbestos is placed between body and neck. Sometimes the bottom is made of copper, this costs more and is unnecessary. At the

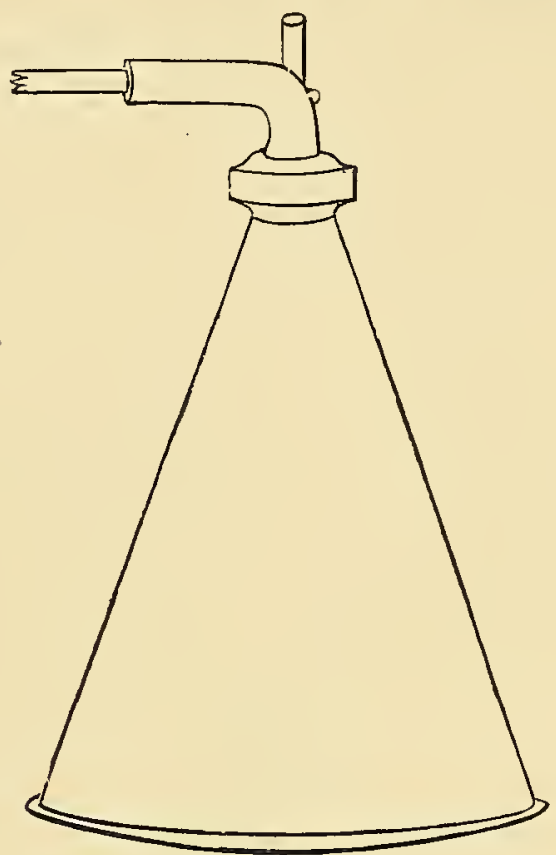

FIG. 27.

top may be seen a small cylindrical projection; in this is placed pretty tightly a cork, and so a safety-valve is obtained. If any stricture occur in the gas-way the cork will be blown out. The neck of a retort should never have a square turn, but always be rounded, as in Fig. 27.

No violent heat is needed to drive off the oxygen, in fact, too much heat, especially at first, retards operations, seeming to cause the mixture inside to form a cake, with an outside more or less impervious to heat. The retort may be put on a dull red fire, but we prefer a gas burner such as some made by Fletcher, of Warrington, Eng., under such a name as " radial" burner. A coke stove makes a good heating appliance, and even an apparatus with a very large wick, known as a "lamp stove" may be employed. But the radial gas burner is probably the best. If by sinking the retort in a suitable receptacle over the burner the heat can be made to surround 
the retort, so much the better, especially if there be a large quantity of "mixture" in proportion to the size of the retort.

From the retort the gas passes along the neck-tube to a purifying bottle. This may be any wide-mouthed bottle, having a bung through which pass two tubes of metal. The retort neck is connected by a rubber tube with one metal tube of the purifier, and this metal tube dips below the surface of water in the bottle to near the bottom of the bottle. The second metal tube has one end inside the bottle but well above the liquid and the other end is outside the bottle, and connected by a rubber tube, either with a second bottle or directly with the gas-bag or tank. The first purifying bottle should be about two-thirds filled with water, to which a small quantity of caustic soda has been added, or caustic potash. This and the water remove nearly all the chlorine that comes over with

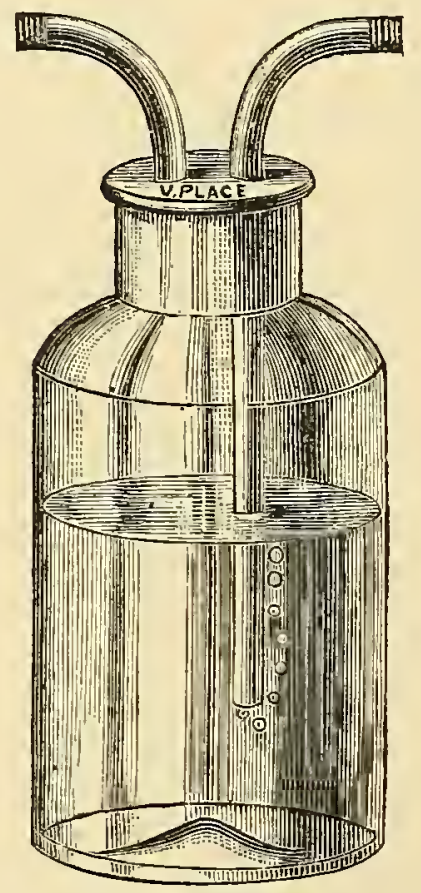

FIG. 28.

the oxygen. If a second bottle containing a similar solution be used the gas will, after passing through it, be practically free from chlorine, as may be verified by the absence of the peculiarly unpleasant smell of the latter gas. Carbonate of soda or of potash will answer almost as well as the caustic alkalis. Figure $2 S$ shows an ordinary purifying bottle. We 
prefer a good india-rubber bung to any metallic cap or fitting, as the rubber bung acts as another safety-valve. And we prefer a glass purifier to an opaque one, as it is well to observe at what rate the gas is coming off as shown by the bubbling inside the bottle.

It is well sometimes to dry the oxygen before putting into the storage receptacle. For this purpose the second purifying bottle may have a small quantity of sulphuric acid put into it, but of course in this case both ingress and egress tubes are kept above the surface of the acid. This process of drying is rarely necessary, a second solution of alkali, or even a quantity of plain water is, however, of considerable utility.

Practice of Oxygen Making.-Having mixed the $\mathrm{KClO}_{3}$ and $\mathrm{MnO}_{2}$ as described, and placed the mixture in the retort, and the retort on the heating apparatus, we connect our system all along, the retort with the first purifier, this purifier with the second if we are to use two. But we do not connect the last purifier with the gas bag or gas holder. Before connecting any two parts of the apparatus we must blow through each separate part to make sure that there is no obstruction in the gas-way. The neck of the retort is to be screwed pretty tightly on to the body, the safety-valve cork pressed firmly but not violently home, and the retort is to be supported in such a way that it cannot be overturned, one fatal accident is said to have occurred through the overthrow of a retort, and consequent clogging up of the neck by the heated mixture.

As the retort is gradually heated a slight crackling may be heard, and probably an occasional bubble will rise in No. 1 purifier. Presently a slight rush of air may be perceived at the free end of the arrangement, viz: at the end of the rubber tube which, later, is to be connected with the bag.

We now light with a match a piece of brown paper or some such material, blow out the flame if any, and hold the smouldering paper in the current of air passing from the free end of the tube. A lighted pipe or cigar is useful and often handy for this test. The presence of oxygen in the current will easily be verified by the paper or cigar bursting into a peculiarly bright flame. The gas-bag-if such is to be used- 
should previously have been as nearly as possible emptied of air; to do this, fold the bag up with the tap open and kneel on it or otherwise press all the air out, shutting the tap instantly. The moment before connecting the tube with the oxygen now issuing from it, the tap of the gas-bag is to be opened; this is sometimes forgotten, and leads to a safetyvalve being blown out. The bag should be on a level higher than the purifiers, for sometimes when gas comes off rather violently water gets blown into the tube leading out of a purifier, and water in a bag would be rather out of place. The oxygen is now allowed to come off steadily; if ever the evolution becomes violent the heat should be lessened either by lowering the gas in the burner, or by taking the retort off the fire or stove. The heating must not be violent at first, as above stated. Very likely after a time the evolution of oxygen will stop and appear to be finished, but if the proper quantity of oxygen has not been obtained (see above) the retort may be shaken or get a smart knock, or may be turned partly on one side; and often even if the retort be left alone the oxygen will of its own accord begin to come off again though the pause may have extended over several minutes. The bag may be filled "drum-tight," it will probably be less tight after the oxygen in it has cooled. A little deftness is needed if the bag be full before the oxygen has ceased to come over. When the bag is nearly full the heat on the retort should be lowered, but not entirely removed; when it is desired to stop operations, the gas-bag tap is closed, the tube connected with it instantly removed; the heat removed from the retort and the tube below water in the first purifier immediately pulled out of the water. If this be not attended to, the water from the purifier. will be sucked back into the retort, which will be burst in all probability. Retorts should not be of cast iron, but of wrought metal which will rip but not fly to pieces.

As soon as the retort is cold it should be well washed out with water; changes of water are to be put in until the water comes out quite clear. The manganese, as stated, may be kept by filtering, in any case it is apt to make a very nasty mess if the contents of the retort are poured out into a sink. The 
beginner should examine the contents of the retort at this stage; if he finds any unaltered chlorate of potash he will know that his mixture was not exhausted. Large cakes in the retort are a sign of over-violent or over-rapid heating.

\section{Hydrogen Making.}

Hydrogen gas pure is stated to give with the lime a better light than ordinary carburetted hydrogen, such as is used for house illumination. Our own experience leaves us in doubt on this point, but our trials were made with a kind of house gas not common, as it was made directiy from paraffine oil and merely purified by water.

It is very easy to make hydrogen practically pure. Scraps of zinc are placed in the bottom of a Woolff bottle having two necks. Into one neck is fitted a rubber bung bored to take a long thistle-head funnel reaching well down into the bottle.

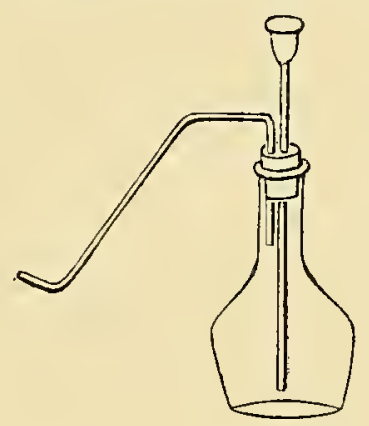

FIG. 29.

The other neck has also a bung fitted with a bent tube, reaching an inch or two inside the bottle and connected outside with a water purifier as for oxygen, which purifier is connected with the hydrogen storage receptacle. Into the thistle-head funnel dilute sulphuric acid is poured (acid one part, water four parts), when the hydrogen will be given off at the delivery tube. The funnel-point must, of course, be below the surface of the acid liquid in the bottle. The purifier contains plain water.

A flask with double-bored rubber bung may be used in place of the Woolff bottle, as in Fig. 29. 


\section{CHAPTER X.}

STORAGE OF THE GASES-I. IN BAGS. PRESSUREBOARDS, WEIGHTING, ETC.

We have under this heading practically only two systems to consider, viz.: Storage in "gas-bags" or tanks, and storage in metal cylinders at high pressure.

With gas-bags "storage" is hardly a proper word to use, because the less time the gas is stored in a bag the better for the bag and for the light. But we may have to put the gas into a bag for use immediately or soon. For a person making his own gas at home there is the alternative of a bag or a metal "holder" or "tank," and in practice the bag will be found the more convenient if the "lantern-display" is to take place away from home; but if the gas is to be used at home, then the metal holder has the advantage.

Gas bags are made of "india-rubber cloth," that is, of rubber lined outside and inside with some kind of cloth. Generally the inner lining is of canvas, the outer of a stuff known as "twill." A gas bag is usually of wedge-shape, and in the middle of the thin end of the wedge is let in a tap. The manner in which this tap is let into the stuff of the bag often makes all the difference between a good bag and a bad one. The tap should screw into, or be soldered into, a large, pretty thick plate inside the bag, if the plate is not thick but inclined to have sharp edges, the bag will sooner or later be cut by it. Two qualities of bags are usually sold, the better quality is invariably the cheaper in the end. But the better quality is not always dearer to purchase, for we know second-rate bags made expensive by the quality of the outer cover. The best bags the writer has ever used are plain black outside, and have 
taps properly let in, and so made as to be locked with a padlock when it is desired. Figure 30 shows one of these taps.

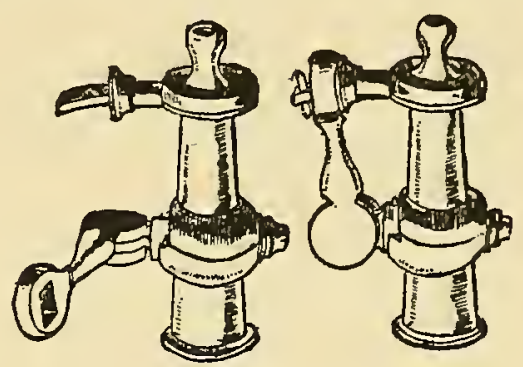

FIG. 30 .

Bags are made in various sizes, a convenient bag holds seven eubic feet of gas, and may be thirty-six inches long, twenty-eight wide, and have a wedge-depth of twenty-four

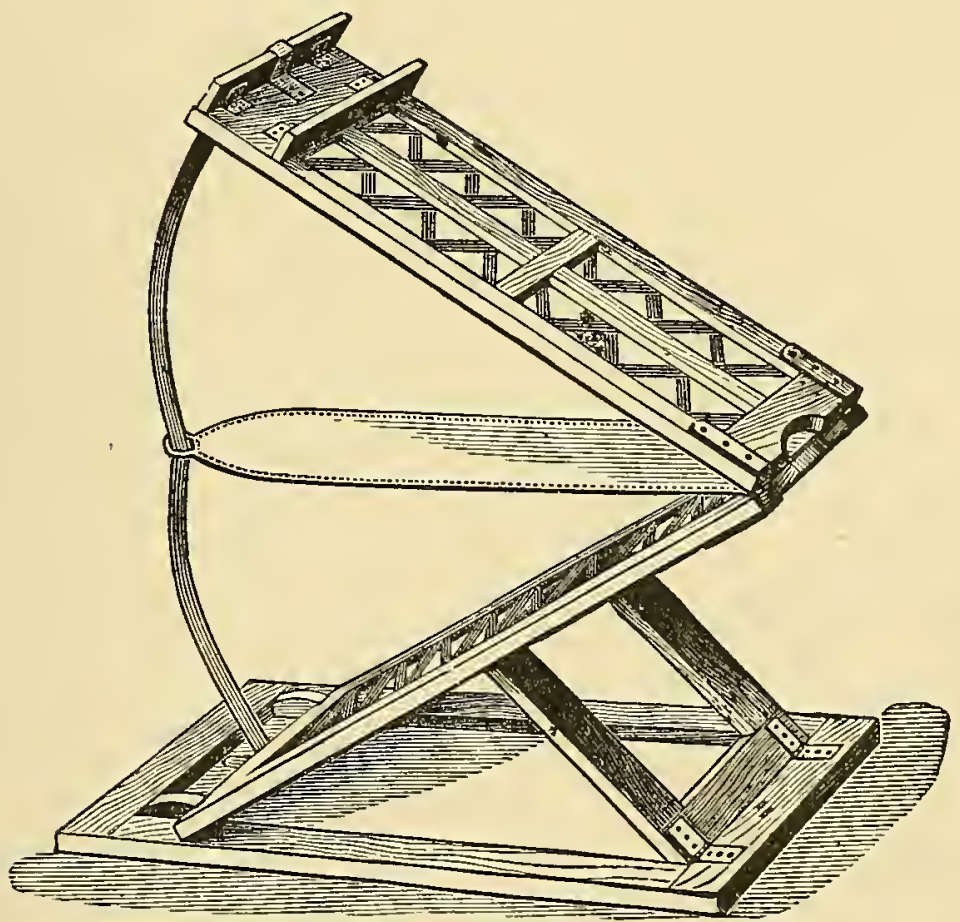

FIG. 31.

inches. For a very long lecture or for unusual pressure the bag may hold about ten cubic feet, and be $40 \times 32 \times$ (wedge) 28 inches. Gas bags used to be made flat on top, and are sometimes so made still, but the wedge is the usual and the better shape.

In order that the pressure may be applied to the bag or bags we place them between "pressure-boards." If we are using 
the blow-through jet we put the oxygen bag under pressure and use hydrogen from the main, so also with the oxycalcium light, one bag only is required. With ether-oxygen and benzine-oxygen one gas only, oxygen, is used under pressure. In these cases a single pair of pressure-boards is required. But as double pressure-boards answer also for single bags, we recommend the purchase of double boards, a figure of an example of such is here given. Fig. 31.

The bag or bags are placed in the jaws of this contrivance, the taps projecting through the hole cut out for them at the apex of the board-wedge. The bags are to be pushed well home into the jaws of the pressure-boards, and the partition, usually of strong sail-cloth, separates the two bags if two are used, or is allowed to lie flat if only one bag is in use. After the bags are in position the strap at back is to be tightly pulled and securely buckled, to prevent the bags from springing backwards. The support seen in front of the board will be found necessary when the bags are large and full; but the support is hinged and folds out of the way when not required. Pressure-boards must be of strong wood, and the hinges at the apex must be very strong. On the ledge seen near the top of Fig. 31 we place the weights. These weights may be twenty-eight pounds or fifty-six pounds each, and should be flat and not round. If any danger can be said to exist in working the mixed gas jet it may be said to lie in the possibility of the weights falling off the pressure-boards and so causing a suck-back of gas. Therefore the weights should be tied on to the ledge in some secure way, more especially if they are round weights. We recommend the worker at home to have fifty-six-pound weights made of lead or iron with a very broad base.

In computing or quoting the pressure on the gas we have nothing to do with the size of bags used, though it is very common to see quotations on this basis of calculation. What we have to measure is the area of the top of the pressureboards. This in square inches divided by the number of pounds weight bearing on the top gives the pounds of pressure that concerns us. A top $40 \times 28$ inches will suit the seven feet 
bag suggested on page 55 , and if we place on our boards one hundred-weight we have a pressure of ten pounds per square inch, which ought with separate gases to give a very fine light indeed. We figure a pair of boards and bags in position.

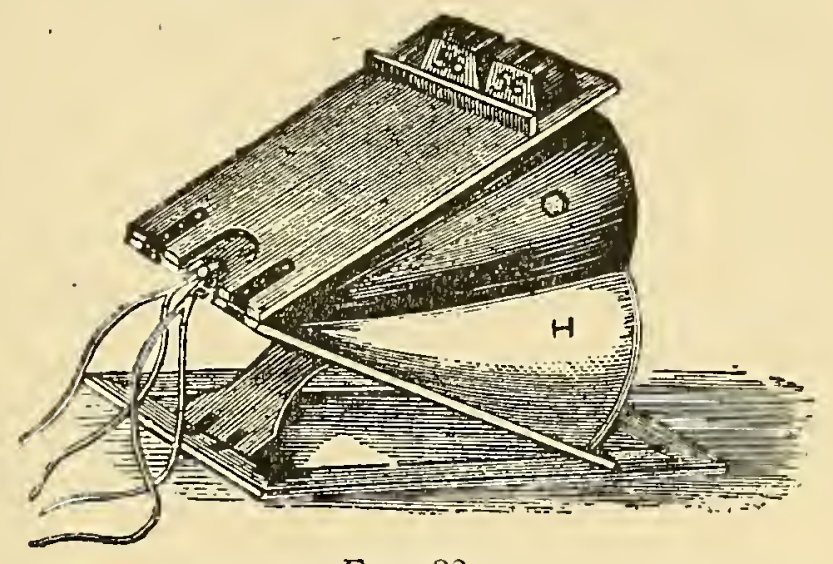

FIG. 32.

For a blow-through jet, fifty-six pounds weight on the pressure boards (40x28 inches) ought to suffice. Gas must not be kept long in rubber bags, such prolonged storage is bad for the bags and bad for the light. The sooner the gas is used after it is made the better. Oxygen kept twenty-four hours in the best bag will give a very poor light, as we have repeatedly found. Even four hours has in our experience made a marked difference on the light. Presumably hydrogen also deteriorates in the same way, probably to a greater extent. Even such a septum as india-rubber can not prevent diffusion by osmosis, and, moreover, the bags themselves suffer seriously by having gas kept in them. Immediately after the "display" or lecture is over the gases ought to be forced out of the bags, the bags being folded and kneeled upon after removal of the taps. If an old bag's inside be examined the effects of oxygen will easily be observed.

Oxygen may be stored for a considerable time over water in . a metal tank, but even under these conditions it deteriorates after a time. Moreover, if the metal of the tank be not thickly tarred or painted the oxygen will attack it. We need not figure a metal tank which consists merely of a small edition of a gas-holder, or what is for some reason unknown to us called a "gascmeter," so often seen at public gas works. 
Before leaving the subject of bags we would say that if in cold weather they become rery stiff they should be warmed before filled with gas. The taps should be kept working "sweetly" with vaseline, or some such lubricant. If a bag happens to get a hole in it, the owner would do well to have it repaired by an expert, rather than at home.

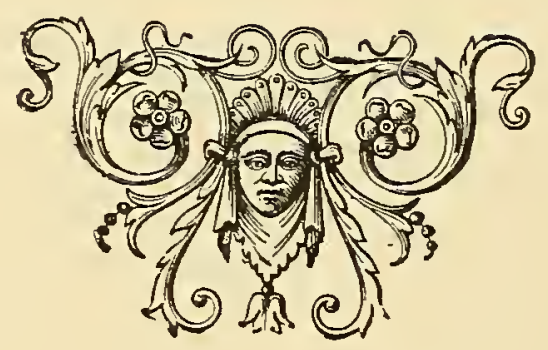




\section{CHAPTER XI.}

STORAGE OF GAS (2). CYLINDERS. REGULATORS. GAUGES.

Since the manufacture of oxygen, and its storage in metal cylinders at high pressure became in Britain an established and successful industry, the use of gas-bags has to a great extent fallen into desuetude, and, indeed, when we compare the advantages and conveniences of the two systems of storage there is not much wonder that bags are gradually dying out. It is long since first oxygen and other gases were stored in cylinders, but when the Brin's Oxygen Company started to make and trade in oxygen at prices far below the previous quotations, the use of their gas and metal cylinders rapidly gained the ascendancy, and "compressed" gases will probably oust gas bags entirely in a few years. Another matter that greatly popularized the cylinder system was the invention by $\mathrm{Mr}$. Beard of a regulator so effective, simple and cheap, that we do not hesitate to stamp it as one of the most satisfactory inventions ever made in connection with the optical lantern.

Barium monoxide gently heated in air takes oxygen from the air and becomes barium dioxide, $\mathrm{BaO}$ becomes $\mathrm{Ba} \mathrm{O}_{2}$. If now the air supply be cut off and the temperature of the $\mathrm{BaO}_{2}$ raised, the $\mathrm{BaO}_{2}$ gives up part of its oxygen and reverts to its original state $\mathrm{Ba} \mathrm{O}$, and these changes can of course be repeated time after time by regulation of air and temperature. All this has long been known, but nobody seems to have been able to devise machinery for utilizing these reactions until Brin's Oxygen Company came before the public with their patent machinery. On Mr. C. H. Bothamley's authority the writer states that the following are the requisites for success in this system of oxygen-isolation. (1) Proper regulation of temperature. (2) Perfect purification of the 
air from $\mathrm{CO}_{2}$ carbon dioxide. (3) Presence of a certain definite amount of moisture in the air. (4) Maintainance of a low pressure in the retorts. The furnace is ingeniously made to regulate its own temperature by the expansion or contraction of metal bars acting on "dampers." $\mathrm{CO}_{2}$ is eliminated from the air by caustic soda and lime; the air is then dried or damped according to necessity, and passes over the hot $\mathrm{Ba} \mathrm{O}$ in long convoluted cylinders, the oxygen is got from the now $\mathrm{BaO}_{2}$ by raising the heat, the nitrogen having been collected or allowed to escape. The oxygen is finally pumped into metal cylinders. It appears that the awkward part of the business is to get rid of the nitrogen. Oxygen made by this process often is accompanied by nitrogen which does not improve the oxygen for our purpose.

Mr. Orchard, of Kensington, London, prepares and compresses gas which, on analysis, has shown 98 per cent. of pure oxygen as tested at the Royal Institution. Probably it would be impossible to produce a purer article than this and impossible to sell it at so low a price as the barium-produced oxygen, but the light produced by the purer gas is decidedly superior in quality to the other. Brin's gas, however, is quite good enough for all ordinary purposes, and its cheapness, together with the facility with which we can obtain it in this country (Britain) gives it a strong hold on our attention. The writer uses Brin's gas almost invariably.*

The oxygen and also hydrogen are forced at very high pressure into metal cylinders. These cylinders are of wrought iron or steel, and should be tested to a point of pressure greater (say three times) than what is to be actually used. In England the cylinders are usually charged to a pressure of "120 atmospheres," or 1800 ponnds to the square inch. To give an idea of the result we may state that in a cylinder thirty inches by five and three-eighths, weighing twenty-eight pounds, we can have forty cubic feet of oxygen; while ten feet of gas, ample for the most prolonged lecture, can with ease be carried in one hand.

* Lately the Brin Company has improved its machinery, and now obtains oxygen with little or no nitrogen. 
It will easily be understood that when we have gas under such pressure as 1800 pounds on the square inch, there is a certain amount of difficulty in managing it, tubes are apt to be blown off, and there is a danger of leakage at all points not solid metal. The valves of these cylinders, therefore, require to be very strongly and accurately made, and a system for regulating the pressure of gas outside the cylinder becomes necessary. The latter desideratum is thoroughly well fulfilled by a small and simple apparatus, Beard's patent gas regulator. By using his contrivance, which is fixed on the valve tube of the cylinder, we can even turn on the gas full without opening our jet taps and without tying our rubber tubes to our jet tubes. This of itself is an enormons gain, for we can turn on

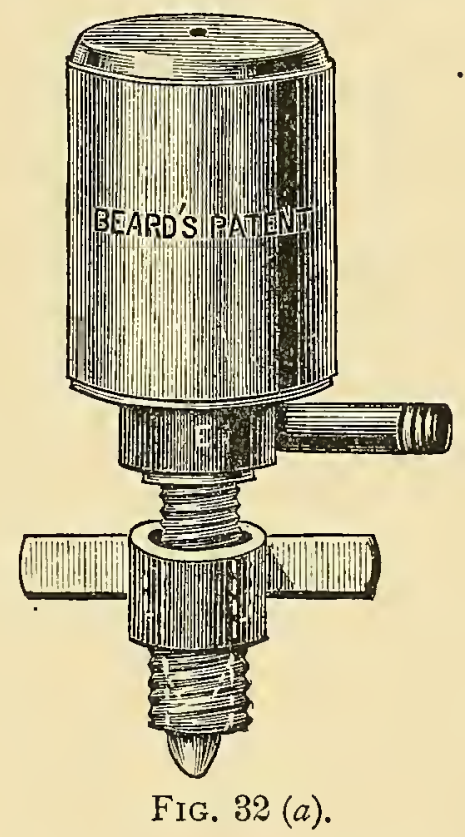

the gas at the cylinder and then proceed to turn up the gases in proportions as required at the jet. Provided there is sufticient pressure of gas in the cylinder to keep the regulator open, the gas comes in a steady stream. As made at present the regulator is set for one maximum of pressure, but we have suggested to Mr. Beard a method by which he may make each regulator adjustable within fairly wide limits to different maxima of pressure. Figure $32(a)$ shows the nature of Beard's regulators. Our frontispiece shows two gas cylinders 
with Beard regulators and also a pressure gauge. This gauge is frequently useful to show the rate at which the gas is being used, or to show at any time what amount of pressure, and consequently - the internal dimensions of the cylinder being known-what amount of gas there is in the cylinder. A cylinder fitted with these two contrivances may be put down as perfectly suitable and convenient for our purposes. We give here a table for use along with a gauge; the figures are for Brin's cylinders and may be taken as sufficiently accurate for any cylinders of the same type as used in Britain.

It must be noted that in adding regulators and gauges to our gas-storage system we are always increasing the chances of leakage; every joint must be very tightly screwed up by a "spanner" or other instrument of like nature.

A rule usually observed, and most useful, is that the two cylinders for $\mathrm{O}$ and for $\mathrm{H}$ are painted in different colors. The oxygen cylinder is generally black or very dark, the hydrogen a bright red.

On next page we give a table showing capacity, size, and pound-pressure of Brin's cylinders. 


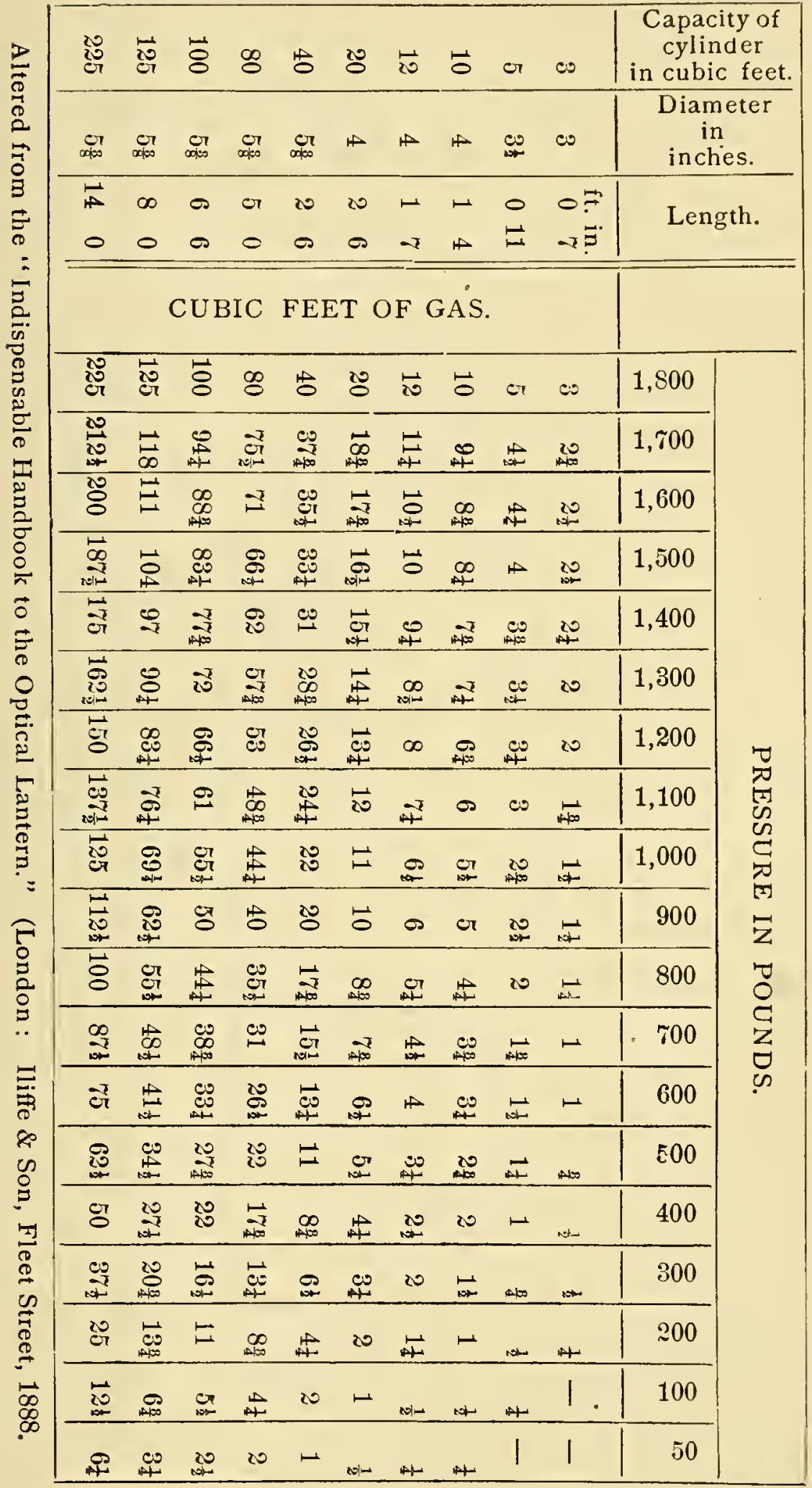




\section{CHAPTER XII.}

\section{SCREENS AND FRAMES.}

We have now to deal with a part of our system which the practical worker will find much more important than the inexperienced or mere theorist might imagine. A good "screen" or surface for receiving the image makes a great difference in the results, a bad screen may easily absorb or disperse uselessly 25 per cent. of the illumination.

A screen ought to be opaque, white, and matt, not translucent (except for certain almost obsolete arrangements), nor "shiny," nor yellow. At one time it was not uncommon, and even yet it may at times be necessary to use a translucent screen, in this case a very thin linen screen is used and is almost of necessity kept damp. But such a system is comparatively poor, and ought to be resorted to only when the other is not available.

If the same room is always to be used for the lantern work, portability of the screen is of no moment, and in such a case we can easily attain to a perfect receiving surface. A smooth, plastered wall is as good a surface as can be got. A stout fabric, such as canvas, may be faced with paper, or it may be heavily coated with sized white pigment. In mixing the pigment a little blue should be added to kill the yellowness of the whitening. If the screen is 'required to roll up like a school map, some care is required in mixing the pigment to make it in such a way that there shall be no cracking when the screen is rolled up. This is a matter for experiment; if when the screen is dry after painting the white can be rubbed easily off by the finger, more glue is required; if the surface is at all glossy, there is probably too much glue. For painting, the canvas is stretched on a frame, laid face upwards, and the pigment laid on as evenly and as rapidly as possible. 
Mr. Hepworth's directions are somewhat as follows: Tack good unbleached calico to a frame so that the seams, if any, lie horizontally. Secure first the four corners with tacks to the frame, then nailing one side at a time to the frame. Give the sheet a good coat of the best size, melted by heat with its own weight of water. The sized sheet is allowed to dry, and thereafter is painted with whiting and melted size. The whiting, water, and size mixture should when first made have the "consistence of cream," when cool it will be like a thin jelly. Mr. Ilepworth then places the frame upright, and proceeds to work the brush charged with the paint up and down and sideways, so as to avoid leaving any lines upon the surface.

We are informed that the best of all "pigments" to mix with the size is zine white; we have not ourselves tried this, but believe that the claim for it is well founded.

Facing a screen with paper requires, we fancy, an experienced hand, the paper cannot be got in large enough sheets, and the laying down of the edges where the sheets join is no easy matter. Of course, if we only require a small screen, as for showing small images to small audiences, single sheets of paper may be procured of sufficient size, and only require at the most to be attached to suitable supports.

Lp to (say) 10 feet square the advantages of a "faced" or sized screen are so great as to quite balance the awkwardness of a 10 feet roller for transportation from place to place. Up to 10 feet we therefore recommend such a screen, even for traveling. But beyond 10 feet the length of roller required becomes very inconvenient, and we have to look for a screen material that may be folded up, and a method of so stretching it when in use as to obviate the creases naturally following the folding. To meet these desiderata, we use rather thick linen or cotton screens, and we stretch them on "screen-frames." Cotton seems to be less used than linen, so we shall confine our remarks to the latter. We believe that pieces of suitable linen can be got up to 10 feet square, but, as we have said, we should prefer a faced or sized screen of that size. If we have to join pieces of linen for a screen, say, of 18 feet, we must avoid having our seam or joint near the centre. In such a 
case it would be better to have a complete square of 10 feet in the centre, with four feet tacked on all round, rather than simply to make an irregular patch-work. As these screens are sold ready made in any usual size, we need not do more than point out that the seams should be as far from the centre as possible, and that they should run perpendicularly rather than horizontally on the picture. If a seam falls coincident with the horizon of a picture the effect is apt to be very unpleasant.

There is no great variety in the designs of screen-frames, or "elevators," as they are sometimes called. A screen frame should be as light as possible consistent with strength sufficient to keep a screen quite taut; it should take down into as many short pieces as is consistent with strength as above; it should be capable of being rapidly put together and taken down; it should afford facility for elevating the screen; it should stand by itself, and it should be capable of being tilted slightly without chance of falling down. When the frame is tilted is the time when strength is required, for a tilted screen will "sag" forward under" such condition unless the frame be strong enough to counteract the tendency to sag. We see it stated in print that the advantage of being able to tilt the screen is more theoretical than practical, but we must dissent from this statement, a tilt is frequently a conditio sine quâ non of real success; in our own experience the screen is tilted nine times out of ten.

We figure an "elevator" such as we find perfect for our purposes up to a twenty-foot screen. The poles are two inches in diameter, the lengths about five feet each, the junctions are strong brass ferrules, the corners are solid metal. The lengths are so made that we need not use all of them at a time unless we wish, so that we may choose our size of screen up to twenty feet, increasing or diminishing by about four feet at a time, or two feet if the lengths are made on purpose for such a choice of sizes. (fig. 33.)

At the foot will be seen strong cross-pieces, which form a base, and with the addition of the four straps attached to the lower part of the frame help to prevent the screen and frame from toppling over if tilted. The tilt is arranged and 
maintained by shortening and lengthening the front and rear straps respectively, and the frame works freely in the holes made for the purpose in the base cross-pieces, so that any tilt can be obtained in an instant.

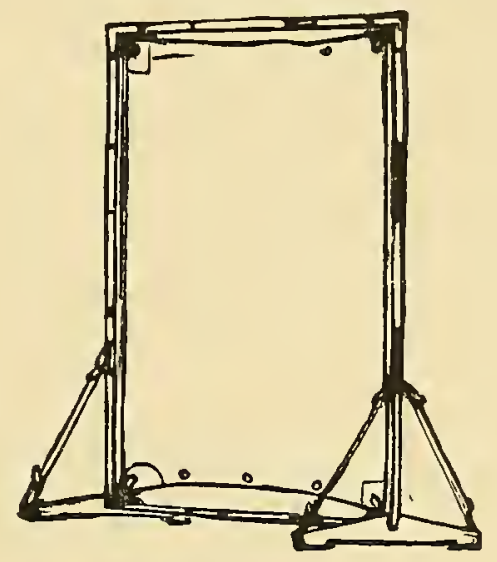

FIG. 33.

There are various methods of mounting a screen on its frame in a hall preparatory to a lecture. Perhaps the most convenient way is to put the poles forming the top of the frame together, joining to these by the solid metal corners the first lengths of poles below the top bar, thus:

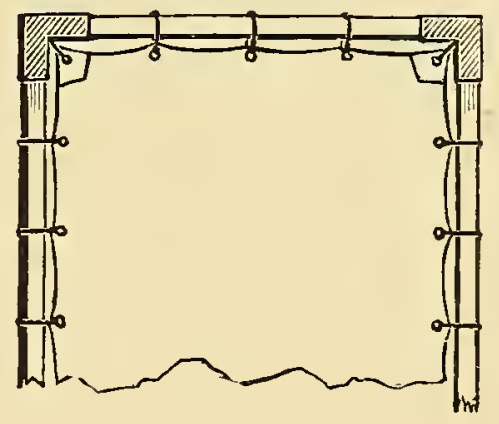

to tie the screen by its tapes to these lengths, and then to join on the next lower poles, tying the screen to these in their turn till the whole is erected. By means of the bottom tapes, and those within reach with or without a ladder, the whole fabric is finally made taut. With a large screen we always fix guys to the metal corners at the top, and fix our guys to anything that comes handy, as a rafter or staples driven in by ourselves 
if the authorities permit. We have a twenty-foot frame of four inch poles which always require guying, andin any case a couple of guys when the sheet is tilted ease the strain on the pole ferules greatly. A very good adjunct to a screen is a pair of tasteful curtains, which may be simply hung on the top of the frame and drawn aside by simple means as the lecture is about to begin.

If an opaque, or "faced" screen is to be used, nothing is required but two side arrangements to support the ends of the roller on which the screen is wound.

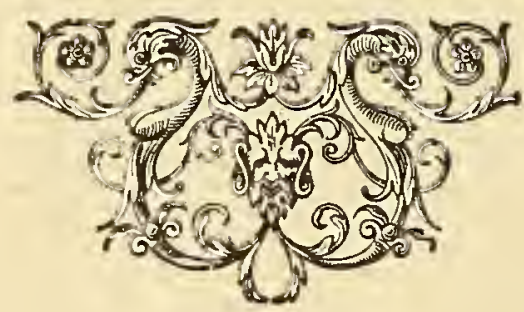




\section{CHAPTER XIII.}

SUPPORTS. SLIDE CARRIERS. READING LAMPS. SIGNALS.

We naturally require some kind of stand upon which to place our lantern, and the larger and heavier our lantern the stronger must be our support. Sometimes stands are made

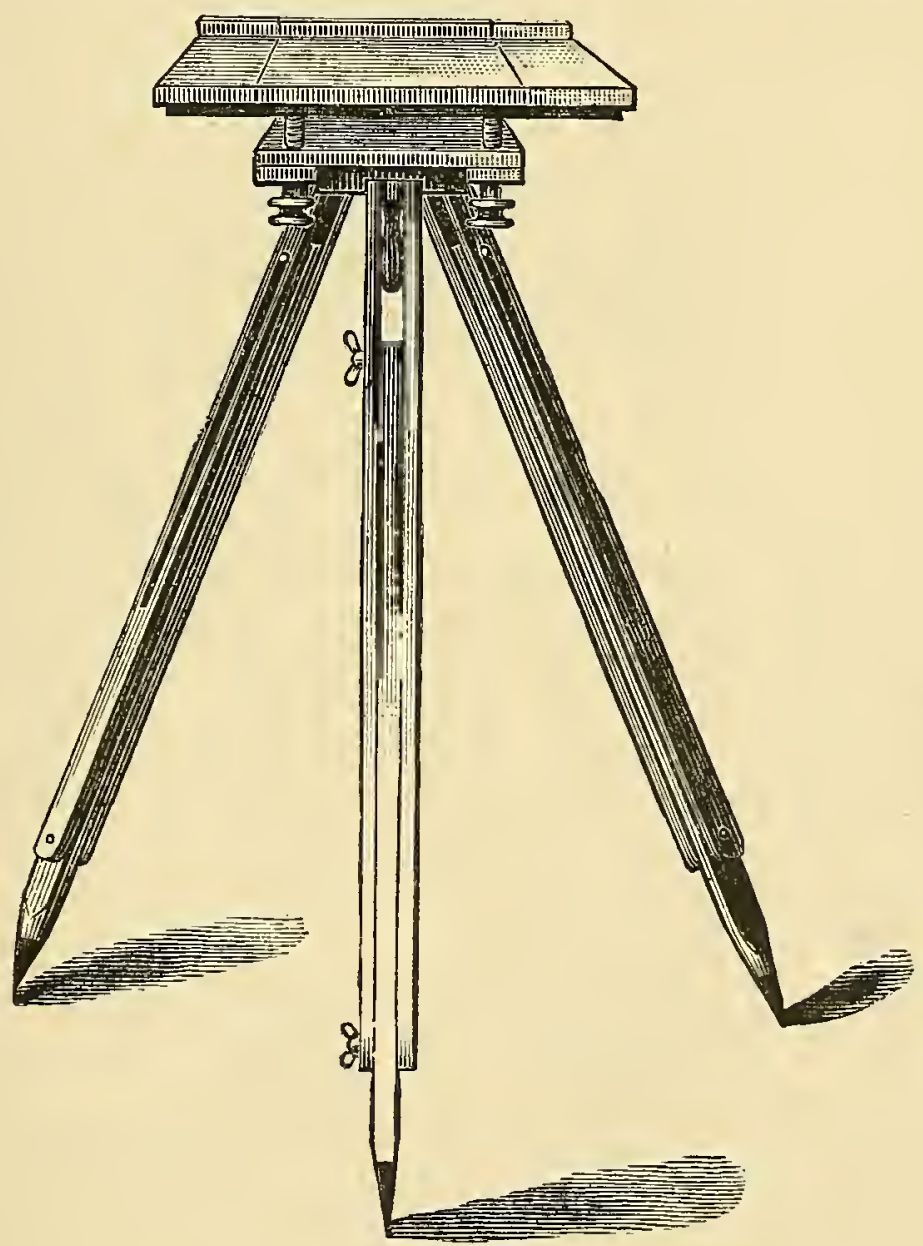

FIG. 34 .

with sliding legs, so that the lantern may be reared up rery high, but we see no use for any such height, in fact our highest 
lantern, if we are using a double or triple, should be as little above the level of our eyes as possible. Even if we are with our lantern in the middle of om audience the lowest lantern needs only to clear the head of the sitter immediately in front, and if tilting the screen is inconvenient, mounting a ladder to see into our lantern is ten times worse. A business-like stand is shown in Fig. 34 .

But the kind of stand used in a photographic studio for carte and cabinet cameras answers very well. Such a stand, however, can hardly be called very portable, and if the box which carries the lantern when traveling be placed on an ordinary table, more especially if a canting table be added (Fig. 35) there will be no necessity for further impedimenta.

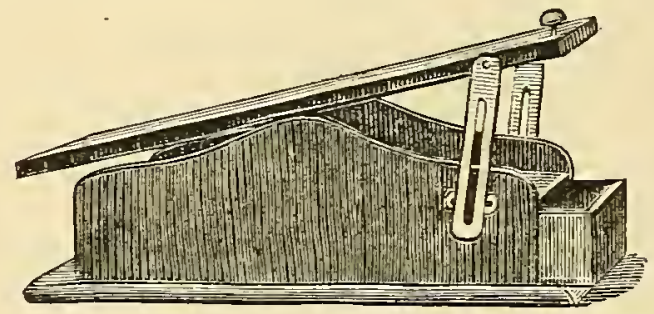

FIG. 35.

"Carriers" may be described as guides by means of which slides are passed through the part of the lantern in front of the condenser. It is important that slides should pass smoothly into and out of their position in the light-way, each slide must find the central position at once without any fumbling on the part of the operator, and when more than one lantern is being used, as for dissolving effects, it is essential to success that the slides should "register," i.e., should hare coincident discs on the

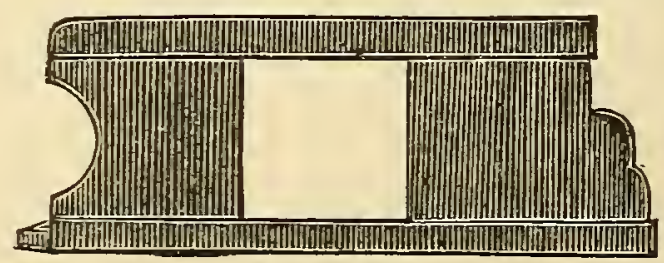

FIG. 36.

screen. For multiple lanterns a certain amount of intricacy in the carriers may be necessary, but for a single lantern the simpler 
the carrier the better. After using nearly every carrier known in the market the writer goes back to the simplest of all, the old "Chadwick," or failing that, one very nearly as simple, made by Mr. Place, of Birmingham. We figure both of these.

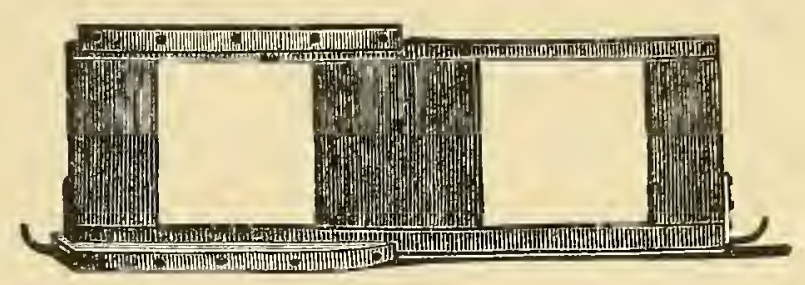

FIG. 37.

Both these carriers are so made as to take and to centre at once any ordinary size of slide. The "Chadwick" (Fig. 36) should be made of thoroughly seasoned, well smoothed wood. The "steps" are made to suit the three different lengths of slides in vogue at one time, one slide pushes the one in front through, one or" other "step" being used as a guide for the hand that pushes the slide. In Mr. Place's carrier the slide is let in from above, a push on the metal projection seen turned up in the figure at once centres the slide, and on further pushing the frame carrying the two slides slips along, and so, one slide is put away as another comes on. For dissolving lanterns "Beard's self-centering" carrier is as good as any.

Some people dislike an interval of darkness, however short, between the pictures, some dislike a period of brightness on the screen. Many efforts have been made, and appliances contrived, to simulate dissolving effects with a single lantern. So far as we have seen, these contrivances are of no value; if any such attempt must be made, the operator may hold in front of the lens while the slides are being changed a ver'y finely ground piece of glass. For ourselves, we see no objection, but rather an advantage, in the short space of semi-darkness produced by the use of a Chadwick or Place carrier. A blaze of light on a white screen for a short time is, in our opinion, most objectionable; it tries the eyes and spoils the first effect of the pictures following. 
There are many kinds of reading lamps, intended for use by the person on the platform. Of course, the object is to throw light on the book or paper without illuminating the screen. By highly ingenious contrivances of this kind we have never been able to read comfortably, and we have repeatedly been left in darkness during the performance. Since first we used a candle shade shown in Fig. 38 we have never used any other reading-lamp.

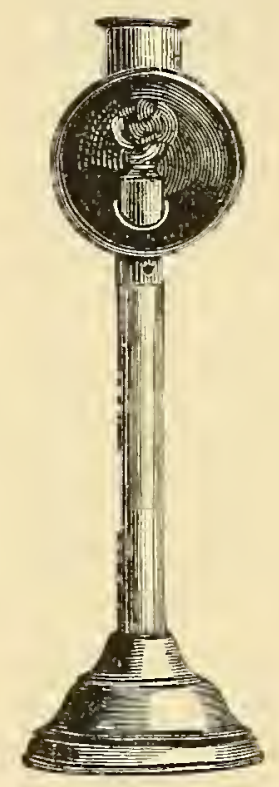

FIG. 38.

A signal between lecturer and lanternist is generally requisite; an electric communication acting on a muffled bell is the neatest device, failing that, we know nothing better than a gentle tap with a knife on a glass of water, or the click of a castanet à la Nuybridge.

All india-rubber tubing used for lantern purposes should be of the very best quality, and of a bore as large as may be consistent with fitting the taps and jet-tubes. The larger the bore the less the friction of the gases in the tubes, and diminution of friction helps greatly towards brilliance and steadiness of light. Tubes should not be unnecessarily long; first, because redundant tubing means extra friction, secondly, because spare coils of tubing are inconvenient and apt to be trodden on and 
to get in the way. Lastly, rubber tubing can hardly be too thick in the walls; very thick-walled tubing is dear to buy but cheap to use. Rubber tubes should be pushed far up on the metal tubes to which they are "sprung," and it is always a good precaution to tie on the rubber tubes to the metal ones.

Various kinds of boxes are made to hold lantern slides; we like a box for each set of slides-each lecture, for instance; and the box should have no grooves, but may have a spring arrangement to push the slides up against each other in the box.

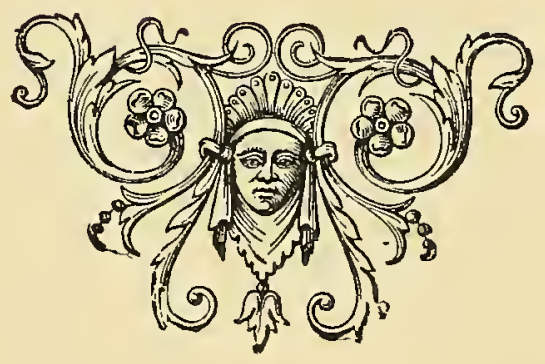




\section{CHAPTER XIV.}

\section{LANTERNS, AND ARRANGEMENTS FOR EXPERIMENTS.}

There are many scientific experiments for full comprehension of which we depend chiefly upon our eyesight, and it is easy to understand that if we can utilize the lantern for showing on a large scale the image of an experiment being made on a small scale, we have found a further use for our lantern. As a matter of fact many chemical, magnetic, optical and other experiments can very easily be shown to a large audience, though conducted on a small scale, and we may add to this the fact that it is possible to add to an ordinary optical lantern a projection microscope, polarising and spectroscopic apparatus, and various other optical appliances.

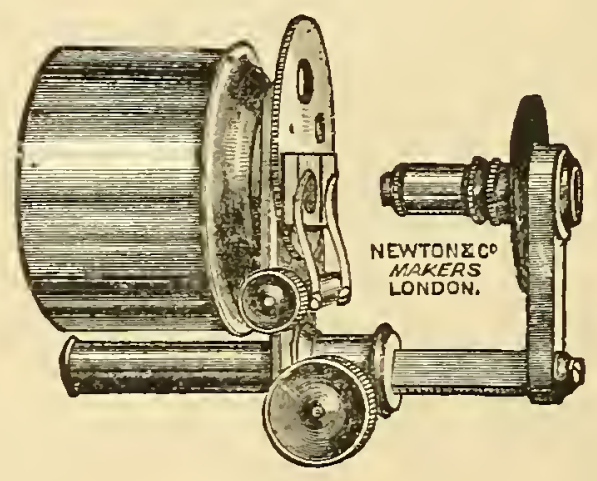

FIG. 39.

It is long since first attempts were made to project images of microscopic objects by means of a microscopical objective and suitable condensing lenses. The animal and vegetable contents of a drop of water hare many times been projected with high magnification on a screen, fleas and other insects have many a time figured on ten feet discs, but lately considerable advance has been made in this line, and images of very minute 
structures may now be projected by even immersion objectives. The more elementary form of lantern microscope is shown in our figure 39 , and little explanation is required.

The entire arrangement seen in our cut takes the place of the lantern projection lens. Behind the micro. slide is a rotating diaphragm with various apertures, and in practice the smallest aperture that will pass the entire image of the object should be used. This arrangement works very well with one low power, that power (or object glass) being the one for which the apparatus is intended, but as soon as one wishes to use a higher power the performance of the apparatus becomes faulty. A superior article is the outcome of $\mathrm{Mr}$. Lewis 'W right's experiment and ingenuity. Here (fig. 40) we have power of using and adjusting a microscope condenser, we have a "fine adjustment" for the micro. objective, as well as an alum cell to prevent the slide being damaged by heat.

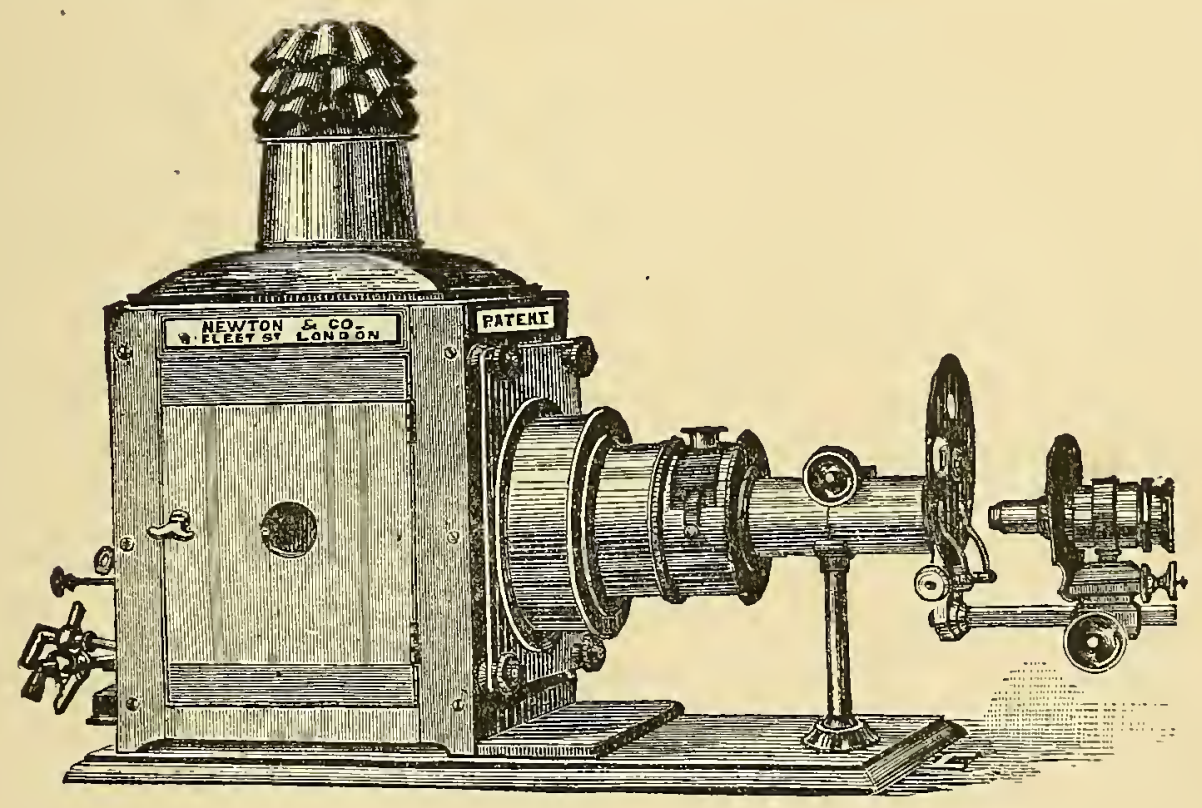

FIG. 40.

A special condenser of the triple type is recommended for this projection arrangement.

In like manner a polarising apparatus may be attached to the front of the lantern, the apparatus, figure 41 , we have seen used with great success. 
Spectroscopic experiments may be demonstrated by means of an ordinary lantern with a slit-diaphragm attached to the front, prisms and collimator being placed on suitable stands between lantern and screen. With an electric lamp and a primary battery, and an apparatus designed by $\mathrm{Mr}$. John Browning, the writer has carried out many interesting experiments on the spectra of metallic and other substances.

- Demonstrations on such lines take a firm grasp of the attention and interest of any audience.

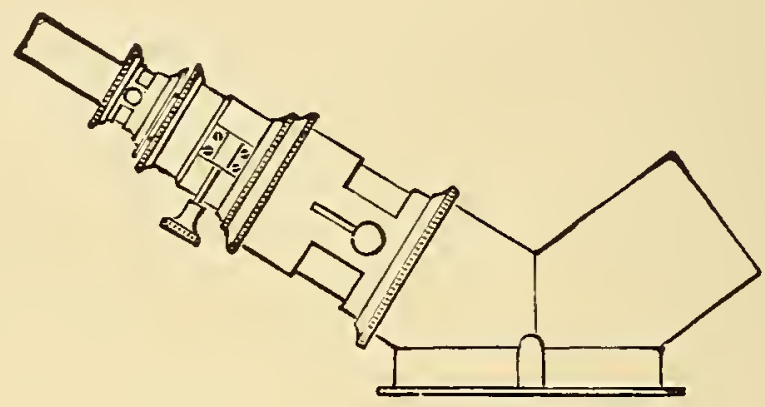

FIG. 41.

For chemical experiments, and, indeed, for many others, an "open stage" is almost a necessity. Fig. 42 shows a lantern well adapted for such work.

A so-called tank or cell, as seen in Fig. 43, may be placed in the open stage, and in this tank chemical reactions may be made to take place, the action being finely displayed on the screen. The same may be said of magnetic, electric, and very many optical experiments. If a sheet of orange or yellow glass be placed between the condenser and the tank a photographic image may easily be developed, coram populo, care being taken to use a very "slow" plate such as a chloride plate used for lantern slides. For these and other experiments with liquid in the cell a pipette should be used to drop in the reagents that determine the action, the cell having been previously nearly filled with one of the liquids. A very interesting series of experiments capable of being well shown by the lantern will be found in the contributions of the late W. B. Woodbury to the English Mechanic some years ago, 
now edited by Mr. George Smith, of the Sciopticon Company, England.

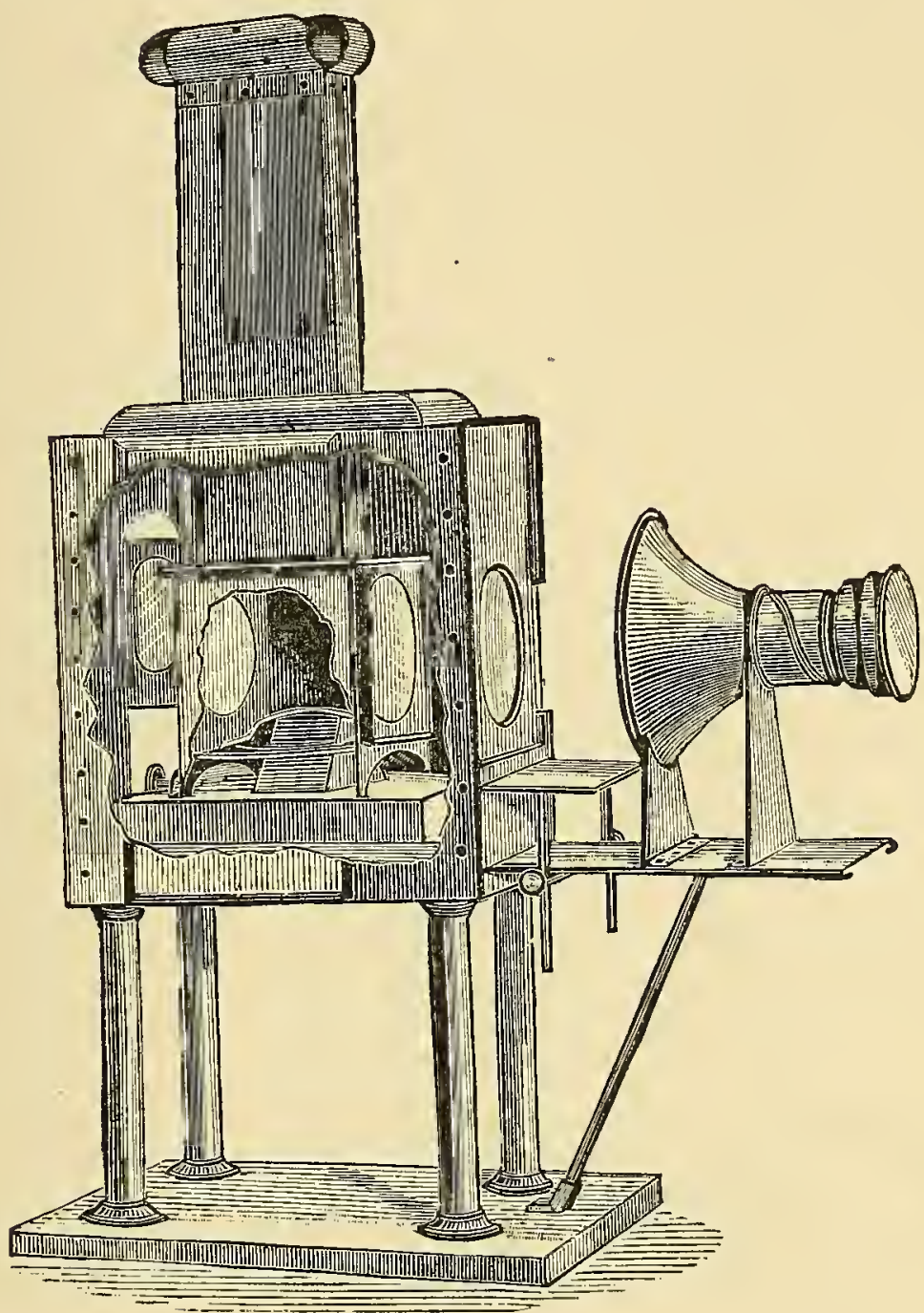

FIG. 42.

We figure on following page (Fig. 44) a good lantern mado scientific for purposes by Messrs Newton, and intended to be used with an electric lamp.

Figure $44 a$ shows a double or biunial lantern, just brought out by Messrs. Newton, of London, and called the "Scientist's Biunial." The writer uses one of these with great satisfaction, both as a small and simple dissolving apparatus and for optical and other experiments requiring an open stage. The chief novelty is that the upper lantern can be turned up so 
that the image is projected towards the ceiling, a plane mirror at suitable angle (see cut) is then fixed to the front of the projection lens so that the image is reflected on to the screen.

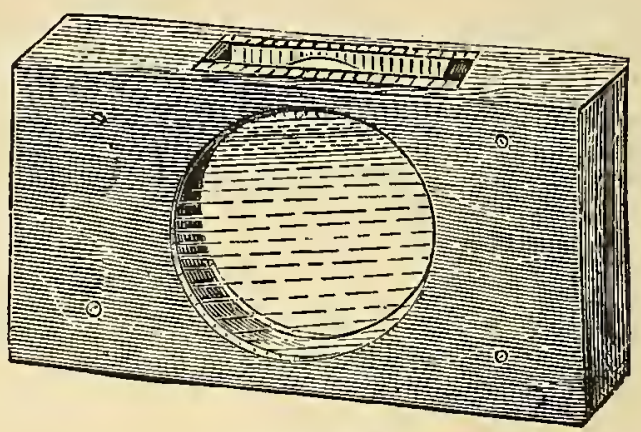

FiG. 43.

If, with the lantern in this position, we make a sketch on a piece of ground or clear glass in the stage of the upper lantern, our sketch will appear, as we draw it, on the screen. Many

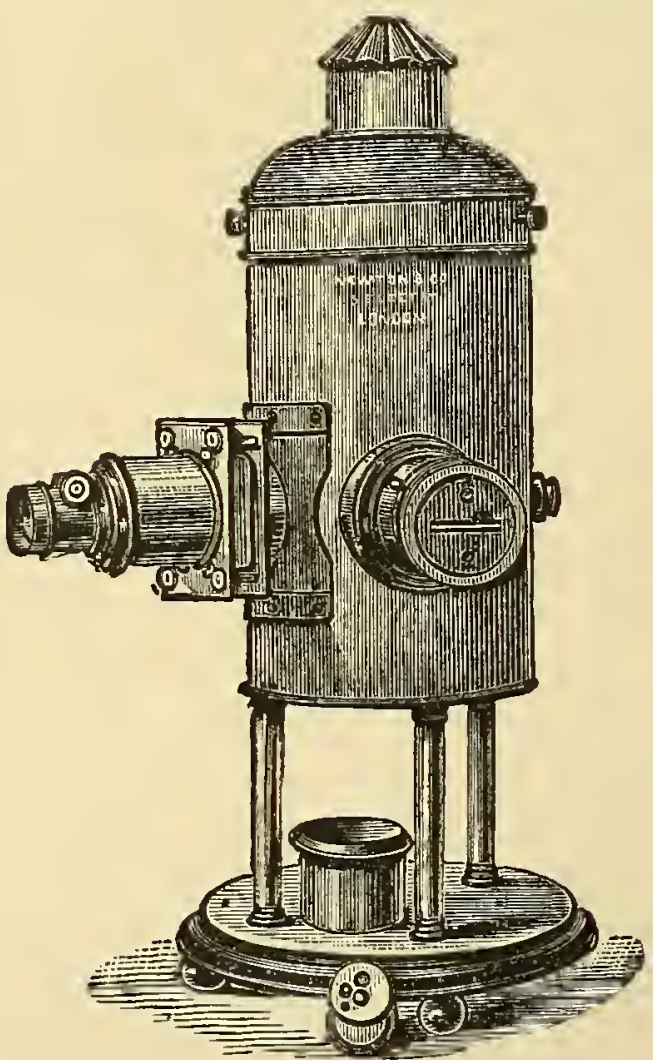

FIG. 44.

pieces of apparatus, specially designed to illustrate certain optical experiments, are made to go with this lantern. The 
lanterns can be separated very easily, and each lantern is a very good and compact instrument in itself.

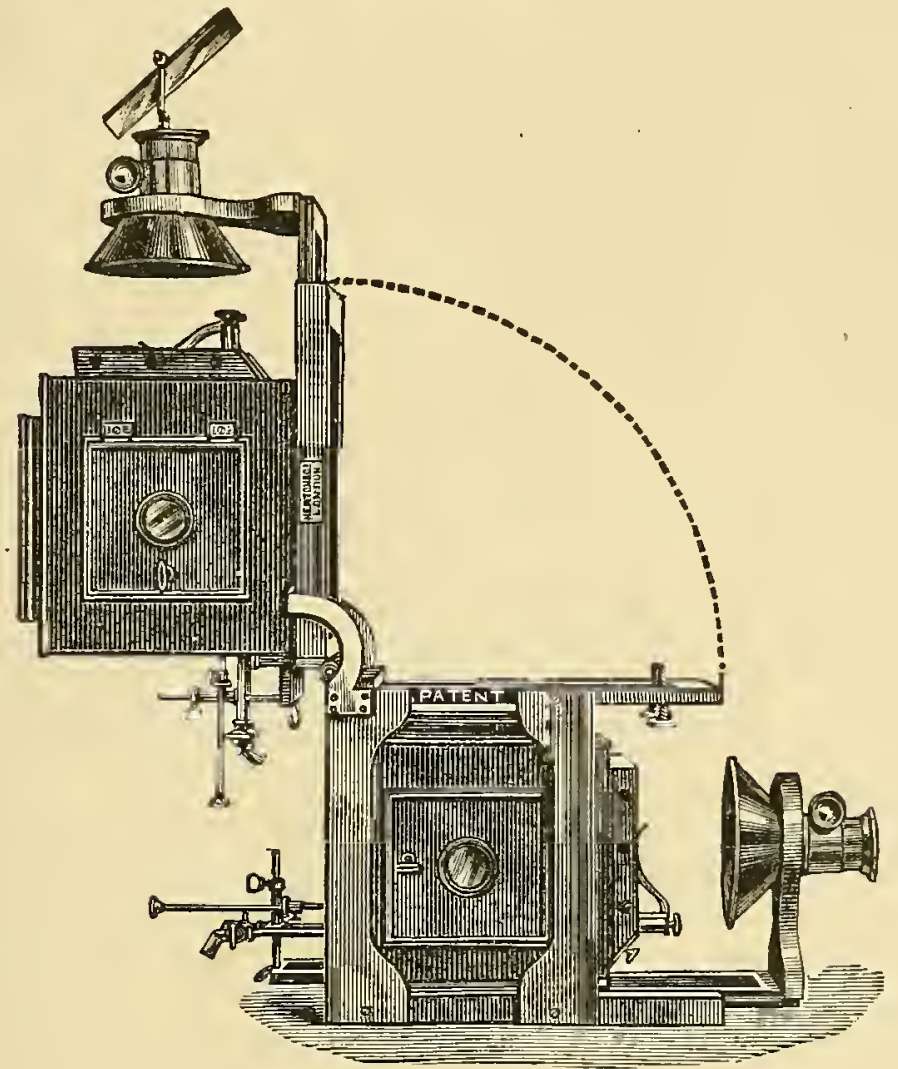

FIG. 44a.

The front carrying the lens can be entirely removed; so also can the support with springs intended to carry the slidecarrier, when one is used. The condenser is $4 \frac{1}{2}$ inches diameter, and a good parallel beam can be projected by suitable manipulation of the lime jet. Altogether, this is a singularly ingenious and complete lantern. 


\section{CHAPTER XV.}

\section{PRACTICAL WORKING OF THE LANTERN, OIL - LAMPS, BLOW-THROUGH JET.}

LitTle requires to be said with regard to lighting and using an oil lamp in the lantern. The lamp itself must be thoroughly clean outside and in, the wick or wicks accurately trimmed, and the full flame turned up not all at once but gradually; the wick ought at no time to be turned so high as to cause a flare; if once this mistake is made the lamp never seems to burn so well till all has been cooled down and the wick retrimmed. With paraftin lamps it is a common and commendable practice to put a lump of camphor weighing (say) one-half ounce with half a pint of the oil. This addition certainly whitens the flame.

As a rule there is no adjustment for raising and lowering an oil lamp in a lantern, but we require by pushing the lamp forward or pulling it backward to get the flame as nearly in the focal point of the condenser as the size of our radiant will permit. This we judge by watching the disc of light thrown on the screen, colored edges on the screen mean that the light is not in focus. With many-wicked lamps we are apt to have an ill-defined image of flame down the centre of the disc: we are informed that all lamps do not necessarily show this defect, and we can say that with all the lamps we have used of moderate pretension to good quality, the defect has been so slight as not to entail absolute failure.

Our chief business, however, is with the lime light, and to it we now address ourselves.

The "limes" are either turned from solid pieces of "hard" or "soft" limestone, or they are composed of a mixture of substances the nature and proportions of which are kept secret. 
The best limes so far as light-giving qualities are concerned are those turned from the natural limestone, but for some reason they are never turned true, the hole up the centre is seldom true and the cylinder-shape is never accurately kept. The limes known as "Excelsior" are turned accurately enongh, but are slightly inferior as radiants. As, however, the distance from nipple to lime is a factor of considerable importance in producing the best light, and as of necessity this distance varies as we turn the badly-shaped limes, the Excelsior limes may in the event give the better light. If we could get the "Nottingham" limes truly turned we should never use any other; as matter's stand we use Excelsior or Nottingham as they come to our hand, except for a very powerful light when the Excelsiors are not available. Probably the best lime for the blow-through jet is the "Excelsior," which is too soft for the mixing jet.

The limes are sold in hermetically sealed tin boxes with a quantity of powdered quicklime, or in glass bottles with luted corks and usually withont the quicklime. The limes have a great avidity for moisture and will quickly go wrong if any moisture reaches them; so we must take every precaution to prevent the access of damp. Various plans have been tried to secure the limes from damp, our favorite system is to wrap a piece of paper round each lime and dip it into "paraffin wax" just above melting point. Some makers send out their limes already rolled in paper, this gave us the idea of the paper, for without it the paraffin is apt to stick to the lime cylinder. Mr. Hepworth points out this, and suggests the precaution of keeping the paraffin wax at a low temperature. Opticians sell long brass tubes to hold one dozen, six, or three limes end to end, these tubes have well-fitting screw lids and are very useful. To one of these (Fig. 45) we added a little chamber in the lid, fitted with fine gauze; into this chamber is put calcic chloride, which is not without

FIG. 45 . use as a protection against damp for the limes. In any case a tin of limes once opened is no longer a safe recep. tacle for limes, more than once we have known a tin burst and 
ten or eleven limes lost under such conditions. At one time we used a wide-mouthed strong glass bottle, into which we put lime-cylinders quicklime and all as soon as we opened a tin, luting a tightly-fitting cork with melted paraffin; this was fairly satisfactory, but inferior to the brass cylinders mentioned.

Before "lighting up" for a display two or three limes should be baked in an oven or on a hob; one is placed on the lime-pin and the hydrogen at once lighted. The best distance from nipple to lime is a matter to be decided by experiment, a mixing jet usually has its nipple much closer to the lime than a blow-through, the distance for a mixing jet may vary from one-sixteenth to one-quarter of an inch, we have seen the approach so close as almost to amount to contact, and that in the hands of an excellent operator. In all jets there is an arrangement for adjusting the position of the lime with regard to the nipple; of course the lime is moved, not the nipple.

We shall now suppose, first, that a blow-through jet is to be used; we have a bag full of oxygen between pressure-boards, or a cylinder full of the gas, while our hydrogen tube is connected with the gas supply of the hall or room. If we use a bag we must have a weight of say fifty-six pounds, to which we may add one of twenty-eight pounds in case of need. Before lighting anything we open our bag tap, and our $O$ jet-tap connected with the bag by a rubber tube, having previously put our weight on the boards, and we allow the $\mathrm{O}$ to escape for about fifteen seconds to expel air from the gas way. If we omit this, our lighting up may start with a little "crack," which is unpleasant. Then we shut off the oxygen and light the hydrogen, keeping the flame about an inch and a half in height or less. Next we gently and gradually turn on the oxygen, till we get a fairly good light without much redness or scattering of the gases. We may at this juncture turn our lime round a few times to see that it keeps its distance from the nipple and also to let it get pretty well heated all over. Next we turn up the $\mathrm{H}$ a little, at once the flame will become red, a little more $\mathrm{O}$ will once more produce the blue and bright light, and so on we 
may go, $\mathrm{H}$ and $\mathrm{O}$ time about till at last we get to a point of brilliance that we cannot pass, and that may be taken as the best light our apparatus will give. Extra weight on the bag may or may not improve the light.

If we are using $\mathrm{O}$ in a cylinder with a regulator we proceed in just the same way. We open the cylinder first, then the jet tap, and here we go on increasing one gas after the other, $\mathrm{H}$ always first, till we find that we cannot turn on enough of $\mathrm{H}$ to redden the light, then the $\mathrm{O}$ tap will have to be manipulated till the best effect is prodnced. During these steps there may be hissing of the gases, but there is no danger, and when the light is right the hissing will stop, unless there is some defect in the jet.

Never put on nor take off weights while the gas is burning. Never ailow any person to lean on, nor in any way to touch a gas-bag while the jet burns.

Always light $\mathrm{H}$ first; always turn down $\mathrm{O}$ first. Always tie weights on to the pressure-boards, and never use round weights. Never use any such things as fenders or boxes of glass plates for weight. Bags of heavy sand, made in suitable shape and tied on to the pressure-boards answer well.

Amount of weight, per se, is not the important factor for a good light, but proportion of weight to diameter of gas-way is the factor that makes or mars.

If anything goes wrong turn off the $\mathrm{O}$ at once, the $\mathrm{H}$ as soon after as possible.

A red light means too much $\mathrm{H}$ in proportion to $\mathrm{O}$. A peculiar lurid blue point of light means too much $\mathrm{O}$ for the $\mathrm{H}$.

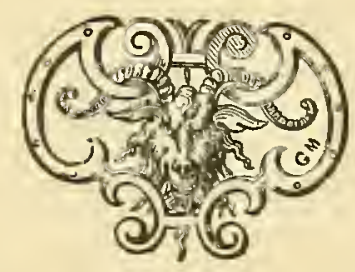




\section{CHAPTER XVI.}

\section{PRACTICE WITH MIXING JETS.}

The use of a mixing jet entails two bags or two cylinders with a greater weight in the case of bags, but it enables us to get a light certainly twice as brilliant as can be got with a blow-through jet, and moreover the area of incandescent lime is with the mixing jet considerably smaller than with a blowthrough, which, as pointed out in an earlier chapter, is an advantage of great weight when we desire the best optical effect.

When bags are used it is undeniable that there are possible dangers, but the contingency of accident is indeed remote if anything like common sense and common care be brought to bear on the operations. A mixture of oxygen and hydrogen in certain proportions will certainly on ignition explode, and that with violence if the gases are confined in any chamber offering much resistance. But in olden days the two gases used, as the custom, to be mixed in one bag and burned at a nipple, yet we are not aware of any accident having happened, nor was an accident at all probable so long as there was a pressure on the containing bag. Now-a-days we put each gas in a separate bag, and we put the two bags in the jaws of one pair of pressure boards which we weight; unequal pressure on the bags is therefore out of the question, and sucking back of one gas into the bag containing the other is seemingly physically impossible. But even supposing that the gases do get mixed in one bag there is no likelihood, still less any certainty of an explosion, provided pressure is kept on the bag. All the accidents that have ever come to our notice have arisen from setting a light to a mixture of the gases in a bag not under pressure, and no reasonable person is likely to do such a thing if he is sober, and aware of the effect of igniting 
such a mixture. Even supposing a bag to contain hydrogen alone it is a foolish thing to bring a light near it, especially if there is no pressure on it. Hydrogen burns on being mixed with air, but hydrogen alone is not combustible, nor a supporter of combustion.

A lighted candle thrust into pure hydrogen will be extinguished. Even if hydrogen and oxygen are mixed, but one of the gases is in large proportion to the other, say nine of $\mathrm{H}$ to one of $\mathrm{O}$, or nine of $\mathrm{O}$ to one of $\mathrm{H}$, there is no explosion or ignition, the gases ignite slowly and there is steady combustion. But two parts of $\mathrm{H}$ to one of $\mathrm{O}$ will explode with violence on ignition. We gather, then, that even if a little of one gas gets into a bag containing a considerably larger proportion of the other gas there is no danger of violent explosion, so that in order to produce an explosion we would almost require deliberate intention. But each bag should be used for one gas alone, and never for the other gas, and each bag should be conspicuously marked with " $\mathrm{O}$ " or " $\mathrm{H}$," both on the side and at the.wedge. And if there is any doubt at any time as to the contents of a bag, the test should never be made with a light placed anywhere near an unweighted bag. Gas cylinders in like manner should be conspicuously marked. vreferably by being painted in different colors.

We suppose our two bags to be filled each with its own gas, we place the two bags in the pressure boards. First we place the $H$ bag in position, taking care to shove the tap well through the hole in the pressure boards intended for it, we then let down the partition, (see fig. 31) and on this we place the $O$ bag. Then we connect the bags with the jet tubes by strong rubber tubes, taking care to spring the rubbers well up on the taps and jet tubes. Having put our weights on the boards we allow a little oxygen to escape at the nipple of the jet, and thereafter close the $\mathrm{O}$ tap. The lime cylinder being on its pin and the surface of the lime about one-eighth of an inch from the nipple, we light the hydrogen. (If the "cut-off" arrangement, (fig. 25) is used, the cut-off cross-piece is turned so that both gas-ways are full open.) Now we turn on a little $\mathrm{O}$, 
when the flame is a brilliant point we raise the $\mathrm{H}$ a little, then the $\mathrm{O}$ again, and so on till we have the best light we can get, or until the jet begins to "roar" beyond endurance. (Having got the best light, if the cut-off is in use, we turn the latter completely off, the $H$ will continue to burn gently, and on turning the cut-off open again we shall find the light as we left. it-at its best. Using the cut-off with cylinders alone does. not answer, but with Beard's Regulators on the cylinders, the cut-off will work quite well.) For a mixing-jet where two bags are used in one pair of pressure boards, having a surface of top of 40x30 inches, $112 \mathrm{lbs}$. will be found a good average pressure. In our experience no "composite" lime will stand the amount of heat produced by this pressure and a good jet; a "solid" lime will be required, $i$. e., one turned from limestone.

When we are dealing with multiple lanterns and dissolvers, we have, of course, to follow the above course with each jetgetting all the jets to burn as nearly as may be with equal brilliance, a matter of no slight difficulty at times. But when once we have got our jets to work equally well, a good dissolver will ensure the changes being properly made, and if our slides are of equal density we shall have equally brilliant images on our screen.

As has been already said, the light should be arranged and everything centred and focused before the audience begin to enter the hall. This is all the more important when the lantern is placed among the audience. The cut-off arrangement. enables us, having once regulated the light, to turn it down till we require it for the lecture, and then to get it as we left it in an instant. If the "cut-off," or an equivalent, be not available, we must at the beginning of the lecture turn up the gases again as neatly and as quickly as we can.

The cautions given in the end of last chapter apply equally for the mixing-jet, and ought to be studied beforehand, and committed to memory. 


\section{CHAPTER XVII.}

\section{PREPARATIONS FOR LECTURE.}

A person lecturing for the first time cannot reasonably expect to meet with such success as he may hope to achieve after some practice. This remark holds good for an ordinary lecture or public address of whatever kind, but it has much greater weight when applied to lectures illustrated by means of the lantern, with all its incidental cares. A few remarks suggested by experience may therefore not impertinently nor inaptly be addressed to the young or the intending lecturer, and these remarks naturally range themselves under two heads, viz.: points to be noted with regard to the actual lantern operations; and points to be attended to by the lecturer during his actual occupation of the platform.

If any fiasco ever takes place in regard to a lantern display, it is most likely to happen through some part of the apparatus being left behind or not procured. And if anything is forgotten, it is pretty sure to be a small article. One does not, as a rule, forget to pack and carry the lantern, nor the pressure boards, we are far more likely to forget the key for opening the valve of the cylinder. The limes are not seldom left at home, and, like the valve-key, are almost impossible to get unless the lecture is to be given in a city or large town. We propose, therefore, to give, as a sort of memoria technica, a full list of all the articles required. This list will be found on page 106.

It is always well to examine the hall where the lecture is to be given, before it is actually time to start the erection of the screen. Sometimes the hall or the platform is of such a construction as to prevent the use of our ordinary screen or screenframe, sometimes the arrangements are such that we can advantageously aispense with our screen-frame altogether. 
Sometimes there is great difficulty in finding a suitable site for the lantern, and very often, put the lantern where we may, there is a gas bracket or some such obstacle between the lantern and the screen. If we see these matters a day beforehand, we can frequently have them remedied in time, if we do not see the difficulties till the last moment, we may not have time to remove them. Gas brackets in particular have to be seen to, we have more than once had to cause the removal of a rigid pendant.

It is by no means necessary to have the lantern on the middle line of the hall; it is often very convenient both for lanternist and audience to have the lantern quite at the side of the hall; in such a case, of course, the screen is not erected at right angles to the central line of the hall, but at a greater or less angle to it. If there is no gallery or other eminence at the back of the hall and at a suitable distance from the platform, this plan of "angling" the screen and putting the lantern at one side of the auditorium is not only passable but very desirable, for the lantern is not surrounded by the audience and none of the audience can be directly behind the lantern, and so be dazzled or have the view obstructed by it. We strongly recommend the placing of the lantern at one side, where no gallery is available right in front of the screen. Anything is better than having the gas-bags or cylinders closely surrounded by the audience.

Undoubtedly the best site for the lantern is the front of a gallery straight in front of the screen. Sometimes, however, this gallery front is too far distant from the screen for the dise we require. Roundly speaking, the diameter of the dise should be about one-third of the length from back to front of the hall. If we have a hall forty-five feet from gallery to platform we will get a fifteen feet disc with a nine-inch lens, abont a seventeen feet dise with an eight inch lens; if our distance be sixty feet we shall get a twenty feet disc with a nine inch lens, a fifteen feet dise with a twelve-inch lens. If we have only one projection lens, say of eight inches focal length, we will frequently have to go to the body of the hall with our lantern. One thing we would try to impress upon our 
reader; a good small disc is vastly superior to a poor large one, and the small bright disc is better seen than the larger poorly lighted disc. The foremost of the audience should be kept well back from the screen, the larger the disc the further back the front row of seats should be placed. In most cases the best place for seeing is at about a distance from the screen of three times the diameter of the disc, not less certainly than two times, but, of course, short-sighted persons will see better if they are closer to the screen than these distances.

We will suppose the screen to have been erected, the site for the lantern chosen, the lantern unpacked and on its table or stand in the selected position. In choosing the spot for the lantern we must take care that the optical axis of the system is perfectly perpendicular to the screen, in other words, that the lantern is right opposite the centre of the screen. The tilt required for the screen may be judged with fair accuracy by eye, but a safer way is to centre the disc on the screen, place a slide in the carrier, and tilt the screen until the foreground and top of the picture are alike in focus. For centering the disc we use a blank slide, that is to say, a circular mask mounted between two glasses of lantern slide size, the centre of the circle being marked on one of the glasses with ink or a piece of paper gummed to the glass. (To make a good ink-mark on glass lick the glass with the tongue, let it dry, then put on the ink. If soot is dusted orer the ink when dry the mark will be all the better.) It must not be forgotten that though the whole of the circular disc may be shown on the screen, an oblong (or cushion-shaped) picture may overlap the screen, so allowance must be made for this. In any case the picture should fall well within the limits of the screen, the half-lighted margin of screen round the real picture forms a nice mounting for the latter. If it be seen that one side of the picture, or of the mask-image on the screen is more sharply focused than the other, the screen is not at right angles to the optical axis, and the lantern or the screen must be shifted.

The beginner should certainly see to all these matters some hours before the show is to begin; the lantern ought to be in 
position and the lenses focused, so that when the time comes to light up there may be no alteration of position required. Two or three limes may also at this stage be put to bake in an oven, or on a hob, a well-baked lime is a considerable advantage.

Of course, if either or both of the gases is to be made by the operator, it should be done a few hours before the display is to begin, and we advise the tyro to make plenty of gas. A few pence wasted are well repaid by peace of mind, the oldest lecturer is not without his qualms as to the gas supply, for one never knows what accident may occur. Gas-bags should on no account be left without surveillance in an open hall, even if the bags be locked; and if cylinders are used, the owner should not surrender charge of the keys. There are always clever fellows about who are eager to show off their knowledge, and a cylinder of oxygen yields many beautiful experiments!

Immediately before the final lighting up the front lens should be well warmed. The condenser very quickly warms when the gas is lighted, but the front lens does not get so much heat, so it warms slowly and is apt by "sweating" to spoil some of the first pictures. But it may be removed only after the image is centred and focused, so that as soon as the lens is replaced the image is found to be in statu quo antea.

During this afternoon visit to the scene of action the lecturer should see his platform arranged; his desk, chair, light, signal, water-bottle and glass. It is too late to do these things when the audience begins to come in. The lanternist may see that his slides are in order, but he must not leave them in the hall. Practical jokers are not extinct, and fools are numerous. 


\section{CHAPTER XVIII.}

\section{MANAGEMENT OF LANTERN DURING LECTURE.}

Having arranged all our apparatus so as to get a satisfactory light, we proceed to centre our disc on the screen, to "register" our dises if we propose to dissolve, to focus our light and our projection lens. These operations are all to be done by experiment and cannot usually be performed in any stated order, they depend much on each other. Perhaps the easiest plan is to focus the light first. We begin by projecting some kind of disc on the screen, a blank slide being in the carrier. (The carrier itself is usually centred by removing the projection lens, and looking down the nozzle till by eye we get the aperture in the carrier central with the nozzle. A very good plan is to put a "stop" or make a mark on the carrier when centered, so that we may be able at any future time to centre it at once.) Probably our disc at first has no particular shape and is unevenly lighted; by pushing and pulling, and moving to one side and the other, and by raising and lowering the jet we finally get a brilliant round disc evenly lighted, and with sharp colorless edges on our screen, and if our lantern is properly placed, our disc is in the centre of the screen. As already said, if the disc-edge is not equally sharp all round the lantern is not "square on" to the screen; if the bottom or top of the disc is unsharp the cant or tilt is wrong; if one side is out of focus the angle of screen to lantern is wrong. If our pictures are to be of shape other than circular we must try a mask of that other shape. We finally remove the blank slide, and put in the first slide of the lecture; this we very carefully focus, and we are now ready to begin.

If the lecture is to last, say, eighty minutes, two limes will assuredly be required, three will be better if we have a chance of changing more than once. A pair of "pliers" should be 
at hand to remove the used lime, in fact a pair of plumber's pliers is what no lanternist should be without. The hole up the middle of the limes should be cleared out before the lecture, sometimes the lime is not put on its pin without trouble, and anything savoring in the smallest degree of a hitch must be carefully avoided. The lime must be turned at intervals, greater or shorter, according to the force of our jet. A blowthrough jet requires its lime turned, say, every four minutes; a mixing jet under heavy pressure works best when the lime is almost constantly on the move. Clockwork has often been used to drive the lime slowly round. Anyhow, a deep-pit on the lime must never be allowed. Of course, a soft lime pits more readily than a hard one.

It is a sign of mismanagement when an operator has to keep altering his jet-taps; if the light first attained be of proper quality, and the jet properly made, no tampering with taps should be needed at all. It is just possible that a few minutes after the lighting up a slight alteration may be required (for some reason when this happens it is the oxygen that requires to be slightly increased, as a rule), but in a general way we do not require to alter anything until the pressure in the cylinders or bags falls inaterially lower, which is always near the end of a lecture and often does not occur at all. But if the light becomes too red or too large in extent, we are forced to reduce the hydrogen, which is, perhaps, preferable to increasing the oxygen. Unless the jet is in some way clamped in its position care is necessary to avoid knocking the end of the jet or the rubber tubes, and so uncentring the light. Moreover, the slides should all slip sweetly into the carrier; we rather object to a carrier into which slides are dropped, as the carrier is apt to be knocked out of centre unless it is clamped as suggested at page 26.

The slides must all be in order and convenient to the hand of the lanternist, and they should be distinctly marked so that the lanternist may know in the semi-obscurity of the lanternvicinity how the slides go into the carrier without having to hold them up between his eye and the screen, or near the back of the lantern. In England, if there is any standard 
slide-mark at all, it is this: The slide is laid down as the picture actually appears in nature or is intended to appear on the screen, and two marks are affixed, one to each top corner. These two marks go into the carrier next the light and downwards.

Slides that have passed through the lantern should be kept quite apart from those still to pass.

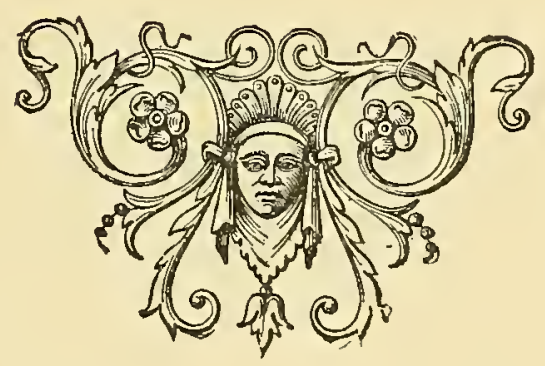




\section{CHAPTER XIX.}

\section{DEPORTMENT ON THE PLATFORM.}

The young lecturer is sure to be more or less nervous, but in different lecturers the nervousness shows itself in different ways. One is full of diffidence and tremors, the other is assertive and inclined to "swagger." If the diffident one has himself superintended all the preparations, knows that his apparatus is good, and his gas plentiful, he may keep his mind quite at rest, he has done his "level best," and nervousness now may spoil the whole. If the assertive one will only realize that a forward manner is offensive to his hearers, and certain to vitiate his success in their estimation, he may, perhaps, subdue for the time his conceit.

There are some who think that glitter of brass on the lantern and gold lace curtains over the screen will make up for any shortcomings of the slides or of the lecture, while there are others who fancy that disregard of external appearances looks business-like and savors of the veteran lecturer. Probably both these parties are wrong, and excellence lies midway between the two extremes. All apparatus should be in thorough working order, and scrupulously clean, and the screen is all the better for having the frame-poles concealed by a tasteful but simple pair of curtains. On the other hand acres of bright brass do not make a good lantern any more than a dress suit constitutes a good lecturer. There is a very good story told of a lecturer whose lantern was so resplendent with bright brass work that he found the audience all sitting with their backs to the screen and their faces to the lantern, they could not believe that such a very grand instrument was not the intended object of their attention.

There should be a thorough understanding between the lecturer and the lanternist, certain signals should be arranged 
for communication between them in case of mistake. For example if by some mismanagement a slide comes in the wrong order or reversed as to right and left, it is most awkward for the lecturer to hold a dialogue with the lanternist. It has already been stated that the neatest kind of signal consists of an electric communication between speaker and lanternist, the bell at the lantern being muffled. The effect is exceedingly good when the lantern can be hidden from the audience altogether as in a little room at back of the hall, the front of the projection lens coming close to a hole made for it, and the lanternist having a small window through which he can view the screen and the platform. The writer once lectured under the following pleasant conditions. A screen 30 feet square, and quite opaque, a disc about 28 feet diameter, the screen draped with red curtains at each side. The radiant, an electric are of 12,000 candles nominal power, worked by an engine in another street. The lantern entirely hidden from view, and electric communication with the lantern room. The pictures come on the screen as if by incantation, for the lecturer designedly concealed his "push" from the audience.

The lecturer ought always to make a few remarks to the audience before turning down the gas or other light illuminating the hall, and while he is making these introductory remarks he should carefully study the faces in various parts of the hall in order to learn whether all can hear him well. Ears turned to the front, and gaping mouths, are sure signs that the speaker is not heard, and he must alter his voice and enunciation accordingly. Shouting is never a good way of making oneself heard, a loud conversational tone is the utmost amount of force likely to be useful. Slow, deliberate enunciation is what is wanted. Every syllable must be distinctly pronounced, and rapid utterance must never be practised. - The nervous lectures is almost certain to speak far too quickly, and consequently is very apt to stammer and get mixed in his ideas, so the more nervous we are the more carefully must we study slow, precise speech.

In a popular lecture jokes are valuable, in fact nearly necessary. But the jokes must not be too stale, a jest familiar 
to everybody is worse than useless. We must try to suit our jokes to our audience, jokes that convulse a Scotch audience are lost in England on the very same class of people, probably a successful "quip" for a California lecture would fall flat in Boston. We must not be vexed-or at least we must not show vexation-if our jokes miss fire, we must try again with a different projectile. The writer places considerable importance on a good stock of jests for popular lectures, if we cannot compose a sally of wit ourselves we may find what suits the purpose in books, and, as we said, provided the jokes are not really pre-adamite they are sure to tell, and add to the success of the lecture.

Sometimes a foolish audience is apt to become unruly when the gas is turned down. This is almost always the fault of the lecture or the lecturer. If the lecture is uninteresting boys are sure to lose patience, and indeed who does not sympathize with them? It is a fearful trial of patience to sit in the dark and see poor slides and hear dismal inanities uttered. If such a case should occur, and if any serious interruption to the lecture took place, we should simply cause the gas to be turned up, and decline to proceed unless order should be maintained. But the worst thing a lecturer can do in such cases is to lose his temper. If he keeps calm, and even benignant, it will be a very low audience that will not yield to his good nature.

In lantern lectures extending beyond forty minutes, there should always be an interval during which the hall is illuminated with the usual lights. This affords a rest to all concerned, and allows the lanternist to change his lime and see that all his apparatus is in order. But the interval must not be long, five minutes is perhaps the longest that will be safe. If the audience is put into bad humor by being kept waiting the danger of a disturbance is tenfold increased.

. Unless the lecturer is very glib of speech, and has his subject at his finger ends, the lecture ought to be written or printed. An extempore lecture when good is a grand success, but when poor is apt to be a dismal failure, and the lecturer is set down as a conceited fool for attempting it.

To those unaccustomed to prolonged stretches of public 
speaking, especially when nervousness is felt, a lecture of, say, eighty minutes, is a severe tax on the throat. Drinking large quantities of water only makes matters worse sometimes, a tiny tablet or pellet of chlorate of potash will be found as good as anything to take. Borax is sometimes added to the potash, but the advantage is very doubtful. Not much liquid of any kind should be taken before lecturing, but hot drinks, as tea and coffee, are the worst of all things.

No one but a very old hand can sing and speak in one lecture.

Ninety minutes is the longest time advisable for the duration of a lantern lecture.

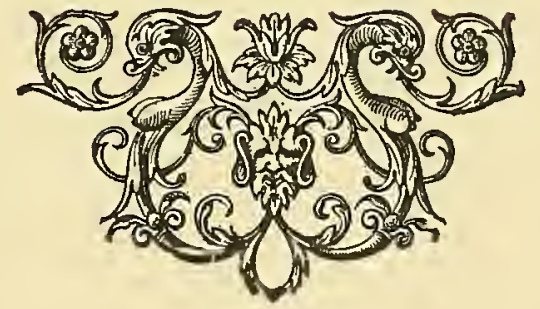




\section{CHAPTER XX.}

\section{ARRANGEMENTS FOR THE LANTERN IN A LEC- TURE-ROOM.}

As one of the chief aims of this book is to simplify and increase the use of the optical lantern in lecture-rooms forming parts of universities, colleges, schools, and other educational and recreative institutions, we may do well to suggest a few of the steps that may be taken to render the lantern a permanent instalment of the place. In such a case it is indubitably the best plan to have an opaque screen, and the best screen is, as previously stated, a plastered wall, smooth and matt in surface. Almost equally good in all respects, most convenient in many, is a strong opaque "faced" screen, such as was described in a previous chapter. This may very well roll up like a map, to be let down at the teacher's will. If it is convenient to set up the lantern straight opposite and at right angles to the screen, the latter may be allowed to hang down naturally; if the lantern must go below the centre of the screen the roller may be brought a few inches out from the wall at top, and the roller at foot of the screen may be placed and held close against the wall. If the lantern goes more conveniently on a higher level than the centre of the screen, as will be the case in many lecture-rooms of the amphitheatre style, then the roller at top may be as close to the wall as possible, while the roller at foot of the screen may be pulled out and held a few inches from the wainscot or lower part of the wall.

In nearly all cases such as we are treating now a ten feet disc will be ample; and a blow-through jet sufficiently powerful, indeed, a good oil-lamp will answer for such a disc. On the score of convenience the lime-light will probably be found preferable, for the requisite illumination can be got up more rapidly than with oil, and the effect, especially with the 
ordinary run of slides aud with objects projected through a lantern microscope or a polarizer, or a prism, will certainly be better with lime than with oil. We recommend a good-sized cylinder of oxygen, say forty cubic feet, or else a metal tank of the gas, but not a bag if the cylinder or tank can be obtained. Of course the tank would not be large enough to hold more than six or ten cubic feet. Bags for such a purpose would be wasteful even if they were not tampered with by the students. While thus recommending the blowthrough jet, we must say that we have almost entirely given up its use, preferring from every point of consideration the mixing jet with two cylinders and two regulators. For a lecture-room we should suggest one of the open-stage lanterns such as Fig. 42 ; such a lantern is useful for every condition likely to arise. A part of the outfit onght to be the arrangement for showing opaque objects. For special illustrations such as spectrum analysis special accessories must, of course, be added.

The matter that seems to give teachers the greatest amount of perplexity is that of darkening the lecture-room during the day time, and even when the gas is lighted. The gas is easily arranged by putting within reach of the teacher, the lanternist, or an attendant, a bye-pass tap, whereby the gas of the room can be lowered "to the blue" without being extinguished. If the electric light be used for the room it can easily be switched off, and here it may be said that if electricity be used for the illumination of the room or building, we should certainly utilize it for the optical lantern, even were we restricted to an incandescent lamp. The electric light has its disadvantages for the lantern, but its performance is so good when in good order, and its convenience so great at all times that, when available, it should certainly be utilized for our purpose.

For blocking out daylight the simplest and best contrivance is a shutter on the "Louvre" principle. In Britain we have a shutter known as Clarke's patent, and it answers our purpose admirably. It is made of slips of wood joined by strips of strong cloth, and the shutter simply folds up into 
a coil which occupies, when the shutter is open, a receptacle at top or bottom of the window. This shutter, when well fitted, completely blocks out light; it is opened and shut in a few seconds. But even this is not necessary to success, for a blind made of opaque stuff, fitted in runners, for instance, close to the sides of the window, will shut out light sufficiently for our purpose. Absolute darkness is not essential to even a good image on the screen, while a powerful lantern will project a useful picture even when the room is only in semiobscurity. We have seen a very successful series of lantern illustrations in a room where every person present was visible to the lecturer, though only dimly. But it must be understood that where pictures, and not mere instruction, are the object, the room should be as dark as possible; we only say that instruction of a class is possible in a dimly lighted room. And if our lantern slides be dense, or our microscopic objects thick or heavily stained, then the room must be really dark.

Throughout this book the writer has had in his mind the instructor rather than the entertainer. The optical lantern, as a means of imparting instruction to classes, has never occupied the place it ought to occupy on its merits. In the interest of teacher and student alike, we venture to hope that the optical lantern will soon take the place it deserves.

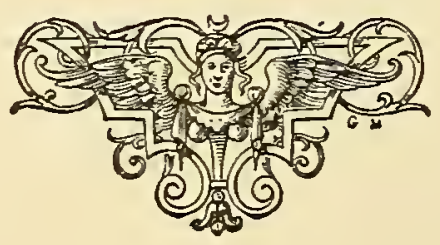




\section{CHAPTER XXI.}

\section{ENLARGING WITH THE OPTICAL LANTERN.}

As those who possess an optical lantern frequently wish to use it for enlarging from photographic negatives or positives, it may not be out of place for us to give a few remarks on the subject.

If the original negative be of lantern-slide size, or if the part we wish to enlarge cover an area of not more than three and a quarter inches square, we shall not require any alteration of our lantern with four-inch condenser provided the front lens racks out far enough. But if we propose to enlarge from entire quarter plate negatives, we shall require a larger condenser, and so also for every larger size of negative. To find the size of condenser necessary to illuminate properly any size of plate which we may wish to enlarge a simple rule is to take the diagonal of the plate; the diameter of the condenser must be a little more than the diagonal of the plate. Thus to enlarge a "half-plate," $6 \frac{1}{2} \times 4 \frac{3}{4}$ inches (E'nglish size), a condenser of diameter not less than eight and a quarter inches should be used.

We are less tied down in the choice of a projection lens, as the focal length is practically immaterial for any such work as we are likely to attempt. But lenses sold for the lantern only, and not having their visual and actinic foci coincident will not answer for enlarging, or will not answer the purpose nearly so well as a lens corrected for photography. But any photographic lens will be available, if it give rectilinear images and if we can rack our lantern front sufficiently to give the lens play.

Manufacturers produce lanterns having the front so made as to stretch outwards from the stage to a considerable extent. sometimes this motion is attained by bellows, sometimes br 
telescope joints. One probably is as good as the other. The reason for this stretch of front lies in the fact that in order to get a focused image twice the size of the original, the centre of the lens must be one and a half times the focal length of the lens distant from the object to be enlarged. Thus, with a sixinch lens to get an enlargement twice the area of the original, the centre of the lens-usually very near the stop-must be nine inches distant from the object to be enlarged. If a copy of size equal to that of the original be required, the front must rack out so that the centre of the lens can be placed at twice the focal length of the lens from the object being copied. At the end of this chapter we give a table extracted from the almanac of the British Journal of Photography. This table shows at a glance the distances from centre of lens to object and to receiving surface for various degrees of enlargement or reduction.

The sensitive material on which we project and finally develop our enlarged image is, as a rule, the paper known to photographers as bromide paper, but it may be a slow gelatine plate, or a wet plate or dry collodion plate. The purely photographic part of the operations is ont of place here; we may refer our reader to the "Processes of Pure Photography,"* or any other book of the same series treating of photographic operations.

The substances used for the photography of enlarged images are usually very sensitive to actinic light, and bromide paper, for instance, will be damaged if any stray light from the lantern or from the illumination of the apartment reaches it, unless such stray light be of a yellow or red color. If there is much light about the apartment, however non-actinic the light may be, the difficulty of focusing the image will be found great. The best plan is to enclose the entire lantern in a box, letting the lens-front alone protrude, and allowing the necessary draught to reach the light either by "trapped" apertures, or by some arrangement of thick cloth. Reflec-

* "Processes of Pure Photography," by Burton and Pringle. New York : Scovill, 1889. 
tions, it must be remembered, must be kept from the sensitive material as sedulously as direct stray light.

The paper or other sensitive material is to be placed in front of the projection lens, and the receiving surface must be perpendicular to the optical axis of the condensing and projection systems. If this is not attended to some part of the enlarged image will surely be blurred. Paper may be tacked with drawing pins to a board or a wall, or it may le held in an easel in front of the projection lens. The easel

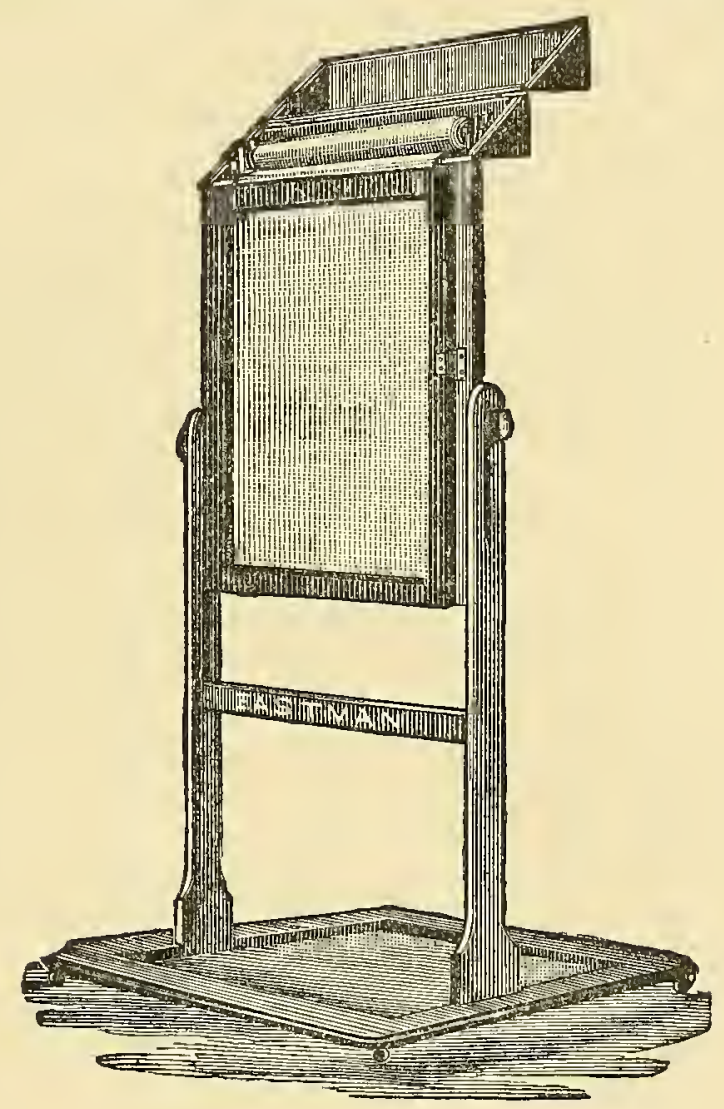

FIG. 46.

may be free on the floor, but it is better when convenient to have it either running on a track or sliding in slots or grooves along the optical axis of the system. Fig. 46 shows a very useful easel made to hold a long roll of bromide paper or cut sheets, as may be desired.

The accurate focusing of the projected image may be adjusted either by racking out and in the projecting lens, of 
by pushing backwards and forwards the easel. The former is perhaps easier, the latter perhaps preferable. If accuracy in amount of enlargement is not of vital importance, the former method may be adopted. We may project the image and focus it either on a white surface, as a sheet of paper, thereafter replacing the white paper by our sensitive surface; or we may even pin our bromide paper over the plain paper on which we focused; or we may place on the lens a cap of nonactinic glass and focus directly on our sensitive surface, removing from the lens the non-actinic cap when the focus is adjusted. The question of exposure comes under the head of photography, so we shall not here discuss it at length. The actinic force of the radiant, the intensity ratio of the lens, the density of the object to be enlarged, and the sensitiveness of the receiving surface being all taken as fixed terms, the exposure varies directly with the areas of enlargement and inversely with the utilized area of the condenser. 
THE OPTICAL LANTERN.

TABLE FOR ENLARGEMENTS.

Copied from the "British Journal Almanac for 1882."

\begin{tabular}{|c|c|c|c|c|c|c|c|c|}
\hline Focus of Lens. & \multicolumn{8}{|c|}{ Times of ENLARGEMENT AND ReduCtion. } \\
\hline $\begin{array}{c}\text { Inches. } \\
2\end{array}$ & $\begin{array}{c}1 \\
\text { In. } \\
4 \\
4\end{array}$ & $\begin{array}{c}2 \\
\text { In. } \\
6 \\
3\end{array}$ & $\begin{array}{l}3 \\
\text { In. } \\
8 \\
23 / 4\end{array}$ & $\begin{array}{c}4 \\
\text { In. } \\
10 \\
21 / 2\end{array}$ & $\begin{array}{c}5 \\
\text { In. } \\
12 \\
22\end{array}$ & $\begin{array}{c}6 \\
\text { In. } \\
14 \\
2 \frac{1}{3}\end{array}$ & $\begin{array}{c}7 \\
\text { In. } \\
16 \\
2 \frac{2}{7}\end{array}$ & $\begin{array}{c}8 \\
\text { In. } \\
18 \\
2 \frac{1}{4}\end{array}$ \\
\hline $21 / 2$ & $\begin{array}{l}5 \\
5\end{array}$ & $\begin{array}{l}71 / 2 \\
33 / 4\end{array}$ & $\begin{array}{c}10 \\
3 \frac{1}{3}\end{array}$ & $\begin{array}{r}121 / 2 \\
31 / 8\end{array}$ & $\begin{array}{r}15 \\
3\end{array}$ & $\begin{array}{r}17 \frac{1}{2} \\
2 \frac{11}{12}\end{array}$ & $\begin{array}{l}20 \\
2 \frac{8}{7}\end{array}$ & $\begin{array}{r}22 \frac{1}{2} \\
2 \frac{13}{16}\end{array}$ \\
\hline 3 & $\begin{array}{l}6 \\
6\end{array}$ & $\begin{array}{l}9 \\
41 / 2\end{array}$ & $\begin{array}{r}12 \\
4\end{array}$ & $\begin{array}{l}15 \\
33 / 4\end{array}$ & $\begin{array}{c}18 \\
3 \frac{3}{5}\end{array}$ & $\begin{array}{c}21 \\
3 \frac{1}{2}\end{array}$ & $\begin{array}{c}24 \\
33 \frac{3}{7}\end{array}$ & $\begin{array}{c}27 \\
3 \frac{3}{8}\end{array}$ \\
\hline $31 / 2$ & $\begin{array}{l}7 \\
7\end{array}$ & $\begin{array}{r}101 / 2 \\
51 / 4\end{array}$ & $\begin{array}{c}14 \\
4 \frac{2}{3}\end{array}$ & $\begin{array}{r}171 / 2 \\
43 / 4\end{array}$ & $\begin{array}{l}21 \\
4 \frac{1}{5}\end{array}$ & $\begin{array}{r}24 \frac{1}{2} \\
4_{1}^{1} \\
\end{array}$ & $\begin{array}{r}28 \\
4\end{array}$ & $\begin{array}{r}31 \frac{1}{2} \\
3 \frac{15}{16}\end{array}$ \\
\hline 4 & $\begin{array}{l}8 \\
8\end{array}$ & $\begin{array}{r}12 \\
6\end{array}$ & $\begin{array}{l}16 \\
51 / 4\end{array}$ & $\begin{array}{r}20 \\
5\end{array}$ & $\begin{array}{c}24 \\
4_{5}^{4}\end{array}$ & $\begin{array}{c}28 \\
4 \frac{2}{3}\end{array}$ & $\begin{array}{l}32 \\
4 \frac{4}{7}\end{array}$ & $\begin{array}{l}36 \\
4 \frac{1}{2}\end{array}$ \\
\hline $41 / 2$ & $\begin{array}{l}9 \\
9\end{array}$ & $\begin{array}{r}131 / 2 \\
63 \% 4\end{array}$ & $\begin{array}{r}18 \\
6\end{array}$ & $\begin{array}{r}221 / 2 \\
55 \% 8\end{array}$ & $\begin{array}{c}27 \\
5 \frac{2}{5}\end{array}$ & $\begin{array}{r}31 \frac{1}{2} \\
5 \frac{1}{4}\end{array}$ & $\begin{array}{l}36 \\
5 \frac{1}{7}\end{array}$ & $\begin{array}{c}40 \frac{1}{2} \\
5 \frac{1}{16}\end{array}$ \\
\hline 5 & $\begin{array}{l}10 \\
10\end{array}$ & $\begin{array}{l}15 \\
71 / 2\end{array}$ & $\begin{array}{c}20 \\
6 \frac{2}{3}\end{array}$ & $\begin{array}{l}25 \\
61 / 4\end{array}$ & $\begin{array}{r}30 \\
6\end{array}$ & $\begin{array}{c}35 \\
5 \frac{5}{6}\end{array}$ & 40 & $\begin{array}{c}45 \\
5 \frac{5}{8}\end{array}$ \\
\hline $51 / 2$ & $\begin{array}{l}11 \\
11 \\
\end{array}$ & $\begin{array}{r}161 / 2 \\
81 / 4 \\
\end{array}$ & $\begin{array}{l}22 \\
71 / 8 \\
\end{array}$ & $\begin{array}{r}271 / 2 \\
6 \% 8 \\
\end{array}$ & $\begin{array}{l}33 \\
61 / 2 \\
\end{array}$ & $\begin{array}{r}38 \frac{1}{2} \\
6 \frac{5}{12} \\
\end{array}$ & $\begin{array}{l}44 \\
6 \frac{2}{7}\end{array}$ & $\begin{array}{r}49 \frac{1}{2} \\
6 \frac{3}{16}\end{array}$ \\
\hline 6 & $\begin{array}{l}12 \\
12\end{array}$ & $\begin{array}{r}18 \\
9\end{array}$ & $\begin{array}{r}24 \\
8\end{array}$ & ${ }_{71 / 2}^{30}$ & $\begin{array}{l}36 \\
7 \frac{1}{6}\end{array}$ & $\begin{array}{r}42 \\
7\end{array}$ & $\begin{array}{c}48 \\
6 \frac{6}{7}\end{array}$ & $\begin{array}{c}54 \\
6_{4}^{\frac{3}{4}}\end{array}$ \\
\hline 7 & $\begin{array}{l}14 \\
14\end{array}$ & $\begin{array}{l}21 \\
101 / 2\end{array}$ & $\begin{array}{l}28 \\
9 \frac{1}{3}\end{array}$ & $\begin{array}{l}35 \\
83 / 4\end{array}$ & $\begin{array}{l}42 \\
8 \frac{2}{5}\end{array}$ & $\begin{array}{l}49 \\
8 \frac{1}{6}\end{array}$ & $\begin{array}{r}56 \\
8\end{array}$ & $\begin{array}{c}63 \\
7 \frac{7}{8}\end{array}$ \\
\hline 8 & $\begin{array}{l}16 \\
16\end{array}$ & $\begin{array}{l}24 \\
12\end{array}$ & $\begin{array}{l}32 \\
10^{\frac{2}{3}}\end{array}$ & $\begin{array}{l}40 \\
10\end{array}$ & $\begin{array}{c}48 \\
9 \frac{3}{5}\end{array}$ & $\begin{array}{c}56 \\
9 \frac{1}{3}\end{array}$ & $\begin{array}{l}64 \\
9 \frac{1}{7}\end{array}$ & $\begin{array}{r}72 \\
9\end{array}$ \\
\hline 9 & $\begin{array}{l}18 \\
18\end{array}$ & $\begin{array}{l}27 \\
131 / 2\end{array}$ & $\begin{array}{l}36 \\
12\end{array}$ & $\begin{array}{l}45 \\
111 / 4\end{array}$ & $\begin{array}{l}54 \\
10 \frac{4}{5}\end{array}$ & $\begin{array}{l}63 \\
10 \frac{1}{2}\end{array}$ & $\begin{array}{l}72 \\
10 \frac{2}{7}\end{array}$ & $\begin{array}{l}81 \\
10 \frac{1}{8}\end{array}$ \\
\hline
\end{tabular}

It is assumed that the photographer knows exactly what the focus of his lens is, and that he is able to measure accurately from its optical centre. The use of the table will be seen from the following illustration: A photographer has a carte to enlarge to four times its size, and the lens he intends employing is one of six inches equivalent focus. $\mathrm{He}$ must, therefore, look for 4 on the upper horizontal line, and for 6 in the first vertical column, and carry his eye to where these two join, which will be at $30-71 / 2$. The greater of these is the distance the sensitive plate must be from the centre of the lens and the lesser, the distance of the picture to be copied. To reduce a picture any given number of times the same method must be followed, but in this case the greater number will represent the distance between the lens and the picture to be copied; the latter, that between the lens and the sensitive plate. This explanation will be sufficient for every case of enlargement or reduction.

If the focus of the lens be twelve inches, as this number is not in the column of focal lengths, look out for 6 in this column and multiply by 2 ; and so on with any other numbers. 


\section{Memoranda for a Lantern Displat.}

Lantern: Condenser, projection lenses, support.

Jet: Limes in box, tubing, needle for nipple, (dissolver and tubing).

(Lamp: Wicks trimmed, oil with camphor, scissors).

Pressure-boards: Weights.

Bags: Bag-taps, (back-pressure valves).

Cylinders : Regulators, key, spanner.

Screen : Screen-frame, cord, tape, (curtains), a few staples or brass hooks with screw.

Reading-lamp: Signal, manuscript or book, list of slides in order-for lecturer.

Slides in box: List of slides in order-for lanternist.

Miscellaneous: Gas pliers, hammer and nails, screw driver and screws, gimlet and bradawl, instrument to bore out lime-hole, file, extra tubing, matches, tape measure. Lubricate taps of jet and bags (see that gas way of jet is clear).

For Oxygen Making: Retort, retort neck, tubing, oxygen mixture, heating stove and tube if for gas, purifying bottles-one or two, metal tubing for same, rubber tubing for same, alkali.

Squeeze all air out of bag, lubricate tap, lock for bag, bag marked $\mathrm{O}$.

For Hydrogen: Generating bottle, scrap zinc, acid, purifier, metal tubing, rubber tubing, or, large tubing and metal cone, or "adapter" to join gas supply from main of building to the $\mathrm{H}$ bag, gas pliers and wrench.

Squeeze air out of bag, bag marked $\mathrm{H}$.

Note: Never put grease or oil on metal fittings of cylinders, nor on regulators, nor gauges.

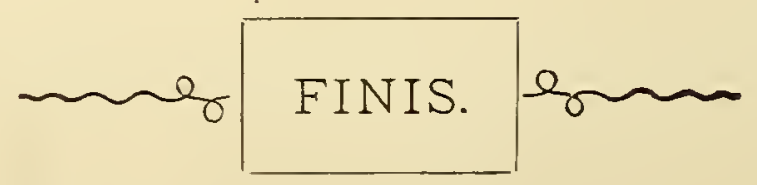




\section{N DEX.}

Angle of Impact on Lime..... Angling the Lantern and Screen Area of Condenser... ....... Arranging the Lantern........ Bags, Sizes of ............. Barium Oxides for Oxygen Making ..................

Battery, a one Lens..........

Beard's Regulator............

Benzoline Saturator, Scott's...

Best Light, How to Get ......

Biunial Lantern for science...

Biunial Lanterns.............

Blow-through System, Disadvantages of..............

Body of Lantern............

Bore of Jet Tubes ...........

Brin's Oxygen Company......

Bromide Paper for Enlarging. 102

Broughton's Ether Tank. .... 41

Browning's Spectrum Apparatus 76

Bull's-eye Condenser........ 16

Bye-Pass on Dissolvers....... 34

Camphor Added to Paraffin... 80

Canting Lantern Table....... 70

Carrier, Self-Centering, Beard's 71

Carrier, Use of............. 12

Carriers, Chadwick and Place. 71

Carriers for the Slides....... 70

Cell to Condenser, To Fit Loosely.................

Chad wick, W. I., His Table. .

Chadwick Carriers............

Check Action Lime Turner....

Chlorate of Potash..........

Common Salt in Oxygen Mix-

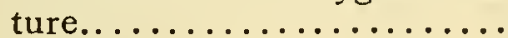

Condenser, Area of.........

Condenser, Construction of...

Condenser, Dallmeyer's.......

Condenser, Double Plano-con-

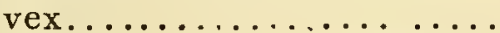

Condenser, Focal Length of ................13 et seq.

Condenser, Functions of..... 11

Condenser, Limit of Focal

Length.............. 13

Condenser, Mounting in Cell. 16

Condenser, Plano-convex.. . . 16

Condenser, Use of ........ 13
PAGE

Condenser Elements, Requisites for ................. 18

Condensers, Long Focus..... 15

Condensers for Long Focus Lenses..............note, 18

Curtain Effect............ 29

Curtains for Screen.......... 68

Cut-Off, Newton's " Pringle".. 45

Cut-Off, Practice with....... 85

Cylinders, To be Colored Differently............... 62

Cylinders for Gas, Pressure in. 60

Dallmeyer's Condenser....... 19

Dallmeyer's Projection Lens. . 20

Dangers of Mixed Gases.... . 84

Darkening Lecture-Rooms. . . . 99

Deterioration of Gases....... 57

Diameter of Disc, Suitable.... 88

Disc, Best Size for.......... 88

Dissolver, the " Star,". ..... 34

Dissolvers, Described....... 34

Dissolvers, Functions of ..... 32

Dissolving Lanterns. . . . . . . . . 29

Drying Oxygen........... 51

Easel for Enlarging......... 103

Educational Lecture-Rooms... 98

. Effects,"............... 29

Electric Lantern, Newton's... 78

Enlarging............... 101

Enlarging, Exposure Required 104

Enlarging, Size of Condenser. 101

Enlarging, Table for........ 105

Enlarging Easel ........... 103

Enlarging Lantern, Sketch of.. 101

Enlarging on Bromide Paper.. 102

Enlarging Practice, To Focus. 103

Eth-Oxo System........... 38

Ether Tanks.............. 41

Excelsior Limes........... 81

Experiments, Electric, Optical, Etc..................

Faced Screens............. 65

Fletcher's Burner............ 49

Focal Length of Projection Lens.................. 20

Foci, Conjugate.......... 11

Focus of Lens and size of Room............... 21

Front Lens, The........... 19

Gas Bag Taps, Locking. .... 55 
PAGE

Gas Bags................ 5t

Gas Bags, Qualities of....... 54

Gas Bags Becoming Stiff..... 58

Gas Brackets............. 88

Gas Cylinders, Description of. 60

Gasoline Saturator, Scott's ... 42

Hall for Lecture, Examination

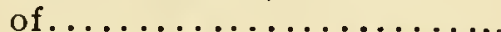

Hepworth, T. C., His Method of Painting Screens.........

Hughes, Cylindrical Miniature Hydrogen, Pure and Carburetted Compared...........

Hydrogen, To Prepare........

Impact angle of Gases........

Imperfections in Condensers. .

Interchangeable Jets........

Ives' Saturator ...............

Jet, Blow-through............

Jet, Mixing ...............

Jet, Newton's Mixing ........

Jet, Oxy-Calcium..........

Jet-Taps ...................

Jet-Taps...................

Jets, Noisy.................

Keeping $\mathrm{O}$. in Bags..........

Landscape Single Lens Projec-

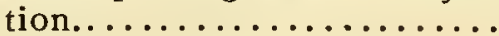

Lantern, Functions of.......

Lantern, Opening at back of, to Cover.................

Lantern, "The Scovill"........

Lantern Body, Size of........

Lantern Body or Box.........

Laverne \& Co., their Lanterns

Lecture, Duration of.......96-97

Lecture, Preparations for..... 87

Lecturing, Manner in........ 95

Lens, Functions of Projection.

Lime, Arrangements for Turn-

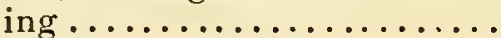

Lime Box, Author's.........

Lime Discs ................

Lime-Light, General Descrip-

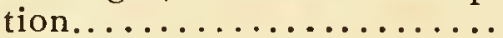

Lime-Shield, Wood's..........

Limes, Baking.............

Limes, Cracking.............

Limes, Described............

Limes, Excelsior............

Limes, Nottingham or Hard...

Limes, Soft and Hard.........

Limes, To Preserve. .........

Manganese Dioxide ..........

Marcy's Sciopticon............

M a ybridge; His Castanet

Signal..................

Mechanical Jet-Stage.........
Memoranda of Necessaries. PAGE Miniature Lantern, Author's... 106

Mixed Gases.............. 84

Mrxing Jets.............. 37

Mixing Jets, Designs of ....... 37

Mixing Jets, Practice with.... 84

Mounting a Screen on its Frame.. .............. 67

Multiple Lanterns............ 29

Newton, of London, their Lantern.................. 25

Newton's, Wright, Projection

Microscope.............. 75

Newton's Blow-through Jet.... 36

Newton's Mixing Jet ........ 39

Newton's Scientists' Biunial... 77

Nipples................ 40

Noise in Jets, Causes of ...... 40

Noisy Jets . ............... 40

Noisy Jets, To Cure......... 40

Nottingham Limes.......... 81

Oakley, Lantern made by..... 26

Oakley's Cut-Off............ 46

Object of the Book......... 9

Objections Raised Against

Lantern................

Obstructions in Gas-way......

Oil Lamps, Practice with..... 80

Oil Lanterns...........23 et seq.

Opaque Objects, front for..... 24

Open Stage .............. 26

Open Stage Lantern......... 77

Optical System............. 10

Orchard's Uxygen........... 60

Otway's Dissolver........... 32

Oxy-Calcium Jet.......... 35

Oxygen, To Prepare....47 et seq.

Oxygen Making, Brin's System 59

Oxygen Making, Practice of... 51

Oxygen Mixture.......... 47

Oxygen Mixture, To Test..... 48

Oxygen Retort........... 49

Painting a Screen............ 64

Paraffin, Camphor in........ 80

Photographic Lens for Projection................... 19

Pits and Pitting of Lime....... 39

Pits on Lime, Danger of...... 44

Place, J., his Mixing Jet...... 37

Place's Carriers............. 71

Platinum Tip for Nipple..... 40

Point of Incandescence....... 11

Polarizing Apparatus........ 76

Portrait Lens for Projection... 19

Practice with Lime-Light..... 80

Practice with Mixing Jets..... 84

Precautions with Lime-Light. 83

Preparation of Oxygen....... 47 
PAGE

Preservation of Limes....... 82

Pressure and Bore.......... 40

Pressure Boards............ 55

Pressure Gauge........... 62

Pringle Cut-Off, The........ 45

Projection Lens............ 11

Projection Lens, Back Combi-

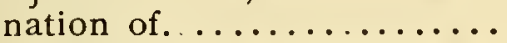

Projection Lens, Dallmeyer's.

Projection Lens, Focal Length of $\ldots \ldots \ldots \ldots \ldots \ldots$

Projection Lens, Taylor \& Hobson's ................

Projection Lens, The......... 19

Projection Microscope... . . . 74-75

Pumphrey's Mechanical Stage. 46

Purifying Bottle for Gases .... 50

Purifying Oxygen .......... 50

Radiant, Position of......... 13

Radiant, The............. 11

Reading Lamp........... 72

Refulgent Oil Lamp, Newton 24

Regulator, Beard's.........61

Requisites for Projection Lens. 19

Retort, Oxygen........... 49

Retort, Safety Valve for... ... 49

Retort, To Clean Out....... 52

Rolling Up Screens.......... 98

Safety-Chamber for Saturators. 43

Safety-Chambers .......... 38

Safety Jet.............. 36

Safety Valve, Chadwick's...... 38

Saturator .. ........... 41

Scientists' Biunial, Newton.... 77

Sciopticon, Marcy's.......... 23

Sciopticon I)issolver......... 30

Scott's Saturator... ........ 42

"Scovill" Lantern, the....... 24

Screen, Functions of......... 11

Screen, Permanent......... 64

Screen, Pigments for........ 64

Screen, Portable.......... 65

Screen, Tilting........... 21

Screen, To Mount a........ 67

Screen Elevators........... 66

Screen Frames............. 66

Screens, Faced with Paper....
Screens, Good and Bad. .... 64

Sharpness, Depends on...... 11

Shutters for Window, Clarke's 99

Signals................ $77_{2}$

Signals to be Arranged....... 94

Site for Lantern in Hall....... 88

Sketching in the Lantern...... 78

Slide, Shapes of........... 11

Slide, Size of............. 11)

Slide, The............... 10

Slide Boxes............... 73

Slide Carriers............. 70

Smith, George, Sciopticon Co. 30

Spectrum Projection, Browning 76

Stand for Lantern. ........ 69

Standard Mark for Slides..... 91

Storage of Gases........... 54

Sweating of Condenser...... 16

Sweating of Glasses.......... 90

Table For Enlargements..... 105

Table for Cylinders......... 63

Tank for Stage............ 76

Tanks for Gases........... 57

Taps of Jets............. 41

Taylor, J. Traill, His Condeners .................. 16

Throat and Voice, The ..... 97

Tilt of Screen, To Judge...... 89

To Calculate Pressure on Bags 56

To Find Distance, Disc,

Focus, etc...................... 20

Tone of Voice ............ 95

Triple Condenser, Taylor's.... 17

Triunial Lanterns. ......... 30

Triunial Lanterns........... 32

Tubing, Qualities and Sizes of 72

Turning the Lime. .......... 44

Unruly Audience........... 96

Varieties of Radiant......... 11

Weights for Gas Bags........56-57

Woodbury, W. B., His Experiments.............. 76

Wright, Lewis, His Jet. . . . . . 39

Wright's Projection Microscope............... 75

Writing on Glass.......... 89

Zinc White for $=$ creens...... 65 







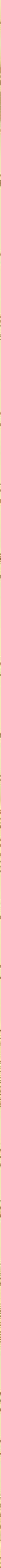


